\title{
Regulation of Glucose Metabolism via the Intra-Islet DPP4/Incretin Axis
}

\author{
By Evgenia Fadzeyeva
}

A thesis submitted in partial fulfillment of the requirements for the Master's degree in Biochemistry

\footnotetext{
Department of Biochemistry, Microbiology, and Immunology Faculty of Medicine

University of Ottawa
} 


\begin{abstract}
Glycemic control in patients with type 2 diabetes (T2D) can be achieved through potentiation of the signalling by glucagon-like peptide 1 (GLP-1) and glucose-dependent insulinotropic polypeptide (GIP). Both incretin hormones have been traditionally characterized to be secreted by distinct enteroendocrine cells within the gut in response to nutrients. Signalling through the incretin receptors stimulates islet hormone release by potentiating glucose-stimulated insulin secretion from the $\beta$-cell and decreasing glucagon secretion from the $\alpha$-cell. However, the bioactivity of GLP-1 and GIP is controlled by post-translational, Nterminal cleavage by the widely expressed serine protease dipeptidyl peptidase 4 (DPP4). As such, DPP4 inhibitors (DPP4i) have been successfully used to treat millions of patients with T2D. DPP4i target the catalytic active site of DPP4 and prevent the cleavage of the incretin hormones, thus prolonging their action.

Recently, studies in genetically modified mice have demonstrated that GLP-1 is not solely an intestinally-derived peptide hormone and proposed that islet-derived GLP-1 is required for proper glucose homeostasis. Therefore, with the current study, we sought to assess whether $\beta$-cell-derived DPP4 is an important target for the regulation of glycemia. Treatment of G/p $1 \mathrm{r} / \mathrm{Gip}^{\beta-c e l l-/}$ mice with the DPP4 inhibitor sitagliptin demonstrated that $\beta$-cell incretin receptor signaling is required to mediate the beneficial effects of this class of drugs on glucose homeostasis. Additionally, Dpp4 4 mice exhibited a significant reduction in hepatic glucose production during hyperinsulinemic-euglycemic clamps. Dpp4 mRNA, DPP4 protein and activity are present in isolated mouse islets, further supporting the islet as an important potential site of DPP4i action. In this study, we show that both DPP4i-treated wildtype islets and islets isolated from Dpp $4^{\beta-}$ cell-- mice exhibit increased glucose-stimulated insulin secretion (GSIS) during perifusion after a high-fat diet feeding. Genetic elimination of Dpp4 from islet $\beta$-cells also improved oral glucose tolerance and insulin sensitivity in female mice, but had no effects on circulating DPP4 or incretin levels. Finally, eliminating Dpp4 from $\beta$-cells or the whole pancreas did not improve whole-body glucose tolerance, response to DPP4i, insulin tolerance, or body weight in male mice fed chow or a high-fat diet. Therefore, we provide evidence for islet-derived DPP4 to have a role in local hormone responses to glucose; however, its role in systemic glucose metabolism is shown to be sex-dependent.
\end{abstract}




\section{Co-Authorship Statement}

The execution of experiments, analysis, presentation of data, and preparation of this thesis was done by me, with the following exceptions:

Dr. Erin E. Mulvihill provided intellectual input and scientific expertise in the creation of the experimental design, hypothesis, and experiment execution.

University of Ottawa Heart Institute Animal Care Veterinary Services (ACVS) provided care for all animals used during the completion of this thesis.

Richard Seymour (ACVS) performed the pancreas inflation with collagenase required for islet isolation.

Dr. Branka Vulecevic, Natasha Trzaskalski, Nadya Morrow, Dr. My Anh Nguyen, Cassandra Locatelli, and Antonio Hanson assisted with all metabolic experiments, including glucose and insulin tolerance tests.

Dr. MyAnh Nguyen, Dr. Erin E. Mulvihill, Natasha Trzaskalski, and Nadya Morrow assisted with animal sacrifices and tissue processing.

Dr. Ilka Lorenzen-Schmidt assisted with breeding mouse colonies and genotyping mice.

Xiaoling Zhao (UOHI Histopathology Core) assisted with tissue processing for paraffin embedding. Dr. Majid Nikpay assisted with LD mapping of Gcg and Dpp4 in C57BL mice. 


\section{Acknowledgements}

First and foremost, I would like to express my deep gratitude to my graduate supervisor, Dr. Erin Mulvihill for her continuous support, patience, and words of encouragement throughout my Master's degree. I feel so very lucky to have you as a mentor, and I sincerely appreciate all your help and guidance during the time of research and the writing of this thesis. Thank you.

I would also like to thank the members of my thesis advisory committee, Dr. Katey Rayner and Dr. Erik Suuronen, for their advice, suggestions, and the hard questions. Your support and scientific input have been essential in the shaping of this project.

Completing this work would not have been possible without the help from Richard Seymour and all the members of the Heart Institute ACVS. All your hard work is greatly appreciated.

I would like to especially thank all the members of the Mulvihill lab - Natasha Trzaskalski, Nadya Morrow, Antonio Hanson, Cassie Locatelli, Dr. My-Anh Nguyen, Dr. Branka Vulecevic, and Dr. Ilka Lorenzen-Schmidt. I am so grateful to have had your help and support throughout these last two years.

Finally, I wish to thank my family for their endless love and support. 


\section{Table of Contents}

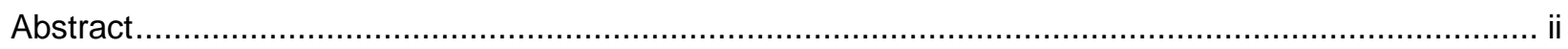

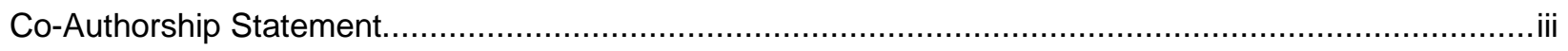

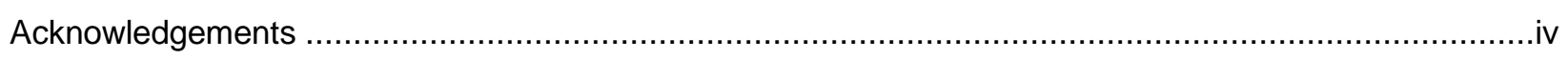

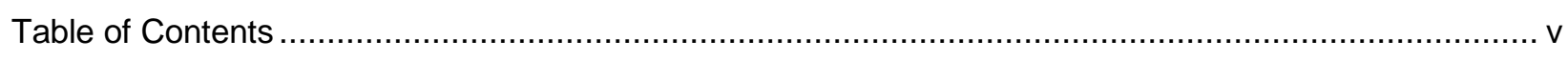

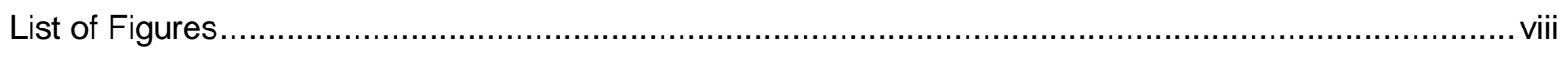

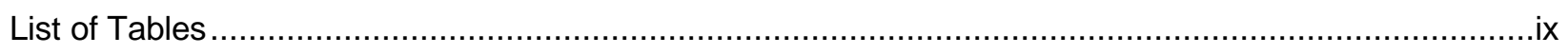

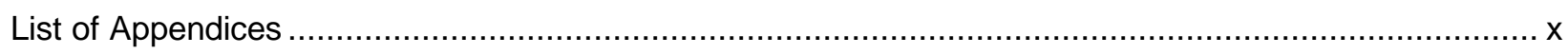

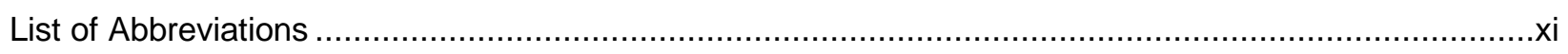

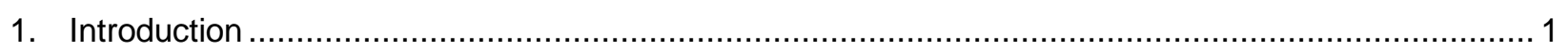

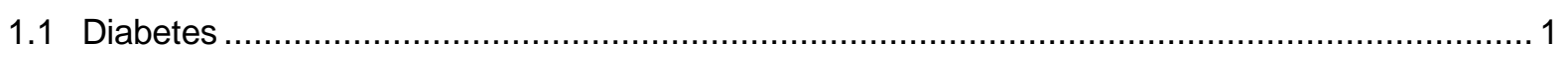

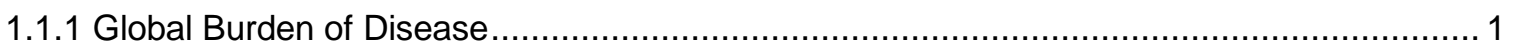

1.1.2 Physiological Regulation of Glucose Homeostasis .................................................. 1

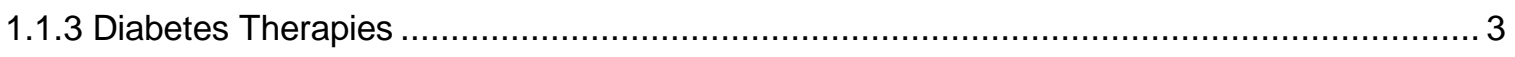

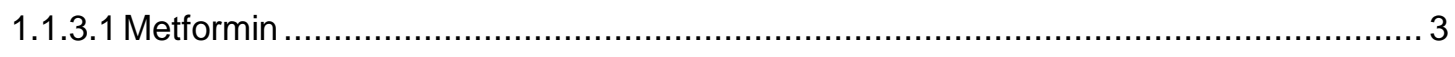

1.1.3.2 Suflonylurea and Thiazolidinedione ............................................................... 3

1.1.3.3 Sodium-Glucose Cotransporter-2 (SGLT2) Inhibitors ........................................ 4

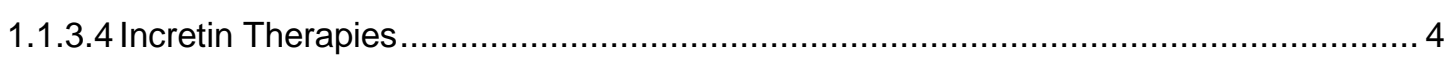

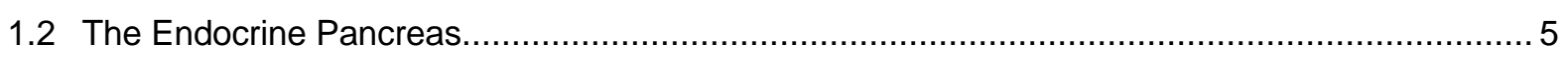

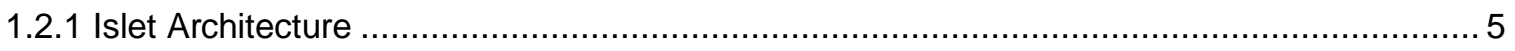

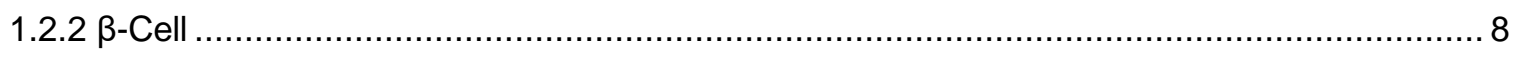

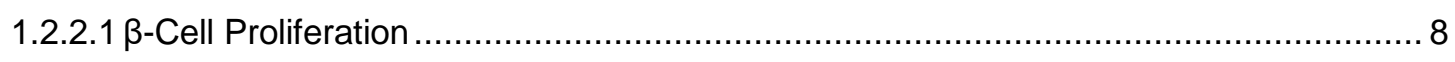

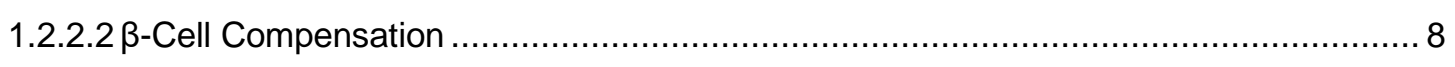

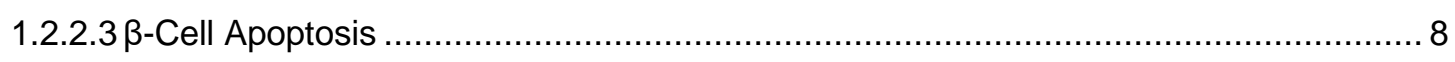

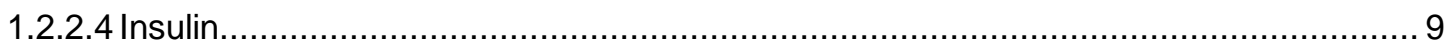

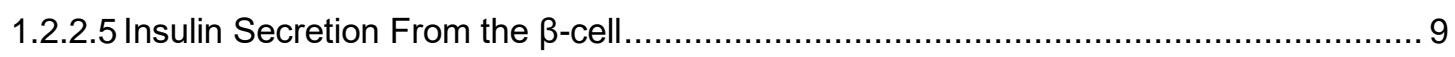

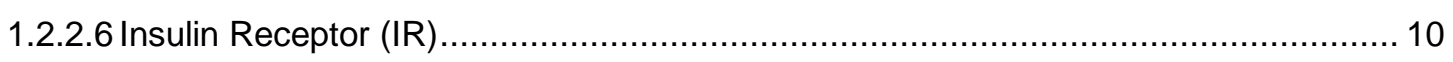

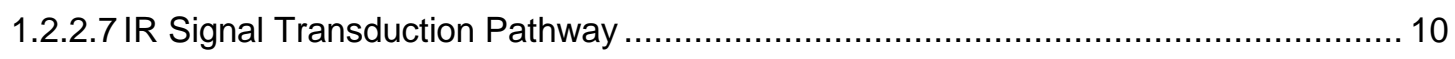

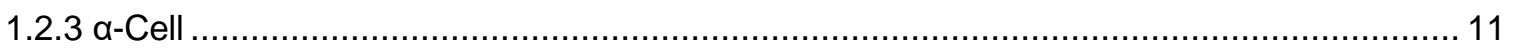

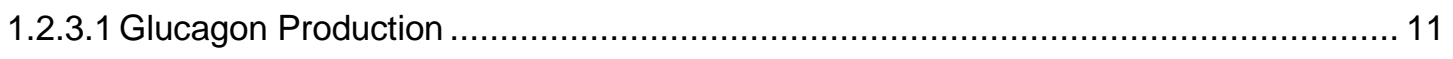

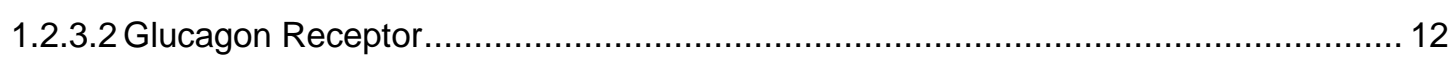

1.2.4 Other Hormone-Producing Cell Types Within the Islet ............................................. 12

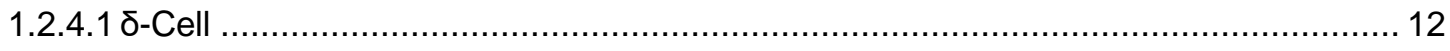




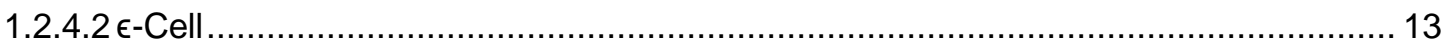

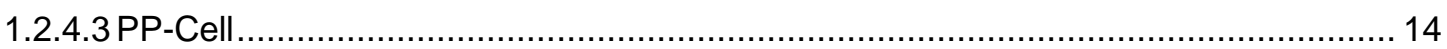

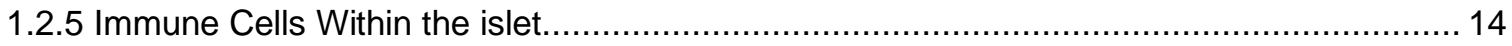

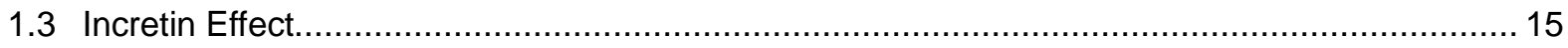

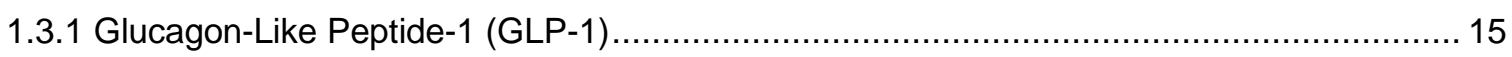

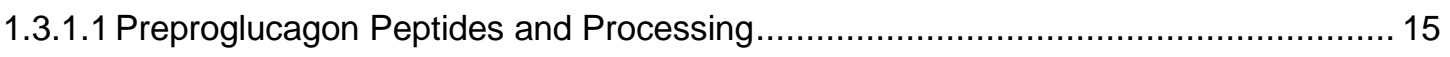

1.3.1.1.1 Preproglucagon in the Intestinal L-Cells ................................................ 17

1.3.1.1.2 Preproglucagon in the Pancreas ......................................................... 17

1.3.1.2 GLP-1, Insulin, and Energy Metabolism ...................................................... 18

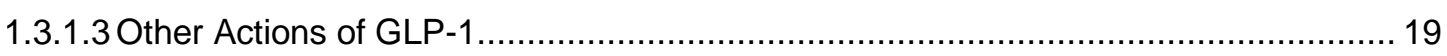

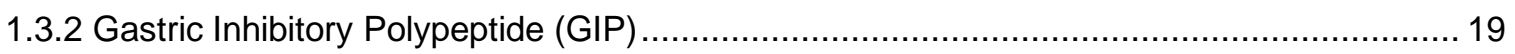

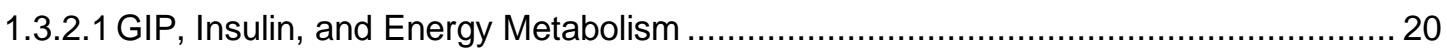

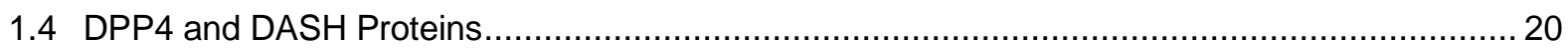

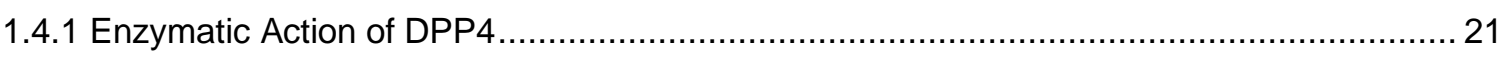

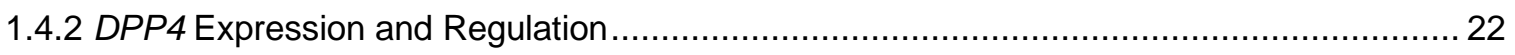

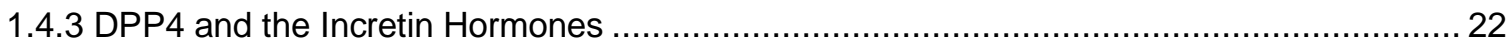

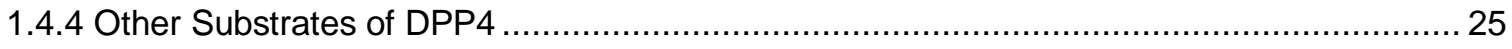

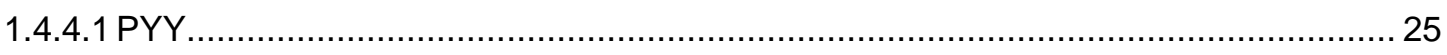

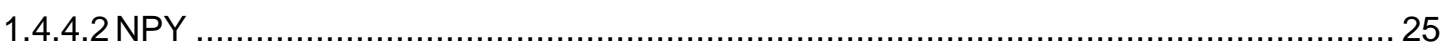

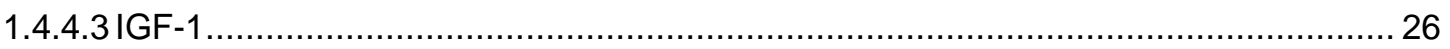

1.5 Incretin-Based Therapies: DPP4 Inhibitors and Incretin Mimetics ....................................... 26

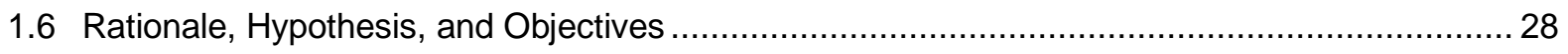

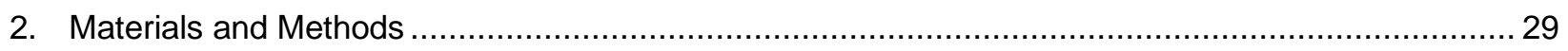

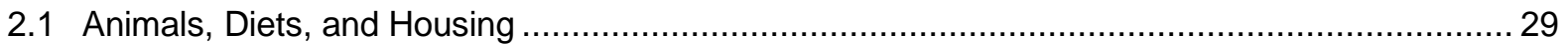

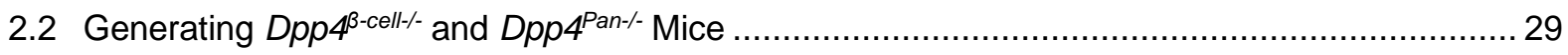

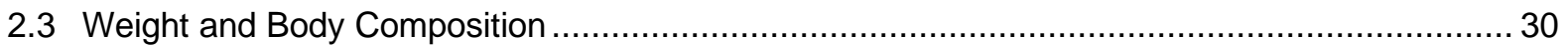

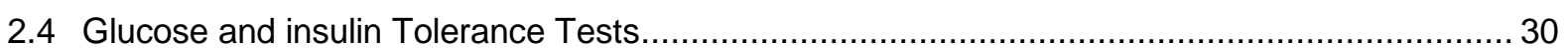

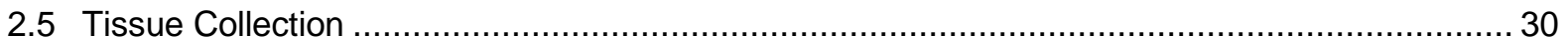

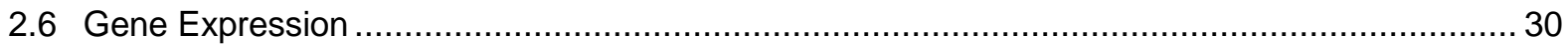

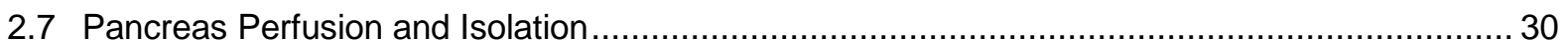

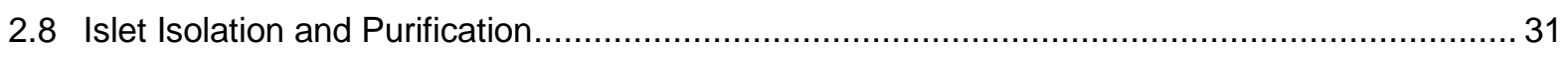

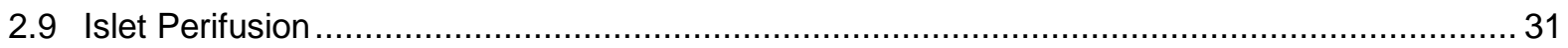

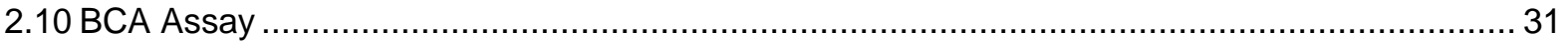

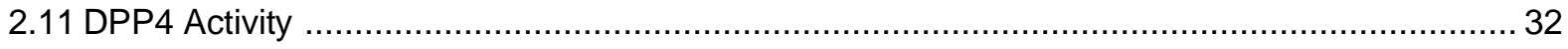

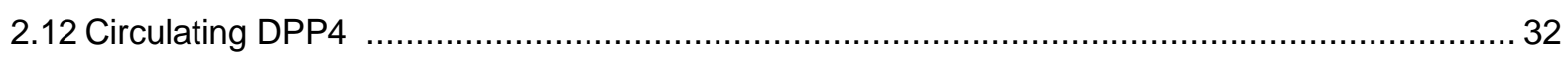

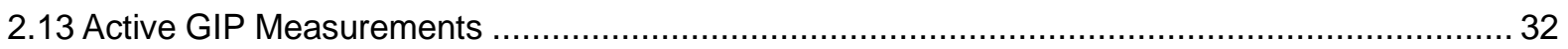

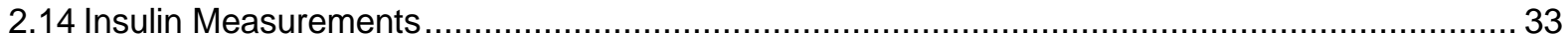




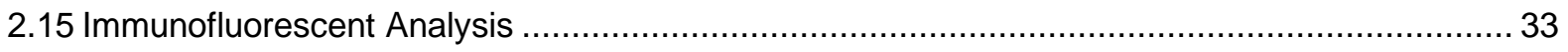

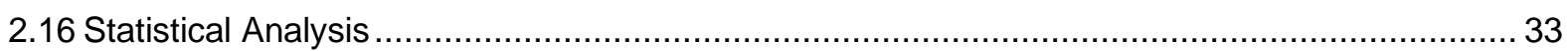

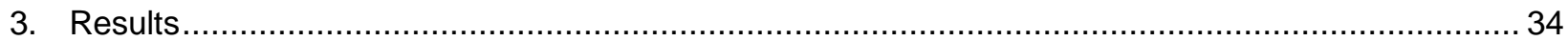

3.1 Activation of the GLP-1R and GIPR Within the $\beta$-cell Is Critical for Regulation of

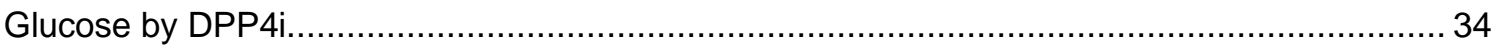

3.2 Genetic Elimination of Dpp4 Leads to Increased Pancreatic Insulin Content and May

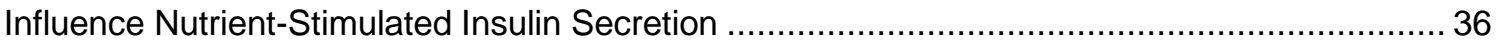

3.3 Dpp $4^{\beta-c e l l-/}$ Mice Have Significantly Reduced Islet DPP4 Activity and Expression ..................... 38

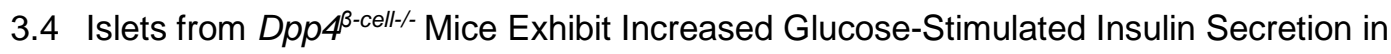
Perifusion

3.5 Dpp $4^{\beta-c \text { cell-- }}$ Male Mice on Chow Diet Exhibit Normal Glucose Tolerance and Retain Glucoregulatory Responses to Sitagliptin

3.6 Elimination of $\beta$-cell-Derived Dpp4 Fails to Improve Glucose Tolerance or Prevent Incretin Degradation in HFD-fed Mice in vivo.................................................................. 44

3.7 $\beta$-Cell-Derived Dpp4 May Play a Role in Glucose Regulation in Female Mice Fed Chow Diet.

3.8 Elimination of $\beta$-cell-derived DPP4 Improves Oral Glucose Tolerance and Enhances Insulin Sensitivity in HFD-Fed Female Mice

3.9 Genetic Elimination of Dpp4 in the Whole Pancreas (Dpp $\left.4^{\text {Pan--/ }}\right)$ Fails to Improve Glucose Tolerance in Mice Fed Normal Chow or High-Fat Diet 50

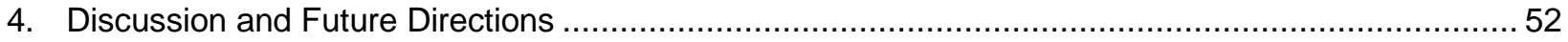

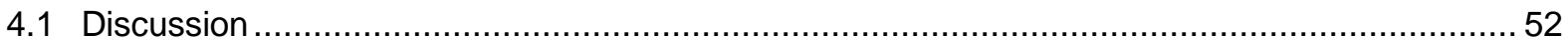

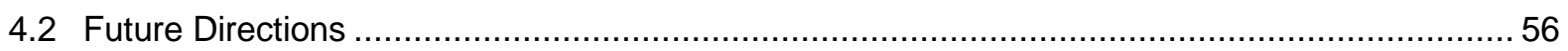

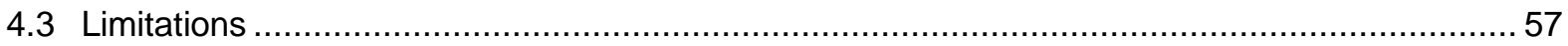

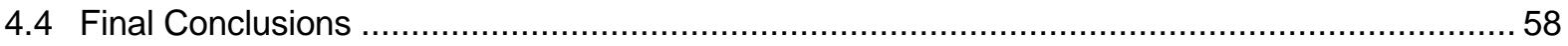

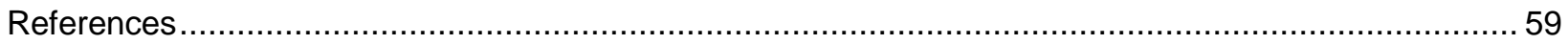

Appendix: Supplementary Figure 1. Linkage Disequilibrium Between Dpp4 and Gcg ........................ 84 


\section{List of Figures}

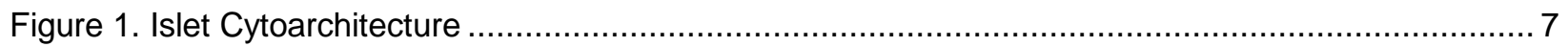

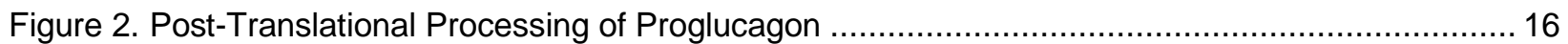

Figure 3. Cellular Sources of DPP4 and Control of the Incretin Axis ................................................ 24

Figure 3.1. Activation of the GLP-1R and GIPR Within the $\beta$-cell Is Critical for Regulation of

Glucose by DPP4i 35

Figure 3.2. Genetic Elimination of Dpp4 Leads to Increased Pancreatic Insulin Content in HFD-Fed Mice, but Has No Significant Effects on Islets While on Regular Chow 37

Figure 3.3. Islets from $D p p 4^{\beta-c e l l-/}$ Mice Have Significantly Reduced Islet DPP4 Activity and Expression

Figure 3.4. Islets from $D p p 4^{\beta \text {-cell-/- }}$ Mice Exhibit Increased Glucose-Stimulated Insulin Secretion in Perifusion

Figure 3.5. Dpp $4^{\beta-c e l l-/}$ Male Mice on Chow Diet Exhibit Normal Glucose Tolerance and Retain Glucoregulatory Responses to Sitagliptin....

Figure 3.6. Elimination of $\beta$-cell-derived DPP4 Does Not Improve Glucose Tolerance or Prevent Incretin Degradation in vivo

Figure 3.7. $\beta$-Cell-derived Dpp4 Has a Role in Glucose Regulation in Female Mice Fed Chow Diet

Figure 3.8. Elimination of $\beta$-cell-derived DPP4 Improves Oral Glucose Tolerance and Enhances Insulin Sensitivity in HFD-Fed Female Mice in vivo

Figure 3.9. Genetic Elimination of Dpp4 in the Whole Pancreas (Dpp4 $\left.4^{\text {Pan-/ }}\right)$ Fails to Improve Glucose Tolerance in Mice Fed Normal Chow or High-Fat Diet. 


\section{List of Tables}

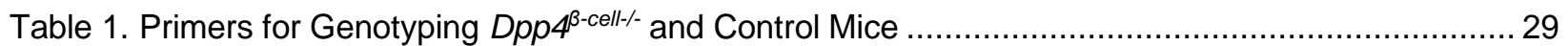




\section{List of Appendices}

Appendix 1. Linkage Disequilibrium Between Dpp4 and Gcg

84 


\section{List of Abbreviations}

\begin{tabular}{|c|c|}
\hline AAV & Adeno-Associated Virus \\
\hline ADA & Adenosine Deaminase \\
\hline ADP & Adenosine Diphosphate \\
\hline ANOVA & Analysis of Variance \\
\hline AS160 & Akt Substrate of $160 \mathrm{kDa}$ \\
\hline ATP & Adenosine Triphosphate \\
\hline BAD & BCL2-Associated Agonist of Cell Death \\
\hline $\mathrm{BCA}$ & Bicinchoninic Acid \\
\hline BSA & Bovine Serum Albumin \\
\hline cAMP & Cyclic AMP; Cyclic Adenosine Monophosphate \\
\hline CD4 & Cluster of Differentiation 4 \\
\hline CNS & Central Nervous System \\
\hline CPE & Carboxypeptidase E \\
\hline DAPI & 4',6-diamidino-2-phenylindole \\
\hline DASH & DPP4 Activity and/or Structure Homologue \\
\hline DIRKO & Double Incretin Receptor Knockout \\
\hline DNA & Deoxyribonucleic Acid \\
\hline DPP4 & Dipeptidyl Peptidase-4 \\
\hline DPP4i & Dipeptidyl Peptidase-4 Inhibitor \\
\hline $\mathrm{EC}$ & Endothelial Cell \\
\hline ELISA & Enzyme-Linked Immunosorbent Assay \\
\hline eNOS & Endothelial Nitric Oxide Synthase \\
\hline ER & Endoplasmic Reticulum \\
\hline FAP & Fibroblast Activation Protein \\
\hline FBS & Fetal Bovine Serum \\
\hline FDA & Food and Drug Administration \\
\hline FFA & Free Fatty Acid \\
\hline FOXO1 & Forkhead Box O1 \\
\hline GABA & Gamma-Aminobutyric Acid \\
\hline GCGR & Glucagon Receptor \\
\hline GCSF & Granulocyte Colony-Stimulating Factor \\
\hline $\mathrm{GH}$ & Growth Hormone \\
\hline $\mathrm{GH}$ & Growth Hormone \\
\hline $\mathrm{GHIH}$ & Growth Hormone-Inhibiting Hormone \\
\hline GIP & Gastric Inhibitory Polypeptide \\
\hline
\end{tabular}




\begin{tabular}{|c|c|}
\hline GIPR & Gastric Inhibitory Polypeptide Receptor \\
\hline GLP-1 & Glucagon-Like Peptide-1 \\
\hline GLP-1R & Glucagon-Like Peptide-1 Receptor \\
\hline GLP-1RA & Glucagon-Like Peptide-1 Receptor Agonist \\
\hline GLUT & Glucose Transporter \\
\hline GRPP & Glicentin-Related Pancreatic Peptide \\
\hline GSIS & Glucose-Stimulated Insulin Secretion \\
\hline GSK3 & Glycogen Synthase Kinase 3 \\
\hline HBSS & Hanks' Balanced Salt Solution \\
\hline HFD & High-Fat Diet \\
\hline i.p. & Intraperitoneal \\
\hline IGF-1 & Insulin-Like Growth Factor-1 \\
\hline IGF-2 & Insulin-Like Growth Factor-2 \\
\hline IP2 & Intervening Peptide-2 \\
\hline ipGTT & Intraperitoneal Glucose Tolerance Test \\
\hline IR & Insulin Receptor \\
\hline IRS & Insulin Receptor Substrate \\
\hline IRS-2 & Insulin Receptor Substrate-2 \\
\hline ITT & Insulin Tolerance Test \\
\hline $\mathrm{KRBH}$ & Krebs-Ringer bicarbonate-HEPES buffer \\
\hline MAPK & Mitogen Activated Protein Kinase \\
\hline MIP1a & Macrophage Inflammatory Protein $1 \alpha$ \\
\hline MMP & Metalloprotease \\
\hline mRNA & Messenger RNA \\
\hline mTOR & Mammalian Target of Rapamycin \\
\hline NPY & Neuropeptide Y \\
\hline oGTT & Oral Glucose Tolerance Test \\
\hline PBS & Phosphate Buffered Saline \\
\hline PC & Prohormone Convertase \\
\hline PDGF & Platelet-Derived Growth Factor \\
\hline PDK & 3-Phosphoinositide Dependent Protein Kinase \\
\hline PI3K & Phosphoinositide 3-Kinase \\
\hline PIP3 & Phosphatidylinositol-3,4,5-Triphosphate \\
\hline PKB & Protein Kinase B \\
\hline PP & Pancreatic Polypeptide \\
\hline PPARY & Peroxisome Proliferator-Activated Receptor Gamma \\
\hline PYY & Peptide Tyrosine Tyrosine \\
\hline
\end{tabular}




$\begin{array}{ll}\text { RER } & \text { Rough Endoplasmic Reticulum } \\ \text { RNA } & \text { Ribonucleic Acid } \\ \text { ROS } & \text { Reactive Oxygen Species } \\ \text { RRP } & \text { Readily-Releasable Pool } \\ \text { SEM } & \text { Standard Error of the Mean } \\ \text { SGLT2 } & \text { Sodium-Dependent Glucose Transporter-2 } \\ \text { SHC } & \text { Src Homology 2 Domain-Containing } \\ \text { SNARE } & \text { SNAp Receptor; Soluble N-Ethylmaleimide-Sensitive Factor Attachment Protein Receptor } \\ \text { SNP } & \text { Single-Nucleotide Polymorphism } \\ \text { SST } & \text { Somatostatin } \\ \text { SSTR } & \text { Somatostatin Receptor } \\ \text { SU } & \text { Sulfonylurea } \\ \text { T2D } & \text { Type II Diabetes } \\ \text { TCA } & \text { Tricarboxylic Acid } \\ \text { TZD } & \text { Thiazolidinedione } \\ \text { UDPG } & \text { Uridine Diphosphate Glucose } \\ \text { VEGF } & \text { Vascular Endothelial Growth Factor } \\ \text { VGCC } & \text { Voltage-Gated Ca2+ Channel }\end{array}$




\section{Introduction}

\section{$1.1 \quad$ Diabetes}

\subsubsection{Global Burden of Disease}

Diabetes prevalence continues to increase globally, affecting an estimated $7 \%$ of people and representing a heavy burden on the healthcare system worldwide (Hu, 2011; Khan et al., 2020). Diabetes is a chronic condition that impairs the body's ability to make insulin or to respond to the insulin secreted in response to food intake effectively. Type 2 diabetes (T2D) specifically is characterized by decreased insulin release and/or insulin resistance, decreased glucose uptake by the peripheral tissues, and elevated hepatic glucose production, all leading to persistent high blood sugar, or hyperglycemia (Bogardus et al., 1984; Samuel and Shulman, 2012). Over time, it can lead to significant microvascular complications affecting the function of the eyes, nerves, and kidneys. Furthermore, patients with T2D are at a significantly increased risk of developing coronary heart disease, ischaemic stroke, and many other cardiovascular complications (Sarwar et al., 2010). The risk of cardiovascular death in patients with T2D is so significant that the FDA mandated all new therapies undergo rigorous cardiovascular outcome trial. The continued rise in diabetes has been attributed to a complex interplay between a variety of factors, including growing urbanization, changing lifestyle habits, genetics, socioeconomic status, and the environment (Ali, 2013; Brown et al., 2004; Popkin and Gordon-Larsen, 2004; Prasad and Groop, 2015). As we continue to learn about the risks and possible causes of T2D, further understanding of the underlying mechanisms is essential for the development of effective treatments.

\subsubsection{Physiological Regulation of Glucose Homeostasis}

In healthy individuals, plasma glucose levels are maintained within a narrow range through a system of islet-derived hormones and neural pathways, that in turn regulate glucose transport proteins, glucose absorption, endogenous glucose production, and glucose uptake and release (Schwartz and Porte, 2005; Schwartz et al., 2013). Two major glucoregulatory hormones secreted by the endocrine pancreas are insulin and glucagon. Glucagon is released from the islet $\alpha$-cell during the fasting state, and it works to increase low blood sugar. Glucagon binds to the glucagon receptor, a transmembrane G-protein coupled receptor expressed predominantly in the liver, with less found in the kidneys, heart, adipose tissue, and the adrenal gland (Svoboda et al., 1994). This binding promotes glycogenolysis in the liver and gluconeogenesis through the cyclic adenosine monophosphate (cAMP) messenger activation (Tengholm and Gylfe, 2017). Conversely, insulin is released from the islet $\beta$-cells in response to elevated blood sugar and food ingestion, and it exhibits a blood glucose-lowering effect through inhibiting endogenous glucose production and stimulating glucose uptake. By binding to its receptor on the surface of cells, insulin promotes the recruitment of the high-affinity glucose transporter 4 (GLUT4) to the surface of skeletal and fat cells, stimulating glucose transport across the membrane and subsequent glucose uptake (Bryant et al., 
2002). The disruption of these processes can lead to metabolic abnormalities, including blood glucose dysregulation and diabetes (Qaid and Abdelrahman, 2016).

Dietary carbohydrates can be used by the body for energy production and storage through several pathways. Glucose entering the small intestine after a meal is translocated from the intestinal lumen into the enterocytes through the sodium-dependent glucose transporter 1 (SGLT-1), and out into the interstitial space via the glucose transporter 2 (GLUT2) (Chen et al., 2016; Thorens, 1996). There, it is directly absorbed into the capillaries to be further delivered to and processed by many tissues, but mainly the liver and skeletal muscle, where glycogenesis and glycolysis take place (Chen et al., 2016). Glycogenesis, or the process of glycogen formation, utilizes glucose molecules from the circulation to synthesize glycogen as a form of energy storage. Glycogenesis starts with phosphorylation of a glucose molecule to G-6-P by hexokinases, followed by G-1-P formation through the transfer of a phosphate group from carbon 6 to carbon 1, and finally, uridine diphosphate glucose (UDPG) formation (Adeva-Andany et al., 2016; Blanco and Blanco, 2017). This transformation allows the glucose molecule to be added to the polymer backbone of the preexisting glycogen. In a combined hyperglycemic-hyperinsulinemic clamp study, the synthesis of muscle glycogen accounted for most of the total-body glucose uptake, and was the principal pathway of glucose disposal in both healthy and T2D subjects (Shulman et al., 1990). In addition to glycogenesis, liver and skeletal muscle contribute to post-prandial glucose disposal through glycolysis (Ferrannini et al., 1985; Kelley et al., 1988). Through a series of steps, glucose is converted to pyruvate, followed by its entry into the tricarboxylic acid (TCA) cycle and oxidative phosphorylation, ultimately leading to the generation of adenosine triphosphate, or ATP.

In the fasted state, the liver plays a major role in glucose homeostasis by elevating blood glucose through two distinct mechanisms. Fasting induces a reduction in insulin signaling and an increase in glucagon, and catecholamine signaling initiates a cAMP-dependent pathway to activate glycogen phosphorylase and glycogenolysis, or the breakdown of glycogen (Han et al., 2016; Petersen et al., 2017). It is the predominant source of glucose released into systemic circulation in the early stages of fasting. Exercise or prolonged fasting resulting in glycogen depletion further leads to gluconeogenesis, or de novo glucose synthesis (Geisler et al., 2016). In this process, hepatocytes use gluconeogenic substrates such as pyruvate, lactate, glycerol, or amino acids to create glucose molecules, which are then released into the circulation and metabolized by extrahepatic tissues (Han et al., 2016). However, the dysregulation of these processes in patients with T2D leads to a significant reduction in postprandial glycogenesis, impaired inhibition of endogenous glucose production following a meal, and a reduction in skeletal muscle glucose disposal (Bokhari et al., 2009; Krssak et al., 2004), all contributing to impaired glucose metabolism and persistent hyperglycemia. 


\subsubsection{Diabetes Therapies}

Current therapies available to patients with $\mathrm{T} 2 \mathrm{D}$ are aimed at reducing the risks associated with the condition through managing hyperglycemia, as well as concurrent features such as dyslipidemia, hypertension, obesity, and insulin resistance. Intensive glycemic control in patients with diabetes mellitus has been shown to significantly delay the onset of diabetic retinopathy, nephropathy, and neuropathy (Ohkubo et al., 1995; UK Prospective Diabetes Study Group, 1998). Various formulations of insulin and insulin analogs continue to be developed for glycemia regulation for both type I and II diabetes. However, in addition to technical risks associated with regular subcutaneous injections, insulin-based therapies carry an increased risk of hypoglycemic episodes which are associated with increased morbidity and mortality (Dimeglio et al., 2004; Hanas and Ludvigsson, 2006; Pickup and Renard, 2008).

\subsubsection{Metformin}

Due to its high tolerability and ease of administration, metformin has been a popular early-phase antidiabetic agent since its introduction in the 1950s. Its primary glucoregulatory action is through a reduction in hepatic glucose output (Jackson et al., 1987; Perriello et al., 1994), while other studies suggest it may also increase glucose uptake into the peripheral tissues (Shaw et al., 2005), improve $\beta$-cell function (Diaz et al., 2017), and enhance insulin sensitivity (Gin et al., 1985). The liver-dominant mechanism of metformin is further supported by more recent clinical data, which demonstrated a pronounced reduction in hepatic glucose production without major changes in peripheral glucose disposal or insulin secretion (LaMoia and Shulman, 2020). However, a large number of patients taking metformin (11-26\%) report gastrointestinal complications while taking both extended- and immediate-release preparations, with approximately 5\% further developing metformin intolerance (Dujic et al., 2015; McCreight et al., 2016). This effect has been linked by other studies with the metformin-associated shifts in the intestinal microbiome composition, although the origin or contribution of this change to glucose-lowering remains unclear (LaMoia and Shulman, 2020). Additionally, although extremely rare, a serious and potentially fatal complication of metformin is metformin-associated lactic acidosis as a result of dehydration and acute renal failure (Vecchio and Protti, 2011).

\subsubsection{Suflonylureas and Thiazolidinediones}

Sulfonylurea (SU) and thiazolidinedione (TZD) drugs offer glycemic control through stimulating insulin secretion and increasing insulin sensitivity, respectively (Proks et al., 2002). SUs directly stimulate endogenous insulin secretion by binding to the ATP-sensitive potassium channels on insulin-producing $\beta$ cells, which causes membrane depolarization and release of insulin-containing secretory granules (Proks et al., 2002). As their glycemia-regulating effect depends on the presence of functional $\beta$-cells, SUs are most effective at the beginning stages of T2D, with over $50 \%$ of patients requiring additional therapy after 6 years (Wright et al., 2002). On the other hand, TZDs exert their glucose-lowering action by improving 
insulin-mediated glucose uptake into the peripheral tissues and hepatic insulin sensitivity (Natali and Ferrannini, 2006). TZDs act as potent peroxisome proliferator-activated receptor gamma (PPARY) ligands, although their exact mechanisms of action have not yet been described, as PPARY is present in a variety of metabolic tissues (Soccio et al., 2014; Tonelli et al., 2004). Through the activation of PPARY in the adipose tissue, TZDs were found to modulate gene expression, induce adipose tissue remodeling and adipocyte differentiation, thereby altering hormone signaling and mediating glucose disposal (Brunmair et al., 2004). Despite their potent insulin-sensitizing action, TZDs are now less popular in clinical use due to significantly increased risks of developing heart failure, macular oedema, and bone fractures (Motola et al., 2012; Soccio et al., 2014).

\subsubsection{Sodium-Glucose Cotransporter-2 (SGLT2) Inhibitors}

SGLT2 inhibitors are a new class of drugs that inhibit renal glucose reabsorption, allowing it to be excreted in the urine. SGLT2 protein expressed in the kidney accounts for $90 \%$ of filtered glucose reuptake (Hsia et al., 2017). The renal threshold for reabsorption of glucose is elevated in patients with T2D, causing a maladaptive response to glucose consumption. Selective SGLT2 inhibition can greatly reduce this threshold, increasing the excretion of glucose in urine and decreasing plasma glucose concentration without stimulating insulin release (Hsia et al., 2017). Clinical studies of SGLT2 inhibition have demonstrated additional beneficial effects, including weight loss and a significant reduction in blood pressure (Desouza et al., 2015; Monami et al., 2014). However, detectable glucose concentrations in urine resulting from SGLT2 inhibition were found to increase the incidences of genital mycotic infections, urinary tract infections, and adverse events related to osmotic diuresis (Davidson and Kuritzky, 2014). Lastly, canagliflozin, a type of SGLT2 inhibitor, was shown to increase the risk of lower extremity amputation, but no specific mechanism or at-risk group has yet been identified (Hsia et al., 2017)

\subsubsection{Incretin therapies}

Finally, two classes of anti-diabetic drugs that have emerged more recently are incretin-based drugs and DPP4 inhibitors, both of which employ the body's innate response to increases in blood glucose. Incretin hormones glucagon-like peptide-1 (GLP-1) and gastric inhibitory polypeptide (GIP) exert a glucoselowering effect through potentiating glucose-stimulated insulin secretion and inhibiting glucagon secretion from the pancreas (Drucker, 2006). They are, in turn, rapidly inactivated by ubiquitously expressed enzyme, dipeptidyl peptidase-4, or DPP4 (Mulvihill and Drucker, 2014). Incretin mimetics, such as GLP-1 receptor agonists (GLP-1RAs), are resistant to degradation by DPP4 in vivo, allowing them to exhibit a prolonged and more potent glucose-lowering effect than native GLP-1. From a clinical perspective, however, GLP-1 agonists can have tolerability issues due to common persistent gastrointestinal discomfort and daily or weekly subcutaneous injections (Lovshin and Drucker, 2009).

Pharmacological inhibition of DPP4 with DPP4 inhibitors (DPP4i), on the other hand, provides a valuable complementary approach for glycemia regulation. DPP4 inhibition prevents incretin degradation, 
improves glucose tolerance, and enhances insulin response in patients with T2D (Mulvihill and Drucker, 2014). DPP4 inhibitors are generally well-tolerated, and short-term studies have not found any major increases in cancer or pancreatitis incidence in T2D patients (Monami et al., 2011). DPP4 inhibitors have demonstrated neither benefit nor harm after completion of cardiovascular outcome trials (Santamarina and Carlson, 2019). While concerns about long-term effects of DPP4 inhibitors, particularly their safety and the role of DPP4 inhibition in the progression of the disease have been raised, (Lovshin and Drucker, 2009; Santamarina and Carlson, 2019; Zhong et al., 2016) the completion of the cardiovascular outcome trials has not validated this unease.

\subsection{The Endocrine Pancreas}

\subsubsection{Islet Architecture}

Pancreatic islets, also known as the Islets of Langerhans, are highly vascularized clusters of endocrine cells within the pancreas that produce and secrete a variety of hormones to regulate metabolism. The major hormone-secreting cell types found in the islets are glucagon-producing $\alpha$-cells, insulinproducing $\beta$-cells, somatostatin-secreting $\delta$-cells, as well as less abundant ghrelin-secreting $\varepsilon$-cells and pancreatic polypeptide (PP) - producing cells (Andralojc et al., 2009; Brissova et al., 2005; Wang et al., 2013). The cytoarchitecture of islets has been found to vary greatly between species, which may correlate with differences in islet adaptability, and plasticity (Kim et al., 2009), although their endocrine function remains similar (Fig. 1).

In the non-diabetic, adult, human pancreas, the total number of islets is estimated to be between 3.6 and 14.8 million, with the number gradually increasing from the head to the tail section of the pancreas (Saito et al., 1978). While numerous, islets were found to take up a total volume of $0.544-1.311 \mathrm{~cm}^{3}$, or $0.4-0.7 \%$ of the total volume of the pancreas (Saito et al., 1978). In humans, they are made up of approximately $40 \%$ a-cells and $50 \% \beta$-cells, with the remainder accounting for other cell types (Brissova et al., 2005; Cabrera et al., 2006; Kim et al., 2009). Human islets exhibit heterogeneous organization, with different cell types distributed throughout the islet with no particular patterns and often apposed to blood vessels (Kim et al., 2009). This type of organization may allow for direct interaction and paracrine signalling between $\alpha$ - and $\beta$-cells independent of external factors.

Laboratory mice and rats are often used in islet biology research, and therefore it's important to acknowledge several key morphological differences between human and rodent islets. First, both mouse and rat islets have a well-defined islet structure, comprising of a "core" of $\beta$-cells surrounded by a "mantle" of $\alpha$ - and $\delta$-cells (Cabrera et al., 2006; Kim et al., 2009). This organization has been suggested to play an important role in the synchronization of the $\beta$-cell activity in mice (Meissner, 1976; Ravier et al., 2005). The proportion of insulin-containing cells is $61-88 \%$ in a mouse islet, significantly higher than a human islet (Brissova et al., 2005). Furthermore, human and mouse islets exhibit distinct vascularization and innervation patterns, which may contribute to more functional differences between the species. Mouse islets 
have increased vessel branching, vessel diameter, and total vessel network compared to human islets (Cohrs et al., 2017). Similarly, mouse islets are densely innervated, while human islet innervation was found to be sparse, with most endocrine cells lacking autonomic innervation (Rodriguez-Diaz et al., 2011). 

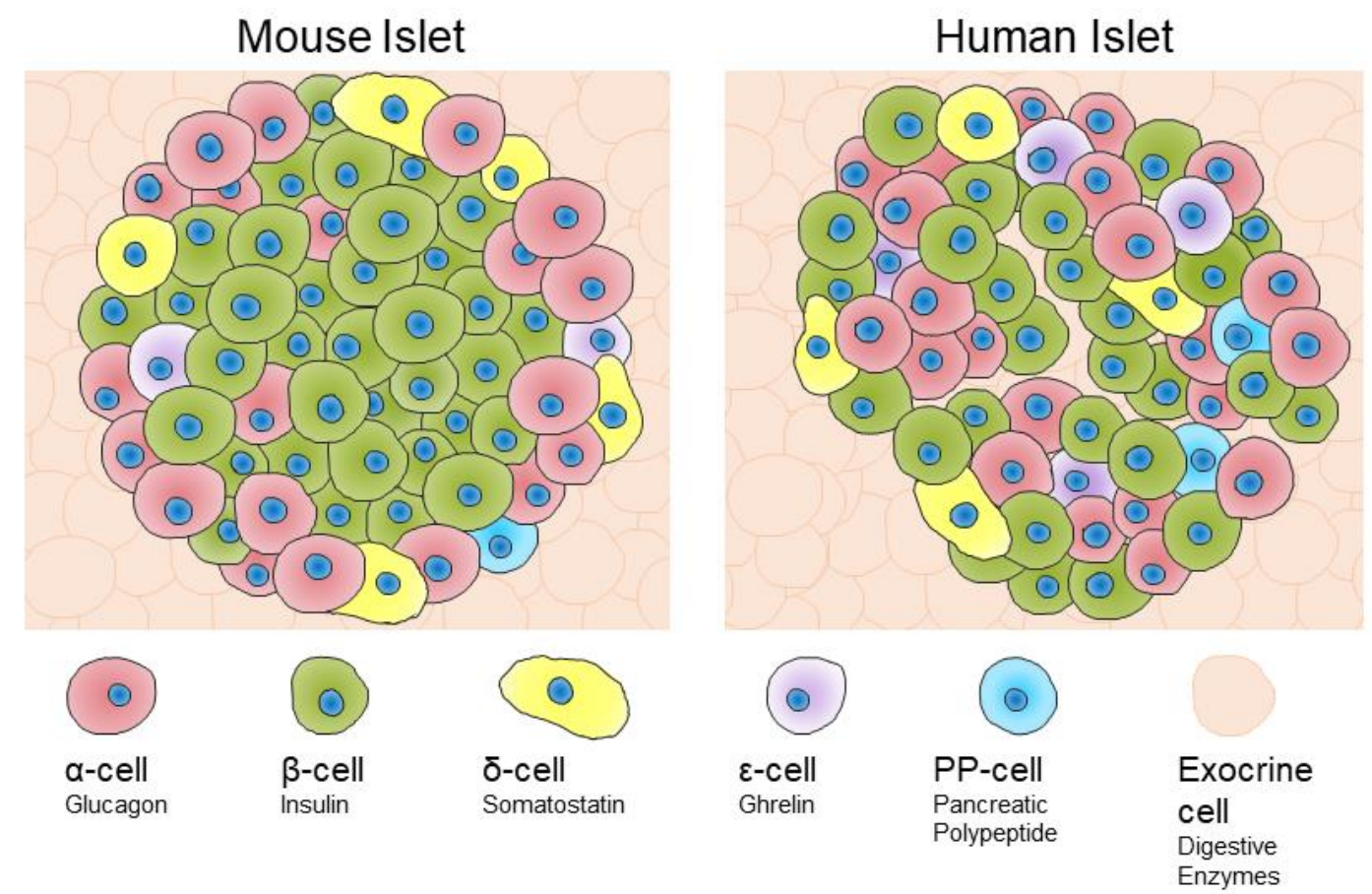

Figure 1. Islet Cytoarchitecture

Adapted from Brissova et al., 2005; Cabrera et al., 2006; Andralojc et al., 2008 


\subsection{2 $\beta$-Cells}

Pancreatic islet $\beta$-cells maintain blood glucose homeostasis through the production and timely secretion of insulin. Insulin stimulates glucose uptake into skeletal cells through the recruitment of GLUT4 transporter to their surface, promotes fatty acid synthesis in the liver, and suppresses the breakdown of fat in adipose tissue (Carmen and Víctor, 2006; Manchester, 1972; Wong and Sul, 2010). At the cellular level, insulin secretion decreases glycogen breakdown and gluconeogenesis through modulating the activity of glycogen phosphorylase and 2,6 biphosphate kinase. Concurrently, it increases glycogenesis and glycolysis through dephosphorylating glycogen synthase and pyruvate kinase, respectively (Wilcox, 2005).

\subsubsection{1 $\beta$-Cell Proliferation}

During pancreatic development, the formation of new $\beta$-cells occurs through two distinct pathways: replication of already differentiated $\beta$-cells, and differentiation of new $\beta$-cells from stem cell precursors, also known as neogenesis (Swenne, 1992). The most studied factors regulating $\beta$-cell growth include glucose, which stimulates $\beta$-cell replication in both fetal and adult rodent islets, as well as insulin and insulin-like growth factor-1 (IGF-1), which stimulate $\beta$-cell replication in neonatal rodent pancreatic cells. Other factors, such as growth hormone $(\mathrm{GH})$, prolactin and placental lactogen, insulin-like growth factor-2 (IGF-2), platelet-derived growth factor (PDGF), and several amino acids, have all been shown to stimulate $\beta$-cell replication in vitro, however, their effects remain to be examined in vivo (Reddy, 2000).

\subsubsection{2 $\beta$-Cell Compensation}

Total $\beta$-cell mass can also increase due to expansion of individual $\beta$-cells (Swenne, 1992). It is often initiated during the pre-diabetic insulin intolerance stage, in which islet $\beta$-cells hypersecrete insulin to cope with the increasing metabolic demand to maintain normoglycemia (Prentki and Nolan, 2006). Increased glucose utilization and oxidation, coupled with increases in free fatty acid (FFA) cycling and intestinal GLP-1 signaling promote $\beta$-cell proliferation and neogenesis while preventing apoptosis, leading to $\beta$-cell mass expansion, or hypertrophy (Prentki and Nolan, 2006). GLP-1 further enhances $\beta$-cell proliferation by activating the Insulin Receptor Substrate-2 (IRS-2) signaling pathway and deactivating the Forkhead Box 01 (FOXO1) transcription factor, thus increasing expression of the PDX1 gene, a factor involved in $\beta$-cell proliferation and survival (Prentki and Nolan, 2006). Insulin and IGF-1 have also been proposed to play important roles in these processes. Similar to GLP-1, they act through the IRS-2 pathway via protein kinase $B(P K B)$ phosphorylation, which inhibits proapoptotic proteins such as BCL2 associated agonist of cell death, or BAD (Prentki and Nolan, 2006).

\subsubsection{3 $\beta$-Cell Apoptosis}

Overtime, chronic exposure to elevated glucose and FFA levels negatively alters islet function and contributes to the progression from insulin intolerance to T2D. The heightened demand for $\beta$-cells to 
produce insulin leads to increased proinsulin peptide biosynthesis, which causes an increase in rough endoplasmic reticulum (RER) protein flux (Donath and Halban, 2004). As RER flux is already high in $\beta$-cells compared with other cell types, this further increase may be contributing to the ER-stress-induced apoptosis (Donath and Halban, 2004). High glucose has been shown to generate reactive oxygen species (ROS), which are toxic to many cell types, and particularly to the $\beta$-cells (Ihara et al., 1999; Ross Laybutt et al., 2002). Furthermore, through a separate pathway, high glucose promotes the production of the proinflammatory cytokine IL-1 $\beta$ from the $\beta$-cell, which inhibits $\beta$-cell function and induces Fas-triggered apoptosis in vitro (Maedler et al., 2002). Both obese and lean patients with T2D exhibit decreased $\beta$-cell volume compared to age- and weight-matched non-diabetic patients (Butler et al., 2003). The rate of $\beta$-cell apoptosis was found to increase 10-fold in lean and 3-fold in obese T2D patients compared to the subjects without diabetes (Butler et al., 2003), suggesting that apoptosis is the mechanism underlying $\beta$-cell mass decrease in T2D.

\subsubsection{Insulin}

Insulin is encoded by the INS gene on chromosome 11 at position 15.5, and its biosynthesis occurs in a set of steps within the $\beta$-cell. First, the mRNA transcript is translated into a single-chain precursor, preproinsulin, consisting of the signal peptide, insulin A- and B-chains, and C-peptide (Liu et al., 2014b). The signal peptide guides the translocation of preproinsulin into the endoplasmic reticulum (ER) lumen, where it is cleaved by signal peptidase, forming proinsulin (Liu et al., 2014b). Within the ER lumen, ER chaperone proteins assist in proinsulin folding and disulfide bond formations, generating a direct insulin precursor with tertiary structure (Bass et al., 1998; Ozawa et al., 2005). Properly folded proinsulin is then trafficked through the Golgi apparatus and packaged into immature granules, which accumulate in the cytoplasm (Liu et al., 2014b). The final steps of proinsulin maturation occur in these granules through endoproteolytic cleavage by prohormone convertases (PC) 1/3, PC2, and exopeptidase cleavage by carboxypeptidase $\mathrm{E}(\mathrm{CPE})$. First, $\mathrm{PC} 1 / 3$ preferentially cleaves at the $\mathrm{B}-\mathrm{C}$ junction, exposing a dibasic Arg31-Arg32 motif, which is removed by CPE to form an intermediate called des-31,32 proinsulin (Furuta et al., 1998; Rhodes et al., 1992). This is followed by similar processing by PC2 and CPE on the other side, converting proinsulin to mature insulin and a C-peptide (Liu et al., 2014b). Mature human insulin is composed of two peptide chains linked together by disulfide bonds. The A-chain consists of 21 amino acids, and the B-chain of 30 amino acids, with two interchain bonds formed between the cysteine residues at A7B7 and A20-B19, and one intrachain bond at A6-A11 (Baker et al., 1988).

\subsubsection{Insulin Secretion From the $\beta$-cell}

The process of insulin secretion from the $\beta$-cell is primarily stimulated by a high concentration of blood glucose and occurs in two stages - rapid but transient early stage, followed by a less intense but more sustained second phase (Bratanova-Tochkova et al., 2002; Komatsu et al., 2013). This biphasic pattern is thought to occur due to the existence of several "pools" of insulin granules within the $\beta$-cell, that 
can be characterized by their release competence and proximity to the plasma membrane (Rorsman and Renström, 2003). The readily-releasable pool (RRP) is found in direct contact with the plasma membrane and accounts for $1-5 \%$ of the total number of insulin granules within a cell, available for immediate secretion following stimulation (Eliasson et al., 1997; Olofsson et al., 2002; Rorsman and Renström, 2003). The depletion of RRP and the exocytotic capacity of the cell are recovered by the physical translocation of granules from the non-releasable pool to the membrane (Rorsman and Renström, 2003). Unlike the RRP, these granules must undergo a series of priming steps involving a formation of SNARE complexes (Xu et al., 1999) and granular acidification by a $V$-type $\mathrm{H}^{+}$-ATPase (Barg et al., 2001) to gain release competence.

Glucose-stimulated insulin secretion, or GSIS, is initiated through membrane depolarization by the KATP-dependent pathway (Komatsu et al., 2013). First, glucose serves as a substrate for ATP generation through glycolysis and oxidative phosphorylation. This increase in ATP and accompanying decrease in ADP leads to a shift in the ATP/ADP ratio, which closes ATP-sensitive potassium (K $\left.K_{\text {ATP }}\right)$ channels and leads to membrane depolarization. This, in turn, opens L-type voltage-gated $\mathrm{Ca}^{2+}$ channels (VGCCs), causing a $\mathrm{Ca}^{2+}$ influx and consequently triggering exocytosis of insulin secretory granules from the $\beta$-cell into the hepatic portal vein (Komatsu et al., 2013; Soria et al., 2004). Experiments in mouse islets have estimated first and second phase insulin secretion to amount to $0.14 \% / \mathrm{min}$ and $0.05 \% / \mathrm{min}$ of the total cell insulin content, respectively (Rorsman and Renström, 2003). In addition to glucose, amino acids like arginine, leucine, and alanine, as well as some neurotransmitters and hormones, have been found to stimulate $\beta$ cell membrane depolarization and insulin release either directly (through an accumulation of positive charges in the $\beta$-cell) or through $\mathrm{Na}^{+}$co-transporters (Charles et al., 1982; Henquin and Meissner, 1981; Hermans et al., 1987; Newsholme et al., 2006; Svendsen et al., 2018). However, most of them are unable

to initiate this process independently and require the presence of glucose concentrations approaching the threshold for insulin secretion to be effective.

\subsubsection{Insulin Receptor (IR)}

Insulin produces its metabolic effects through binding to its receptor located in the cell membrane of target tissues, such as liver, adipose tissue, skeletal muscle, kidney, and the brain (Belfiore et al., 2009). The insulin receptor (IR) belongs to the receptor tyrosine kinase superfamily of proteins, and in humans it is encoded by a single gene, INSR (Ebina et al., 1985; Ullrich et al., 1985). Alternative splicing of the primary transcript results in the generation of either $\alpha$ - or $\beta$-subunit of the receptor (Belfiore et al., 2009). The mature IR protein is a heterotetramer, which contains two extracellular $\alpha$-subunits and 2 transmembrane $\beta$ subunits, linked together by disulfide bonds (Belfiore et al., 2009; Lawrence et al., 2007).

\subsubsection{IR Signal Transduction Pathway}

Insulin binding to the extracellular $\alpha$-subunit induces a conformational change in the IR, which allows the two $\beta$-subunits to associate, and leads to autophosphorylation of the kinase domains (Belfiore et al., 2009). The activated IR tyrosine kinase is then able to initiate a signalling cascade through recruitment 
of several docking proteins, although most effects appear to be mediated through the insulin receptor substrates (IRS) 1 and 2, and the adapter Src homology 2 domain-containing protein (SHC) (Giorgetti et al., 1994; Giovannone et al., 2000; Taniguchi et al., 2006; Valverde et al., 1998; Versteyhe et al., 2009). Phosphorylation of these substrates further leads to the activation of two canonical IR signaling cascades - phosphoinositide 3-kinase (PI3K) pathway and the mitogen-activated protein kinase (MAPK) pathway (De Meyts, 2000). The MAPK signaling cascade is involved in insulin-mediated regulation of gene expression, mitogenesis, and differentiation (De Meyts, 2000). The pathway is activated exclusively through the IR/IRS interaction and is responsible for most metabolic effects of insulin (De Meyts, 2000).

Binding of IRS to the regulatory subunit of PI3K first generates phosphatidylinositol-3,4,5triphosphate (PIP3) (Taniguchi et al., 2006). PIP3 then activates 3-phosphoinositide dependent protein kinase-1 and -2 (PDK1 and PDK2), which induce phosphorylation of protein kinase Akt/PKB at tyrosine308 and serine-473, respectively, leading to PKB activation (Guo, 2014). Finally, the four major downstream targets of PKB facilitate glucose homeostasis through different mechanisms: mTOR (mammalian target of rapamycin) acts as a nutrient sensor and stimulates protein synthesis; GSK3 (glycogen synthase kinase 3) inhibits glycogen synthase; AS160 (Akt substrate of $160 \mathrm{kDa}$ ) regulates the translocation of glucose transporter GLUT4 to increase glucose uptake; and the action of FoxO1 (forkhead box-containing protein O1) which normally activates gluconeogenesis, is inhibited (Guo, 2014; De Meyts, 2000).

\subsection{3 a-Cells}

Pancreatic islet $\alpha$-cells contribute to glycemic regulation by secreting glucagon, a hormone that counteracts the effects of insulin. Glucagon is released in response to hypoglycemia to stimulate hepatic glucose synthesis and glycogenolysis, thus releasing glucose into the bloodstream and increasing blood glucose concentration (Quesada et al., 2008).

\subsubsection{Glucagon Production}

Glucagon is a peptide hormone derived from preproglucagon, a precursor protein encoded by the 180 base pair long GCG gene in humans (White and Saunders, 1986). In addition to the a-cells, the GCG gene is also expressed in the intestinal L-cells and the central nervous system (CNS). Preproglucagon is differentially cleaved by the dominant prohormone convertase (PC) subtype present in each tissue to produce different products. Within the islet, glucagon synthesis occurs in a series of intracellular events similar to insulin synthesis. Following its translation in the ER, the prohormone is transported into the Golgi apparatus for further modification and packaging, after which glucagon-containing granules migrate to the plasma membrane to be secreted (Guizzetti et al., 2014). The granules are released from the $\alpha$-cells through $\mathrm{Ca}^{2+}$-dependent exocytosis, with low glucose driving the influx of $\mathrm{Ca}^{2+}$ into the cell (Ramracheya et al., 2010). 


\subsubsection{Glucagon Receptor}

Glucagon's glucose-lowering action is transduced through binding to the glucagon receptor (GCGR), a G-protein coupled receptor found mainly in the kidney and liver, and with lower expression in the heart, adipose tissue, spleen, gastrointestinal tract, and pancreas. Coupling of the GCGR to adenylyl cyclase allows it to activate the downstream signalling through increased production of CAMP and the PKA pathway (Charron and Vuguin, 2015). This leads to an increase in hepatic gluconeogenesis, glycogenolysis, and fatty acid oxidation (Charron and Vuguin, 2015).

In addition, glucagon acts as a local regulator of islet function, exerting both auto- and paracrine effects within the islet. Activation of the GCGR on the $\alpha$-cell creates a positive feedback loop, upregulating Gcg transcription and stimulating more glucagon secretion through increasing exocytosis in isolated rodent islets (Leibiger et al., 2012; Ma et al., 2005). Interestingly, glucagon also stimulates insulin secretion from the islet $\beta$-cell in the presence of high glucose concentrations (Capozzi et al., 2019; Svendsen et al., 2018). The insulinotropic action of glucagon occurs primarily through the activation of its receptor, GCGR, on the islet $\beta$-cell. However, in the absence of functional $\beta$-cell GCGR, glucagon has been shown to activate GLP1 receptors instead, resulting in insulin secretion similar to that of control mice (Capozzi et al., 2019; Svendsen et al., 2018).

The importance of glucagon/GCGR signalling on islet morphology and physiology has been established using mouse models with conditional Gcgr knockout and Gcgr overexpression. Ablation of GCGR signalling using $\mathrm{Gcgr}^{/-}$mice was found to contribute to the $\alpha$ - and $\delta$-cell hyperplasia, inhibit the maturation of $\alpha$-cells, and delay the differentiation of $\beta$-cells in mice (Vuguin et al., 2006). Disruption of Gcgr was also associated with an increase in the number of pancreatic islets and alterations in the proportion of $\beta$ - to $\alpha$-cells in embryonic islets (Vuguin et al., 2006). On the other hand, overexpression of the Gcgr in insulin-producing $\beta$-cells lead to an increase in glucagon-stimulated insulin release and significantly contributed to the $\beta$-cell volume expansion (Gelling et al., 2009). Taken together, these findings emphasize glucagon as one of the essential regulators of islet function, and, more specifically, $\beta$-cell secretory responses.

\subsubsection{Other Hormone-Producing Cell Types Within the Islet}

\subsubsection{1 $\delta$ cell}

In addition to $\alpha$ - and $\beta$-cells that make up the majority of the cell populations within the islet, there are at least three other types of hormone-producing cells that have been identified. In humans, $\delta$-cells make up around $10 \%$ of the islet cell mass and secrete somatostatin (SST), also known as growth hormoneinhibiting hormone (GHIH) (Cabrera et al., 2006). SST is also expressed in the hypothalamus and throughout the gastrointestinal tract. Glucagon and factors released from the $\beta$-cell, such as GABA and urocortin3, act as positive effectors of pancreatic SST release (Rorsman and Huising, 2018). In turn, SST 
inhibits the release of glucagon and insulin from the islet through its binding to two distinct SST receptors - SSTR2 and SSTR5 (Cejvan et al., 2003; Strowski et al., 2000). This feedback loop provides a mechanism for the control of hormone secretion during hyperglycemia. In animal models, SST hypersecretion has been suggested as an explanation for impaired hypoglycemia-induced glucagon secretion - an effect that could be corrected by SST antagonists (Rorsman and Huising, 2018). In addition, pancreatic $\delta$-cells were found to be critical in the regulation of insulin content, release, and neonatal blood glucose homeostasis through an SSTR-independent pathway, suggesting a role in glucose regulation for $\delta$-cell-secreted factors other than SST (Li et al., 2018).

\subsubsection{2 $\epsilon$ cell}

Less than $1 \%$ of the mature islet cell population are ghrelin-producing $\epsilon$-cells (epsilon cells). Most of the circulating ghrelin in adults originates within the gastrointestinal tract, although lower amounts are expressed in other tissues, including the pituitary gland, the lungs, the kidney, and the pancreas (Van Der Lely et al., 2004). Biological activities of ghrelin can be direct, through the ghrelin receptor binding, or mediated via the pituitary hormones and their efferent pathways (Van Der Lely et al., 2004). Ghrelin acts as a potent stimulant of growth hormone $(\mathrm{GH})$ release, which contributes to a wide variety of physiological functions it exerts throughout the body (Schmid et al., 2005; Sun et al., 2004; Takaya et al., 2000). In addition to acting as a GH secretagogue, ghrelin is directly involved in regulating appetite and food intake, gastric motility and emptying, cell proliferation, cardiovascular function, glucose metabolism, and energy balance (Arta Korbonits et al., 2004; Van Der Lely et al., 2004; Levin et al., 2006; Mihalache et al., 2016; Sun et al., 2004; Thompson et al., 2004). However, the exact role of ghrelin in islet hormone secretion remains controversial. In several rodent studies, exogenous ghrelin administration leads to a reduction in glucose-stimulated insulin secretion in isolated rat pancreas, isolated mouse islets, and INS-1 cell lines (Colombo et al., 2003; Egido et al., 2002; Wierup et al., 2004). Conversely, other studies report ghrelin to increase insulin secretion in rat pancreas and isolated islets (Adeghate and Ponery, 2002; Date et al., 2002; Lee et al., 2002). Similar inconsistencies are seen in human studies, although a more sensitive approach with a steady-state ghrelin infusion by Tong et al. found that exogenous ghrelin reduces glucose-stimulated insulin secretion and glucose clearance in humans (Broglio et al., 2001; Lindqvist et al., 2020; Lucidi et al., 2005; Tong et al., 2010). Finally, a more recent study using mice with a ghrelin knockout reported intra-islet ghrelin signaling to not have any significant effects on insulin secretion (Gray et al., 2019).

Interestingly, pancreatic ghrelin-expressing cells were quite prominent in the human fetal pancreas from mid-gestation to the early postnatal period, comprising $10 \%$ of all endocrine cells and outnumbering those in the stomach (Wierup et al., 2002). This expression is greatly reduced in the adult pancreas, but still evident as single cells in islets, exocrine tissue, ducts, and pancreatic ganglia (Chanoine and Wong, 2004; Wierup et al., 2002). These data, combined with its role in regulating cell proliferation, may suggest that the ghrelin system is involved in islet cell maturation during embryonic development. 


\subsubsection{PP Cells}

Pancreatic polypeptide (PP) - secreting cells, also known as $\mathrm{Y}$-cells or $\mathrm{F}$ cells, are the least abundant islet cell type. The spatial distribution of PP cells in the human pancreas is uneven, with PP-cellrich clusters restricted largely to the uncinate process within the head of the pancreas (Wang et al., 2013). PP is secreted postprandially, and it acts both as a neural and endocrine messenger within the pancreasgut-brain axis (Holzer et al., 2012). It plays a role in appetite suppression through inhibition of gastric emptying, intestinal motor activity, and intestinal electrolyte and water secretion (Batterham et al., 2003; Fujimiya and Inui, 2000; Tough et al., 2006). It reduces food intake predominantly through direct stimulation of the anorexigenic $\alpha$-Melanocyte-stimulating hormone $(\alpha-M S H)$ pathway via its binding to the $\mathrm{Y} 4$ receptor within the hypothalamus (Brereton et al., 2015; Katsuura et al., 2002; Lin et al., 2009). Data on the biological relevance of PP in the regulation of intra-islet hormone secretion are limited. In mouse islets, PP inhibited glucagon secretion through binding to PP receptor 1 on the a-cells (Aragón et al., 2015). However, intravenous infusion of PP did not affect insulin response to glucose and failed to improve glucose tolerance in a dog model of pancreatitis-induced diabetes (Bastidas et al., 1990).

\subsubsection{Immune Cells Within the Islet}

Endocrine (islet) and exocrine tissues of the pancreas contain small numbers of resident macrophages, each with unique properties and characteristics (Calderon et al., 2015). In islets, macrophages represent the only type of myeloid cell (Calderon et al., 2015). These macrophages are found in close contact with blood vessels, and have extensive filopodia-like structures that sample large areas of islets and blood contents (Ying et al., 2018; Zinselmeyer et al., 2018). These cells are highly effective at presenting $\beta$-cell antigens to CD4 T cells (Calderon et al., 2008). A feature of islet pathology in T2D is increased islet inflammation and macrophage infiltration, which induces $\beta$-cell dysfunction (Böni-Schnetzler and Meier, 2019; Butcher et al., 2014; Cucak et al., 2014; Eguchi and Manabe, 2013; Ehses et al., 2007). Under obese conditions, islet macrophages have shown to directly impair $\beta$-cell functions such as GSIS, as well as promote the adaptive expansion of $\beta$-cell mass associated with T2D (Xiao et al., 2014; Ying et al., 2018). Islets isolated from HFD-fed mice secreted more pro-inflammatory factors such as IL-6, IL-8,

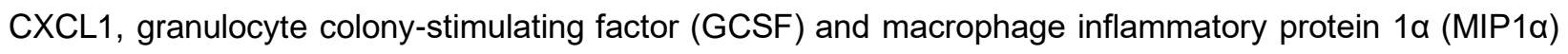
(Ehses et al., 2007). These results were replicated in islets isolated from healthy human donors, where treatment with palmitate increased secretion of pro-inflammatory cytokines and chemokines, mimicking a T2D profile (Eguchi and Manabe, 2013). Interestingly, increased islet macrophage presence in a model of HFD-induced T2D was not due to the recruitment from circulating monocytes. Instead, high-fat diet feeding and developing obesity induced a local proliferation of intra-islet macrophages (Ying et al., 2018). 


\subsection{Incretin Effect}

Hormone secretion from the pancreas is tightly linked to food ingestion through the action of incretin hormones glucagon-like peptide-1 (GLP-1) and glucose-dependent insulinotropic polypeptide (GIP) (Drucker, 2006). The discovery of incretin hormones followed an observation of enhanced insulin secretion in response to glucose ingested orally, as opposed to intravenous intake, even when the same plasma glucose concentration was achieved (Nauck and Meier, 2018; Perley and Kipnis, 1967). This suggested the presence of insulinotropic gut-derived factors, which were later isolated and identified as GLP-1 and GIP (Brown et al., 1975; Holst, 1994; Mojsov et al., 1987). Biologically active incretins inhibit glucagon secretion and augment insulin secretion, resulting in appropriate glucose uptake and utilization. Together, GLP-1 and GIP account for $50-70 \%$ of the postprandial rise in insulin in healthy subjects (Nauck et al., 1986). The incretin effect is greatly diminished in subjects with T2D, even in the very early stages with excellent glycemic control (Aulinger et al., 2016; Knop et al., 2012; Michaliszyn et al., 2014). Interestingly, only the insulinotropic action of GIP in the pancreas is reduced, whereas the response to GLP-1 is largely preserved (Nauck \& Meier, 2016). Since the incretin action of the two hormones is additive, this reduction in GIP sensitivity is the likely reason for the reduced incretin effect. It can be calculated as the difference in insulin secretion during an oral glucose challenge versus one during an iso-glycemic glucose injection. In a recent study, young obese patients with established T2D, as well as age- and BMI-matched non-diabetic subjects, saw $\sim 50 \%$ reduction in the incretin effect relative to the non-diabetic lean group (Aulinger et al., 2016). In the same cohort, only the T2D group exhibited impaired glucose tolerance and insulin secretion during the oral glucose tolerance test, while the lean and non-diabetic obese groups had comparable glucose excursions and $\beta$-cell function (Aulinger et al., 2016). As such, impairment of this measure has been proposed as an early marker of diabetes and $\beta$-cell dysfunction (Aulinger et al., 2016; Holst et al., 2011; Knop et al., 2012). The reduced responsivity to GIP is molecularly attributed to reduced GIPR expression and desensitization in models of T2DM (Lynn et al., 2001; Tseng and Zhang, 1998).

\subsubsection{Glucagon-Like Peptide-1 (GLP-1)}

\subsubsection{Preproglucagon Peptides and Processing}

Preproglucagon ( $G c g$ ) gene is expressed in the enteroendocrine L-cells of the intestine, neurons of the brainstem, and the $\alpha$-cells of the endocrine pancreas. It encodes a 180 amino acid long proglucagon peptide, that is structurally identical in all cell types and is differentially cleaved based on the dominant subtype of the prohormone convertase (PC) expressed in the tissue (Fig.2). In the pancreatic $\alpha$-cells, PC2 predominantly processes proglucagon to produce glucagon, GRPP, and major proglucagon fragment (Drucker et al., 2017; Sandoval and D'alessio, 2015). On the other hand, intestinal L-cells and CNS neurons have greater relative PC1/3 activity, resulting in the production of GLP-1, GLP-2, oxyntomodulin, IP2, and glicentin (Drucker et al., 2017; Sandoval and D'alessio, 2015). These differences in the regulation of the Gcg gene expression and post-translational modifications contribute to the diversity of actions exhibited by its products. 


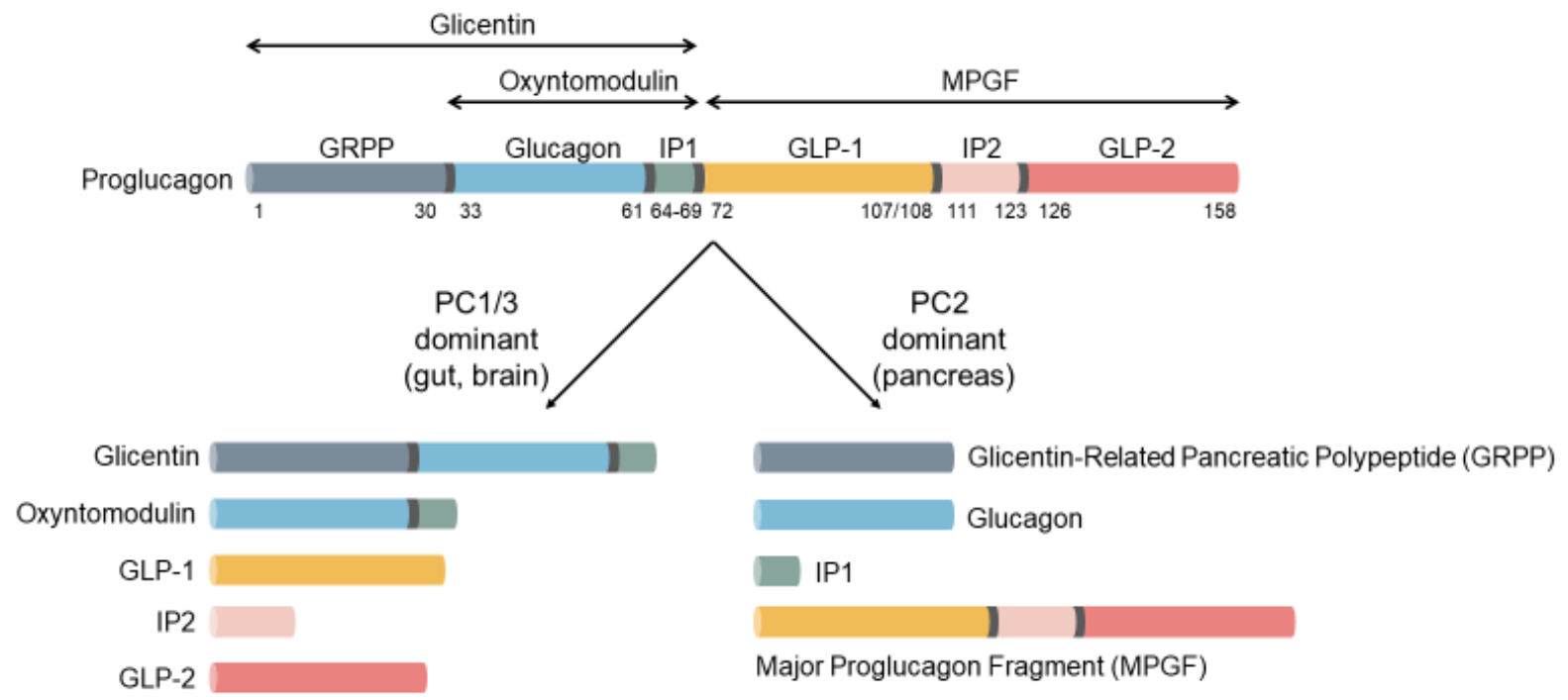

Figure 2. Post-Translational Processing of Proglucagon

Adapted from Sandoval and D'alessio, 2015; Drucker et al. 2017) 


\subsection{Preproglucagon in the Intestinal L-Cells}

Gcg expression can be driven by a variety of physiological factors and chemical agents. Intestinal Gcg expression was found to decrease following a fast, while refeeding stimulated its production in rats (Hoyt et al., 1996). As such, nutrient ingestion is likely a primary physiological regulator of intestinal preproglucagon. Studies in intestinal cell cultures have demonstrated that preproglucagon gene expression is determined by the levels of intracellular CAMP and activation of the CAMP/PKA signaling (Baggio and Drucker, 2007). Thus, interactions with several effectors of the Wnt signaling pathway (a potential mediator of the PKA-dependent gene transcription) in the intestine, including TCF7L2, TCF-4 and $\beta$-catenin upregulates Gcg transcription (Yi et al., 2005; Yu and Jin, 2010). In addition, gastrin-releasing peptide and insulin both increased intestinal preproglucagon mRNA in mouse and rat intestinal cell cultures (Baggio and Drucker, 2007; Yi et al., 2008). Furthermore, a transcription factor Pax-6 is essential for preproglucagon gene expression in both intestine and pancreas, and adenoviral-mediated overexpression of Pax-6 in rat colonic epithelium cells was associated with enhanced endogenous preproglucagon expression in vitro (Hill et al., 1999; Trinh et al., 2003).

\subsection{Preproglucagon in the Pancreas}

In contrast to the intestinal L-cells, pancreatic preproglucagon gene expression is upregulated following fasting and hypoglycemia, and is inhibited by insulin (Baggio and Drucker, 2007; Phillippe, 1989). This inhibition is mediated via the interaction of insulin with the insulin-responsive DNA element within the preproglucagon gene promoter (Philippe, 1991). Furthermore, genetic inactivation of FoxO1, an insulindependent nuclear transcription factor, leads to a $>40 \%$ reduction in pancreatic preproglucagon mRNA transcription, indicating FoxO1 as an important regulator of pancreatic Gcg expression (McKinnon et al., 2006). Factors stimulating preproglucagon mRNA transcription in the islet $\alpha$-cells include activation of the PKC and PKA signaling pathways, cell membrane depolarization, and calcium influx (Baggio and Drucker, 2007). However, there is now more recent and increasing evidence of PC1/3 expression in the pancreatic a-cells and local production of GLP-1 within the islet, although at a lower level (Ellingsgaard et al., 2011; Kilimnik et al., 2010; Sandoval and D'alessio, 2015; de Souza et al., 2020). This intra-islet PC1/3 expression can be further increased under the conditions of hyperglycemia, hyperlipidemia, or metabolic stress such as pregnancy or inflammation (Kilimnik et al., 2010; Sancho et al., 2017; de Souza et al., 2020). As previous studies have localized GLP-1 expression mainly to colonic L-cells, these recent data has shifted the traditional paradigm of GLP-1 secretion and suggested that pancreatic islets are a significant source of GLP-1 secretion, highlighting the importance of intra-islet GLP-1 signalling for glucose homeostasis (Traub et al., 2017). The input from the islet-derived GLP-1 was found to be essential for maintaining glucose homeostasis, especially during metabolic stress induced by high-fat feeding (Capozzi et al., 2019; Chambers et al., 2017; Traub et al., 2017; Whalley et al., 2011). Alpha-cell-derived GLP-1 was required for $\beta$-cell adaptation to metabolic stress and increased secretory demand in mice, while prolonged $\alpha$-cell ablation impaired insulin secretion and glucose tolerance (Traub et al., 2017). Furthermore, reactivation of 
GLP-1 production in the gut of $\mathrm{Gcg}^{-/}$mice did not affect their glucose metabolism, whereas reactivation of GLP-1 in the pancreas mimicked the positive responses seen in intact control mice (Chambers et al., 2017). These findings highlight the importance of intra-islet GLP-1 secretion and signaling in maintaining glucose homeostasis.

\subsubsection{GLP-1, Insulin and Energy Metabolism}

Glucagon-like peptide-1 (GLP-1) is a 30 amino acid-long peptide hormone liberated from the proglucagon peptide. Its two inactive forms, GLP-1[1-37] and GLP-1[1-36] $\mathrm{NH}_{2}$ are cleaved into biologically active forms, GLP-1[7-37] and GLP-1[7-36] $\mathrm{NH}_{2}$, via the action of PC1/3. The two peptides are equipotent and are a major source of the incretin effect (Edwards et al., 1999; Orskov et al., 1993).

GLP-1 release occurs rapidly following meal ingestion, but can be stimulated by individual nutrients, such as glucose and amino acids. Of note, the quick rise of plasma GLP-1 following food intake suggests the effect of neural factors promoting GLP-1 secretion, as the rise occurs well before the nutrients make direct contact with the L-cells (Drucker, 2006). The role of GLP-1 as an incretin hormone extends beyond the augmentation of nutrient-dependent insulin secretion. Its many actions implicated in glucose homeostasis include increasing insulin gene expression, stimulation of somatostatin secretion, inhibition of glucagon secretion, promoting $\beta$-cell health and neogenesis, inhibition of $\beta$-cell apoptosis, delaying gastric emptying, promoting satiety, and increasing peripheral glucose clearance (Baggio and Drucker, 2007; Donnelly, 2012). Under normal conditions, active GLP-1 is secreted from the L-cells as GLP-1 [7-37] and GLP-1[7-36] $\mathrm{NH}_{2}$ via secretory granules, that fuse at the basolateral membrane and are then released into the bloodstream (Mulvihill and Drucker, 2014; Thurmond, 2009). Most GLP-1 signaling occurs through its binding to a single GLP-1 receptor (GLP-1R), a G protein-coupled receptor found within the pancreas, lung, adipose tissue, kidney, heart, smooth muscle, and parts of the CNS (Sandoval and D'alessio, 2015). Notably, active GLP-1 is subject to rapid cleavage and inactivation by dipeptidyl peptidase-4 (DPP4), a serine protease which limits the half-life of GLP-1 to several minutes and eliminates its glucoregulatory action due to a 100-fold decrease in its receptor's (GLP-1R) affinity (Deacon et al., 1995; Knudsen and Pridal, 1996). The binding of active GLP-1 to the adenylate cyclase-coupled GLP-1R present on the $\beta$-cells enhances the production of cAMP and thus activates the PKA pathway. As this pathway does not involve $\beta$-cell membrane depolarization and calcium influx, it is unable to initiate the release of insulin granules from the cell under hypoglycemic conditions. The insulinotropic action of GLP-1 is, therefore, correlated with the degree of hyperglycemia, increasing with greater glucose concentration (Nauck \& Meier, 2018). There is also additional evidence that GLP-1 may act as a glucose sensitizer through mobilizing intracellular $\mathrm{Ca}^{2+}$ and facilitating glucose-dependent mitochondrial ATP synthesis (Holz IV et al., 1993; Tsuboi et al., 2003). In addition, it upregulates the expression of glucose transporters and glucokinases, thus enhancing glucose responsivity in previously resistant $\beta$-cells (Baggio and Drucker, 2007). 
The role of GLP-1 on insulin gene transcription and insulin synthesis has also been studied extensively. It's been shown to act synergistically with glucose to stimulate proinsulin gene expression, cellular levels of proinsulin mRNA, and transcriptional biosynthesis of proinsulin (Drucker et al., 1987; Fehmann and Habener, 1992). Furthermore, incubation with GLP-1 specifically increased the capacity and affinity of insulin and proinsulin binding in a concentration-dependent manner in human monocytes and RINm5F cells (Ebinger et al., 2000).

Finally, considerable attention has been given to the role of GLP-1 in $\beta$-cell health and differentiation. Both GLP-1 and its agonist, exendin-4, induced Wnt signaling required for $\beta$-cell proliferation in INS-1 cell lines and isolated islets (Liu and Habener, 2008). Activation of GLP-1R inhibited $\mathrm{H}_{2} \mathrm{O}_{2}$-induced apoptosis, reduced DNA fragmentation, and improved survival in cultured mouse insulinoma cells via increased expression of anti-apoptotic proteins $\mathrm{Bcl}-2$ and $\mathrm{Bcl}-\mathrm{xL}$ through CAMP- and PI3K-dependent pathways. (Hui et al., 2003). GLP-1 demonstrated a potent protective effect from gluco-, lipo-, and glucolipotoxicity mediated by protein kinase B in human beta-cells and INS832/13 cells (Buteau et al., 2004). It directly reduced cytokine-mediated apoptosis in isolated rat $\beta$-cells after exposure to II-1 $\beta$, TNF- $\alpha$, and IFN-Y (Li et al., 2003). In vivo, GLP-1 agonist exendin-4 significantly reduced streptozotocin-induced $\beta$-cell injury and apoptosis in mice (Li et al., 2003). Lastly, treatment of isolated human islet with GLP-1 preserved islet morphology, reduced the number of apoptotic cells, and enhanced intracellular insulin content compared to untreated controls, providing further support for the therapeutic use of GLP-1 and GLP-1 agonists in islet transplantation (Farilla et al., 2003).

\subsubsection{Other Actions of GLP-1}

Beyond its role in energy metabolism, GLP-1 has been reported to have biological activities in the cardiovascular system. Administration of GLP-1 after ischemia-reperfusion injury increased functional recovery, cardiomyocyte viability, and vasodilation, leading to reduced ischemic damage in mice (Ban et al., 2008). Interestingly, many of these effects were preserved in mice with genetic elimination of the GLP1 receptor (Glp1r/- mice), suggesting a mechanism of action independent of the known GLP-1 receptor. Similarly, a continuous intravenous infusion of GLP-1(7-36) and GLP-1(9-36) in a model of dilated cardiomyopathy in dogs significantly reduced left ventricular end-diastolic pressure, and increased myocardial glucose uptake without an increase in plasma insulin (Nikolaidis et al., 2005).

\subsubsection{Gastric Inhibitory Polypeptide (GIP)}

Mature, bioactive GIP(1-42) is a 42 amino acid-long peptide released from a larger proGIP precursor protein through post-translational cleavage by PC1/3 (Baggio and Drucker, 2007; Ugleholdt et al., 2006). GIP is synthesized within and is secreted from a distinct population of enteroendocrine K-cells, most of which are located in the duodenum and proximal jejunum (Buchan et al., 1978; Mortensen et al., 2003). Its secretion is primarily stimulated through nutrient ingestion and, more specifically, the rate of nutrient absorption, rising 10-15 fold within 15 minutes of food intake (Baggio and Drucker, 2007; Gribble 
et al., 2018). Similar to GLP-1, GIP augments insulin secretion in the presence of normal and elevated plasma glucose concentrations, and is the other major contributor to the incretin effect (Gribble et al., 2018). However, it is important to note the interspecies differences in the regulation of GIP release, which may complicate translation from animal studies to human applications. In humans, fat is the more potent stimulator of GIP secretion, while carbohydrates were found to be more effective in rodents and pigs (Baggio and Drucker, 2007). Biological activity of GIP in vivo is also limited by its short half-life due to cleavage and inactivation by DPP4, which metabolizes over $50 \%$ of circulating GIP after 2 minutes in rodents and 5-7 minutes in humans (Deacon et al., 2000; Kieffer et al., 1995).

\subsubsection{GIP, Insulin, and Energy Metabolism}

There are several similarities between the mechanisms of action and effects of the two incretin hormones. In the pancreas, the actions of GIP are analogous to those of GLP-1, leading to enhanced nutrient-dependent insulin secretion (Baggio and Drucker, 2007; Gribble et al., 2018). Like the GLP-1R, the GIP receptor (GIPR) is a member of a G protein-coupled receptor superfamily, which exhibits its effects through elevation of cAMP and downstream signaling (Gribble et al., 2018). GIPR is expressed in a variety of tissues and organs, including the pancreas, stomach, adipose tissue, the heart, kidneys, and parts of the CNS. Binding of GIP to the GIPR on the $\beta$-cell increases CAMP, inhibits KATP channels, increases intracellular $\mathrm{Ca}^{2+}$, and stimulates insulin exocytosis (Ding and Gromada, 1997; Gromada et al., 1998). These actions are mediated through cAMP-dependent activation of the PKA, PKB, and phospholipase A2 pathways (Baggio and Drucker, 2007).

In addition to its insulinotropic action, treatment with GIP was found to increase intracellular insulin content, biosynthesis, mRNA, and upregulation of genes of glucose sensors like GLUT1 and hexokinase I in insulin-producing cell lines (Wang et al., 1996). Furthermore, stimulation of INS-1 $\beta$-cells with GIP leads to a concentration-dependent activation of the PI3K/PKB/Foxo1 signaling pathway implicated in cell survival and proliferation (Kim et al., 2005). Concurrently, it suppressed Bcl-2-associated X protein (Bax) promoter activity, which is associated with apoptosis activation. Similar effects were observed in dispersed islet cells, where GIP reduced glucolipotoxicity-induced cell death, likely via down-regulation of Bax and up-regulation of $\mathrm{Bcl}-2$ in pancreatic $\beta$-cells (Kim et al., 2005). Together, these results indicate GIP as an important mediator of pancreatic islet health and function.

\subsection{DPP4 and DASH Proteins}

Dipeptidyl peptidase-4 (DPP4, DPPIV), also known as CD26 (cluster of differentiation 26), is a widely expressed exopeptidase that modulates the bioactivity of over 40 identified substrates involved in energy metabolism, inflammation, and immune activation (Mulvihill and Drucker, 2014; Trzaskalski et al., 2020). It's found in many metabolically active tissues (including the liver, kidney, pancreas, spleen, and lungs), numerous cell types (endothelial cells, monocytes, macrophages, lymphocytes), and bodily fluids (blood, bile, urine, cerebral spinal fluid), suggesting a range of global and tissue-specific roles (Deacon, 
2019; Mulvihill and Drucker, 2014; Mulvihill et al., 2017). DPP4 is a member of a larger serine peptidase family of proteins called subfamily $9 \mathrm{~b}$, which is characterized by their structure and function, and also includes fibroblast activation protein (FAP), DPP8, DPP9, DPP6, and DPP10 (Wagner et al., 2016). These enzymes are structural homologues of DPP4 and, with the exception of DPP6 and DPP10, display DPP4like activity and inhibition profiles. Collectively, they are known as the DASH proteins (DPP4 activity and/or structure homologues) (Wagner et al., 2016). FAP, also referred to as seprase, exhibits the highest sequence identity and substrate similarity to DPP4, and is believed to have risen from a gene duplication. Co-localization of FAP and DPP4 in several cell types also leads to the creation of a heteromeric complex (Wagner et al., 2016). Lastly, both DPP8 and DPP9 exist as enzymatically active homodimers, however, unlike DPP4, lack the transmembrane domain and are therefore found intracellularly (Wagner et al., 2016).

\subsubsection{Enzymatic Action of DPP4}

DPP4 is a type II transmembrane protein with a typical C-terminal signal peptide, which concurrently targets the endoplasmic reticulum and serves as a membrane anchor (Röhrborn et al., 2015). The membrane-bound DPP4 protein consists of several distinct domains, including a short intracellular domain [residues 1-6], a transmembrane domain [7-28], followed by an extracellular flexible stalk, a glycosylated region, an adenosine deaminase (ADA) binding domain, fibronectin-binding domain, cysteinerich domain, and the catalytic active site [507-766] (Mulvihill and Drucker, 2014). The extracellular part forms an eight-blade $\beta$-propeller and $\alpha / \beta$-hydrolase domains responsible for binding to ADA and matrix proteins (Zhong et al., 2015). The catalytic activity of DPP4 within its C-terminal is accomplished via the classic catalytic triad (Ser630, Asp708, His740) and is highly conserved in prokaryotes and eukaryotes (Mulvihill and Drucker, 2014; Röhrborn et al., 2015). DPP4 selectively cleaves a dipeptide from the Ntermini of its substrates, exhibiting a preference for proline or alanine in the penultimate position (Deacon, 2019; Mulvihill and Drucker, 2014). Alternate residues like hydroxyproline, dehydroproline, glycine, threonine, valine, or leucine can also be cleaved, albeit at a slower rate (Deacon, 2019; Mulvihill and Drucker, 2014).

The two principal isoforms of DPP4 are a 766 aa-long membrane-anchored form and a shorter soluble, circulating form (sDPP4, [39-766]) liberated from the plasma membrane and thus lacking the cytoplasmic and transmembrane domains (Mulvihill and Drucker, 2014). Both isoforms express catalytic activity, but the exact mechanism by which DPP4 is shed from the plasma membrane and is released into circulation remains unknown. In vitro studies suggest that this process is mediated by metalloproteases (MMPs), more specifically MMP1, MMP2, and MMP14 in shedding from vascular smooth muscle cells, and MMP9 in adipocytes (Röhrborn et al., 2014). Interestingly, shedding from different tissues seems to vary at different disease conditions. For example, plasma concentration of SDPP4 has been shown to increase in T2D, obesity, and NAFLD, but is decreased in rheumatoid arthritis (Anoop et al., 2017; Dawood et al., 2018; Sarkar et al., 2019; Sromova et al., 2015). 


\subsubsection{DPP4 Expression and Regulation}

DPP4 exists predominantly as a homodimer, but can form tetramers consisting of two soluble and two transmembrane proteins, which affects their interaction with proteolytic substrates and possibly mediates cell-cell contacts (Chien et al., 2004; Engel et al., 2003). A study using targeted mutation to disrupt the dimerization ability of DPP4 protein found that monomeric DPP4 exhibits a 300 -fold decrease in catalytic activity, and that the C-terminal loop of DPP4 is essential for the dimerization process (Chien et al., 2004). The DPP4 gene promoter region contains binding sites for several transcription factors, such as STAT1 $\alpha$, NFKB, SP-1, EGFR, and NF-1 (Röhrborn et al., 2015). Stimulation of B lymphocytic leukemia cells with IFNs phosphorylated STAT1a, increasing its affinity to the DPP4 promoter region, which lead to nuclear translocation and increase in DPP4 transcription, expression, and activity (Bauvois et al., 2000). In addition, stimulation with IL-1 $\alpha$, TNFa, and IL-12 has also been shown to regulate the expression of DPP4 (Zhong et al., 2015).

\subsubsection{DPP4 And the Incretin Hormones}

DPP4 is the key enzyme regulating the bioactivity of the incretin hormones, and, therefore, glucose metabolism in vivo. Both GLP-1 and GIP are true physiological substrates of DPP4, and cleavage by DPP4 is the initial and primary route of their metabolism (Mentlein et al., 1993). DPP4 cleaves the bond between Ala2 and Glu3 in active GLP-1[7-37] or GLP-1[7-36] $\mathrm{NH}_{2}$, generating GLP-1[9-37] or GLP-1[9-36]NH 2 , and a dipeptide. Similarly, it liberates GIP[3-42] from GIP[1-42] by cleaving the bond after Ala2 (Mentlein et al., 1993). Cleavage by DPP4 inactivates the glucoregulatory effect of the incretin hormones due to a significant reduction in their respective receptors' affinities (Deacon et al., 1995, 2000; Knudsen and Pridal, 1996). As a result, circulating levels of active incretin hormones are extremely low, and only $10 \%$ of intact GLP-1 secreted into the circulation from the gut reaches the pancreas (Hansen et al., 1999; Hjøllund et al., 2011).

While the role of DPP4 in the regulation of incretin hormone action and glucose homeostasis is well documented, the exact cellular sites essential for the incretin degradation remain elusive due to the widespread expression of DPP4. Mice with whole-body deletion of DPP4 (Dpp4 $\left.{ }^{-/}\right)$are protected against high-fat feeding-induced obesity and insulin resistance, and display reduced glycemic excursion (Conarello et al., 2003; Mulvihill et al., 2017). Ablation of Dpp4 is also associated with elevated plasma GLP-1, GIP, improved metabolic control, reduced islet hypertrophy, and protection from streptozotocin-induced $\beta$-cell death (Conarello et al., 2003; Mulvihill et al., 2017). In two recent studies, Mulvihill et al. and Varin et al. used mouse genetics and pharmacologic DPP4 inhibition to further elucidate the cellular origin of incretinmediated glucoregulation by DPP4. Targeted Dpp4 deletion was achieved by crossing double floxxed Dpp4 mice $\left(D p p 4^{f l o x f f l o x}\right)$ with lines expressing Cre recombinases under the control of tissue-specific promoters, or injecting with an adeno-associated virus (AAV) expressing Cre under the control of the thyroxin binding globulin promoter (Mulvihill et al., 2017; Varin et al., 2019a). Interestingly, ablation of Dpp4 in the endothelial cells $\left(D p p 4^{E C-/}\right)$ lead to a significant increase in both fasting and glucose-induced active GLP-1 and GIP, 
and improved glucose tolerance after high-fat feeding, revealing cells of vascular endothelial origin to be critical for the glucoregulatory action of DPP4 (Mulvihill et al., 2017). In contrast, while enterocyte-derived DPP4 contributed substantially to the intestinal DPP4 activity, Dpp4gut-/ mice did not display improved plasma active incretin levels or glucose tolerance (Mulvihill et al., 2017). Similarly, genetic disruption of Dpp4 in adipocytes (Dpp4adipo-/) reduced plasma DPP4 activity and improved hepatic insulin sensitivity, but had no effect on incretin levels or glucose homeostasis (Varin et al., 2019a). Finally, hepatocyte-targeted Dpp4 elimination (Dpp4 $4^{\text {hep-/ }}$ ) led to an increase in fasting levels of active incretins, but was not associated with improvements in glucose tolerance or increased levels of active incretins following glucose administration (Varin et al., 2019a). Collectively, these findings underline the unexpected complexity of DPP4 biology and extend the idea of selective, tissue-specific DPP4 bioactivity in the regulation of incretin hormone action (Summarized in Fig.3). 


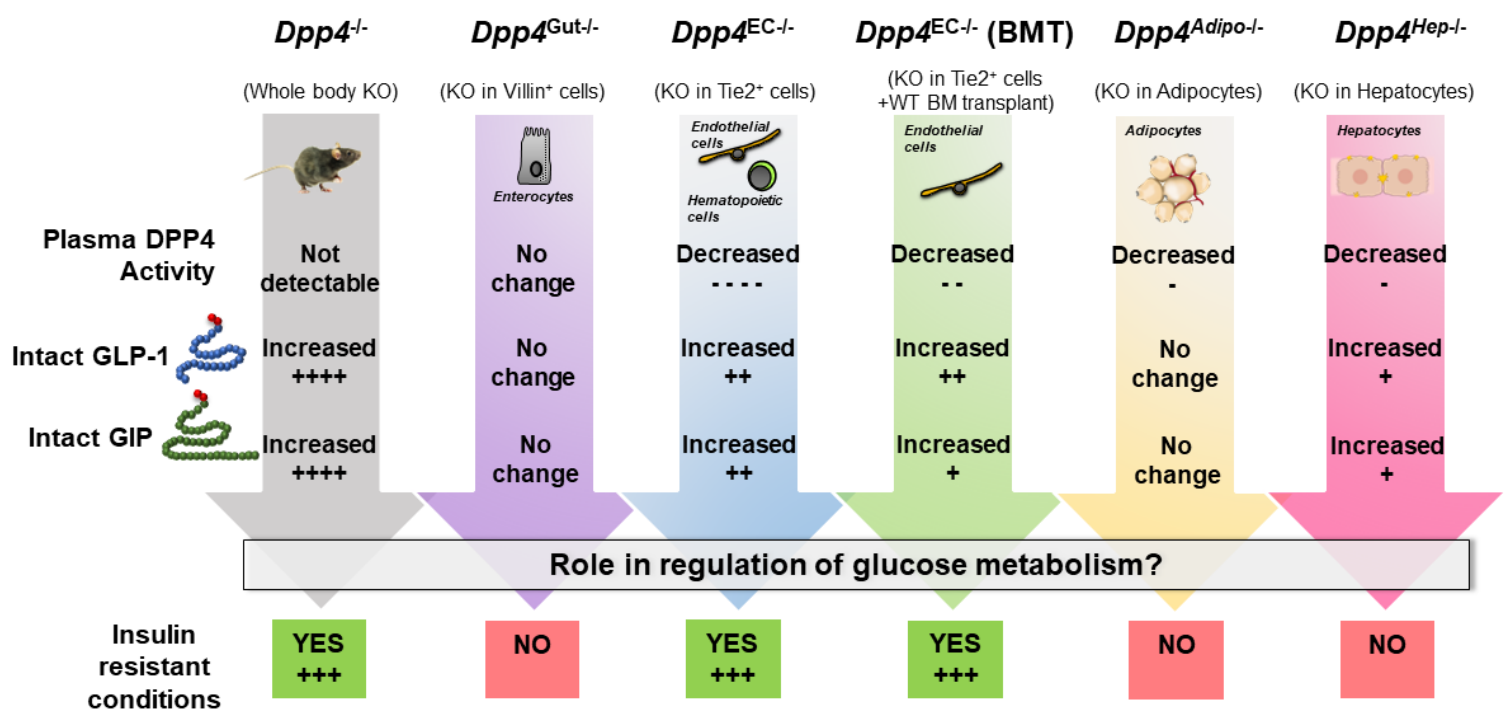

Figure 3. Cellular Sources of DPP4 and Control of the Incretin Axis

A graphical summary of the cellular sites of DPP4 action on incretin cleavage and glucose regulation in the insulin resistant state as determined by mouse genetics.

Adapted from Mulvihill et al., 2017; Varin et al., 2019. 


\subsubsection{Other Substrates of DPP4}

Cleavage by DPP4 can inactivate peptides or generate new bioactive peptides, which allows for regulation of a wide range of biological processes. While many bioactive molecules have been demonstrated to be cleaved by DPP4 in vitro, very few of them are known to be physiological substrates in vivo (Mulvihill and Drucker, 2014). The challenges in identifying the physiological and pharmacological relevance of these peptides are many, and may include the inability to differentiate between cleaved and intact peptides due to the specificity or sensitivity of available immunoassays; absence of selective peptide antagonists; and difficulty in generating mouse knockout models for the receptors of interest (Mulvihill and Drucker, 2014). In addition to the incretin hormones, some other well-characterized substrates of DPP4 which may play a role in the islet include peptide tyrosine tyrosine (PYY), neuropeptide Y (NPY), and insulinlike growth factor-1 (IGF-1).

\subsubsection{PYY}

PYY, a 36 amino acid long peptide secreted from the intestinal L-cells has roles in satiety signaling, gastric emptying, gastric acid secretion, and fluid homeostasis (Gribble et al., 2018). PYY secretion is more effectively stimulated by lipids, and its plasma concentration is positively correlated with energy intake (Degen et al., 2005; Gibbons et al., 2013). Cleavage of PYY[1-36] by DPP4 generates the truncated peptide, PYY[3-36], which exhibits altered receptor selectivity. Unlike the full-length PYY[1-36] that binds to all $Y$ receptor subtypes with equal affinity, the truncated PYY [3-36] stimulates an anorexigenic effect through high-affinity binding to the hypothalamic $Y 2$ receptor, leading to a significant reduction in food intake (Batterham et al., 2002; Shi et al., 2013). Administration of exogenous PYY[3-36] during an intraperitoneal glucose tolerance test in mice has been shown to lower glycemia through GLP-1-mediated improvements in insulin secretion, while PYY[1-36] did not (Chandarana et al., 2013). Furthermore, PYY[1-36] was shown to inhibit glucose-stimulated insulin secretion in isolated islets, while PYY[3-36] had no effect (Chandarana et al., 2013). Finally, studies using PYY[1-36] and enzymatically stable PYY[1-36] analogues have demonstrated a significant increase in proliferation and protection from cytokine-induced apoptosis in treated BRIN BD11 and 1.1B4 $\beta$-cell lines (Lafferty et al., 2019). Collectively, these findings reveal the roles in metabolic processes for both intact PYY [1-36] and PYY[3-36], however, the biological relevance of the cleavage by DPP4 remains uncertain (Trzaskalski et al., 2020).

\subsubsection{NPY}

NPY[1-36] is a 36 amino acid long peptide, co-secreted with norepinephrine by sympathetic nerves and the adrenal medulla and involved in the regulation of mood, cardiovascular and immune functions, vasomotion, appetite, and neuroendocrine axis (Tan et al., 2018). It is implicated in the pathophysiology of several disease processes, and elevated plasma NPY is observed under stress conditions such as exercise, hypoxia, tissue injury, and ischemia (Tan et al., 2018). DPP4 cleaves NPY[1-36] to produce 
NPY[3-36], a shorter peptide with a higher affinity for Y2 and Y5 receptors, which shifts its activity toward a pro-angiogenic profile (Li et al., 2011). Indeed, enhanced expression of DPP4 was found in migrating cells following cell wounding, and its enzymatic activity was required to mediate the angiogenic effects of NPY[336] in HUVEC cells (Ghersi et al., 2001). In a model of chronic myocardial ischemia, swine treated with NPY displayed a significant upregulation of both DPP4 and NPY receptors, with an elevated presence of factors like vascular endothelial growth factor (VEGF), endothelial Nitric Oxide Synthase (eNOS), and platelet-derived growth factors (PDGF). Moreover, treatment with exogenous NPY[3-36] improved myocardial function and increased angiogenesis by stimulating growth factor, pro-angiogenic receptor upregulation, and decreasing anti-angiogenic expression (Robich et al., 2010).

\subsubsection{IGF-1}

IGF-1 is a peptide hormone produced mainly by the liver and structurally similar to insulin (Wrigley et al., 2017). It acts downstream of the growth hormone (GH) and the growth hormone-releasing hormone $(\mathrm{GHRH})$ to promote tissue growth and maturation via activating both MAP kinase and PI3K signaling pathways (Wrigley et al., 2017). IGF-1 was identified as a DPP4 substrate, however, in vivo DPP4 inhibition failed to increase active intact IGF-1 in plasma of pigs or male humans treated with DPP4 inhibitor sitagliptin (Bergman et al., 2006; Faidley et al., 2006; Frohman et al., 1989; Lin et al., 2010). Surprisingly, in a more recent study, treatment with sitagliptin enhanced stimulated GH secretion and free IGF-1 via GH receptor in women, but not men, potentially due to the sexual dimorphism of GH secretion (Wilson et al., 2018).

\subsection{Incretin-Based Therapies: DPP4 Inhibitors and Incretin Mimetics}

The great advancement of the incretin-based therapies is that they augment insulin secretion in a glucose-dependent manner, thus avoiding the risk of developing hypoglycemia if not taken properly. They are generally well-tolerated, do not induce weight gain and in addition to their glucoregulatory effect have been shown to attenuate the post-prandial rise in plasma triglycerides, free fatty acids, and intestinal lipoprotein production (Nauck et al., 2017). Incretin-based therapies aim to enhance the circulating concentrations of active incretin hormones and their receptor signaling, thus correcting the diminished incretin effect. Two classes of drugs, DPP4 inhibitors and GLP-1 receptor agonists (GLP-1RA), have now been established as therapeutic strategies for the treatment of T2D symptoms. DPP4 inhibitors work by selectively inhibiting the catalytic action of the DPP4 enzyme, preventing the degradation and inactivation of the incretin hormones and restoring glycemic control (Trzaskalski et al., 2020). DPP4 inhibitors have also been shown to improve glucose tolerance in mice with genetically eliminated GLP-1R $\left(\right.$ Glp $\left.1 r^{-}\right)$, indicating DPP4i-mediated glucose regulation may occur via additional substrates or through a GLP-1-independent mechanism (Marguet et al., 2000). Another mechanism by which DPP4 inhibitors improve glycemic control is through inhibition of elevated glucagon secretion accompanied by a reduction in hepatic glucose production in T2D (Ahrén, 2007). As a result of the improved islet function, DPP4 inhibition may also improve insulin sensitivity, as observed through indirect measure of insulin sensitivity and hyperinsulinemic- 
euglycemic clamp tests (Ahrén, 2007). DPP4 inhibitors currently approved for the clinical use have no reported effects on body weight, blood pressure, or heart rate, and were not found to increase major cardiovascular events or mortality (Kaneko and Narukawa, 2017; Nauck et al., 2019). DPP4 inhibitors tend to be the second-line therapy after metformin, and are often prescribed together to achieve euglycemia in patients with T2D. Patients on dual therapy experience the additive glucose-lowering effect of both drugs and a trend towards improved cardiovascular outcomes (Trzaskalski et al., 2020). Interestingly, DPP4 inhibitors also lowered the risk of developing autoimmune disease, including rheumatoid arthritis, inflammatory bowel disease, multiple sclerosis, and systemic lupus erythematosus in patients with T2D compared to sulfonylurea combination therapy and thiazolidinediones combination therapy (Kim et al., 2015).

On the other hand, GLP-1RAs are structural homologues of endogenous GLP-1 that are resistant to degradation by DPP4 due to one amino acid substitution from Ala2 to Gly2. GLP-1RA treatment provides pharmacological levels of GLP-1, leading to enhanced glucose-dependent insulin secretion, decreased glucagon secretion, delayed gastric emptying, and increased satiety (Trujillo et al., 2015). In addition, they have been shown to reduce body weight, inflammation, and systolic blood pressure (Nauck et al., 2017). Unlike the DPP4 inhibitors, which are taken as oral tablets, GLP-1RAs are administered as subcutaneous injections. As such, their use may be limited by the adverse gastrointestinal effects, the need for the subcutaneous route of administration requiring self-administration education, and the cost of treatment (Trujillo et al., 2015). The effects of GLP-1 receptor agonists (GLP-1RAs) have also been assessed in humans for their cardioactive properties. GLP-1RAs were found to reduce blood pressure by 2 to $4 \mathrm{mmHg}$, reduce inflammation, and enhance vasorelaxation. Finally, two of the four GLP-1RAs (liraglutide and semaglutide) examined in CV outcome studies in humans demonstrated a significant reduction in major cardiovascular adverse effects, while another two (exenatide and lixisenatide) reported no changes (Holman et al., 2017; Mann et al., 2017; Marso et al., 2016b, 2016a; Pfeffer et al., 2015). 


\subsection{Rationale, Hypothesis, and Objectives}

Pharmacological inhibition of DPP4 improves glycemia regulation through enhancing circulating levels of incretin hormones and potentiating insulin secretion in a glucose-dependent manner. Previous studies report DPP4 originating from endothelial cells, but not enterocytes, hepatocytes, or adipocytes to contribute substantially to circulating DPP4 activity, incretin degradation, and glucose control in vivo (Mulvihill et al., 2017; Varin et al., 2019). However, genetic elimination of DPP4 within endothelial cells could further be improved with systemic DPP4 inhibition, suggesting another cellular source of DPP4mediated glucoregulation.

DPP4 expression has been observed in rodent, pig, and human islets, where it colocalized with the glucagon-secreting $\alpha$-cells in humans and pigs, and $\beta$-cells in mice and rats. In addition, studies evaluating the role of islet-derived GLP-1 have found its input to be essential for maintaining glucose homeostasis, especially during metabolic stress induced by high-fat feeding. Therefore, due to its direct co-localization with the action site of the incretin hormones and GLP-1 secretion, it has been suggested that intra-islet DPP4 may be able to modulate $\beta$-cell function via a paracrine mechanism within the pancreatic islet.

This thesis will address the following hypothesis: islet-derived DPP4 is critical for the paracrine regulation of insulin secretion and glucose metabolism through intra-islet GLP-1 cleavage.

The aims of this thesis are as follows:

Objective 1: Localize and confirm DPP4 expression and activity in mouse pancreatic islets.

Objective 2: Describe dynamic hormone release and changes in local metabolic activity in islets isolated from mice with $D p p 4$ specifically eliminated from islet $\beta$-cell $\left(D p p 4^{\beta-c e l l-/)}\right)$ in response to perifusion with glucose (high/low concentration), KCl, GLP-1, GIP, glucagon, arginine, and DPP4 inhibitor sitagliptin.

Objective 3: Characterize incretin hormone levels, metabolic activity, and phenotype in mice with Dpp4 specifically eliminated from the islet $\beta$-cells $\left(D p p 4^{\beta-c e l l--}\right)$ or the whole pancreas $\left(D p p 4^{\text {Pan-l- })}\right.$ while on chow and after high-fat diet-induced obesity. 


\section{Materials and Methods}

\subsection{Animals, Diets, and Housing}

Mice were housed under a 12-hour light/dark cycle at the University of Ottawa Heart Institute, and maintained on regular chow (Harlan Teklad, 2018, 18\% kcal from fat) or HFD (Research Diets \#D12451, $45 \%$ kcal from fat,) with free access to food and water, unless otherwise noted. For metabolic tests, food was removed at 8 am (5 hours prior to the tests), and replaced upon the completion of the test. Animals were cared for in accordance with the Canadian Guide for the Care and Use of Laboratory animals (CCAC). All experimental procedures were submitted approved under AUP \#2909 and AUP \#2020 by the University of Ottawa Animal Care and Veterinary Service (ACVS). Dpp4 $4^{-/}$mice were re-derived from a colony described previously (Marguet et al., 2000; Sauve et al., 2010). Flox Dpp4 (Dpp4 $\left.4^{f / / f}\right)$ mice (the LoxP sites span the catalytic serine in exon 22 of the Dpp4 gene) were obtained from Merck Research Laboratories (Mulvihill et al., 2017). B6.Cg-Tg(Ins1-cre/ERT)1Lphi/J mice (Tamoxifen-inducible MIP-Cre) and B6.FVB$\mathrm{Tg}$ (Pdx1-cre)6Tuv/J mice (PDX-Cre) were obtained from Jackson Laboratories (Bar Harbor, ME USA). B6;129S4-Gcgem1(cre/ERT2)Khk/Mmjax mice (GCG-Cre) were obtained from Jackson Laboratories (Bar Harbor, ME, USA).

\subsection{Generating $D p p 4^{\beta-c e l l-/}$ and $D p p 4^{\text {Pan-/ }}$ Mice}

To generate $\beta$-cell specific Dpp4 knockout mice, MIP-Cre-expressing mice were crossed with $D p p 4^{f / / f l}$ mice, resulting in $D p p 4^{f / /+}$ (loxP heterozygous) offspring. Intercrossing Cre+ and Cre- Dpp4 loxP heterozygotes resulted in four genotypes: wildtype with no Cre (WT), wildtype expressing Cre (MIP-Cre), double floxxed Dpp4 with no Cre $\left(D p p 4^{f / / f}\right)$ and double floxxed Dpp4 mice expressing Cre (Dpp $\left.4^{\beta-c e l l-/}\right)$. Tail or ear clips were collected from newly weaned mice, and the genomic DNA was isolated for genotyping. Primers used for genotyping are summarized in the table below (Table 1).

\begin{tabular}{|l|l|l|}
\hline & Forward & Reverse \\
\hline$D p p 4^{f / f f l}$ & GAA TAT GAT CCT TGT CAG AGC AGC C & CTG CAC TCA GAA GTC TCA CTG \\
\hline Cre & ATC CGA AAA GAA AAC GTT GA & ATC CAG GTT ACG GAT ATA GT \\
\hline
\end{tabular}

Table 1. Primers for Genotyping Dpp $4^{\beta-c e l l-/-}$ and Control Mice

MIP-Cre recombinase activity was induced by administering tamoxifen (Sigma-Adrich, \#T5648) in corn oil ( $50 \mathrm{mg} / \mathrm{mL}$ ) at $5 \mathrm{mg} / \mathrm{mouse} /$ day for 5 continuous days to all groups. Similarly, to obtain the pancreas

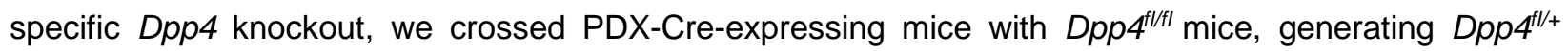
offspring. We then crossed Cre+ and Cre- Dpp $4^{f /+}$ mice, which produced four genotypes: wildtype with no Cre (WT), wildtype expressing Cre (PDX-Cre), double floxxed Dpp4 with no Cre $\left(D p p 4^{f / f / f}\right)$ and double

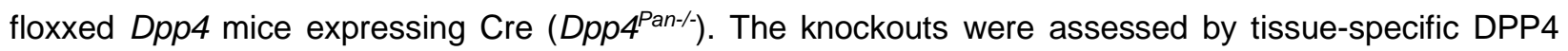
activity assay and immunofluorescent analysis of pancreatic and liver (control) sections with a DPP4- 
specific antibody. Experiments were carried out in all groups described above as well as in full-body Dpp4 knockout group $\left(D p p 4^{-/}\right)$. All experiments used age- and sex-matched littermates as control subjects.

\subsection{Weight and Body Composition}

Body weight was measured and recorded once every week. Body composition was measured by EchoMRI quantitative nuclear magnetic resonance (NMR) system (Houston, TX, USA) once every 4 weeks and before sacrifice. Fat (\%) was calculated as $100 \% \times$ (fat mass $(\mathrm{g})$ ) / (total mass $(\mathrm{g})$ ).

\subsection{Glucose and Insulin Tolerance Tests}

For glucose tolerance tests, mice were fasted for 5 hours, and then administered water or sitagliptin (Januvia, $10 \mathrm{mg} / \mathrm{kg}$ ) by oral gavage. Thirty minutes later, mice were administered glucose in PBS (2 g/kg of body weight) by oral gavage (oGTT) or by intraperitoneal (i.p.) injection (ipGTT). For insulin tolerance tests, mice were injected i.p. with $0.6 \mathrm{IU} / \mathrm{kg}$ (Humalog, Lilly) in PBS. Blood for glucose measurements (Medisure glucometer) was collected via tail vein every 15 minutes up to 90 minutes post-glucose administration. Blood for active incretin measurements was collected 30 minutes prior to and 15 minutes after glucose administration in $\mathrm{K}^{2} \mathrm{EDTA}$ coated tubes with the addition of $10 \% \mathrm{v} / \mathrm{v}$ DPP4 inhibitor (Aprotinin, Fisher BioReagents 9087-70-1).

\subsection{Tissue Collection}

Animals were euthanized by isoflurane inhalation and blood was collected by via cardiac puncture. The skin and abdomen were dissected, and the heart, kidney, liver, spleen, and the gut were removed, weighed, and flash-frozen in liquid nitrogen and stored at $-80^{\circ} \mathrm{C}$ for future analyses. Separately, liver sections and the pancreas were removed, weighed, and fixed in 4\% paraformaldehyde for $24-48$ hours, and stored in $70 \%$ ethanol for histological analyses.

\subsection{Gene Expression}

RNA was isolated from tissues using Trizol reagent (Life Technologies, Mississauga, Ontario, Canada). First-strand cDNA was synthesized from total RNA using the SuperScript III synthesis system (Invitrogen). Specific mRNA abundances were measured by quantitative real-time PCR (qRT-PCR) on an ABI Prism Sequence Detection System (Applied Biosystems) according to the manufacturer's instructions. The standard curve method was used to determine mRNA concentrations, and each gene was normalized to cyclophilin (Ppia) expression.

\subsection{Pancreas Perfusion and Isolation}

Mice were fasted for 16 hours overnight, starting at the end of the light cycle prior to sacrifice. Animals were euthanized by isoflurane inhalation and cervical dislocation, and blood was collected via cardiac puncture. Mice were placed on a surgical board in the supine position and sterilized with $70 \% \mathrm{EtOH}$. 
The skin and abdominal muscles were dissected to expose the viscera. The pancreatic duct was clamped with hemostatic forceps, and $5 \mathrm{~mL}$ of cold sterile collagenase solution $(7.5 \mathrm{mg} / \mathrm{mL}$ collagenase (Sigma C7657) in HBSS (5 mM glucose, $1 \mathrm{mM} \mathrm{MgCl}_{2}$ ) was injected via the common bile duct to distend the pancreas. The pancreas was then excised, placed into a $50 \mathrm{~mL}$ centrifuge tube containing $10 \mathrm{~mL}$ of the cold collagenase solution, and kept on ice until incubation.

\subsection{Islet Isolation and Purification}

Tubes with distended pancreata were incubated in a $37^{\circ} \mathrm{C}$ water bath for 12 minutes, after which they were manually shaken 15-20 times to disrupt the tissues. The digestion process was stopped with the addition of $25 \mathrm{~mL}$ of ice-cold HBSS to each sample ( $5 \mathrm{mM}$ glucose, $1 \mathrm{mM} \mathrm{MgCl} 2,1 \mathrm{mM} \mathrm{CaCl}$ ) and centrifugation at $1000 \mathrm{rpm}$ for 1 minute. The supernatant was removed, and the wash process was repeated for a total of 3 times. The final pellet was resuspended in $5 \mathrm{~mL}$ of complete RPMI medium (10\% FBS, $1 \%$ penicillin/streptomycin), and $5 \mathrm{~mL}$ of Histopaque (Sigma, 10771) were underlaid to each tube. Samples were centrifuged at $2400 \mathrm{rpm}$ for 18 minutes, and the islets collected at the Histopaque-medium interface were collected into $10 \mathrm{~cm}$ petri dishes containing $6 \mathrm{~mL}$ of RPMI media. Islets were placed in the incubator at $37^{\circ} \mathrm{C}, 5 \% \mathrm{CO}_{2}$ for 10 minutes for recovery, and then handpicked into a new $3.5 \mathrm{~cm}$ dish using a P10 pipette. Handpicking was repeated to achieve purity of $98-100 \%$, and islets were placed in a cell culture incubator at $37^{\circ} \mathrm{C}, 5 \% \mathrm{CO}_{2}$ for $16-24$ hours to recover before perifusion experiments.

\subsection{Islet Perifusion}

Biorep Perifusion System (Biorep Technologies) was used to stimulate and collect the secretions of pancreatic islets in vitro for all perifusion experiments. All solutions were prepared in fresh $\mathrm{KRBH}$ buffer (115 mM NaCl, $5 \mathrm{mM} \mathrm{KCl}, 2.5 \mathrm{mM} \mathrm{CaCl}_{2}, 24 \mathrm{mM} \mathrm{NaHCO}_{3}, 10 \mathrm{mM} \mathrm{HEPES}$, and 1\% BSA; pH = 7.4). After incubation, equal numbers of islets (50 or 75-80 islets per mouse) were handpicked and placed into tubes containing $2.8 \mathrm{mM}$ glucose-containing $\mathrm{KRBH}$ buffer. Perifusion chambers were assembled according to the manufacturer's manual, and islet samples were placed between two layers of the polyacrylamide bead suspension (Bio-Gel P-4, Biorep). Islets were equilibrated for 48 minutes with the $2.8 \mathrm{mM}$ glucosecontaining buffer, and then perifused in intervals based on the experimental conditions. Flow rate (100 $\mu \mathrm{l} / \mathrm{min})$ and temperature $\left(37^{\circ} \mathrm{C}\right)$ remained constant for every experiment, and the type of treatment is indicated at the top of each figure (Arginine, Sigma, \#A5006; GLP-1 7-36, Bachem; GIP - (D-Ala²)-GIP, Bachem \#4054476; glucagon, Lilly). Effluent fractions were collected at 2-minute intervals into clear 96-well plates kept at $4-8^{\circ} \mathrm{C}$ during collection, which were then frozen and kept at $-80^{\circ} \mathrm{C}$ for further assays.

\subsection{BCA Assay}

For use in the BCA and DPP4 activity assays, tissues were homogenized using a liquid nitrogencooled mini mortar and pestle set. Homogenization/lysis buffer (0.1mM EDTA, 1\% v/v glycerol, 0.0067\% $\mathrm{v} / \mathrm{v}$ Brij-35) was added to powderized samples, which were then left on ice for 10 minutes to promote lysis. 
Samples were then centrifuged at $10000 \mathrm{rpm}$ for 10 minutes at $4^{\circ} \mathrm{C}$, and the supernatant was collected and used in the assays immediately. The bicinchoninic acid (BCA) assay (Pierce Rapid Gold BCA Protein Assay Kit, Thermo Fisher) was used to quantify protein concentration in tissue and cell/islet samples according to the manufacturer's instructions. Briefly, $20 \mu \mathrm{L}$ of sample or BSA standard were added per well of a clear 96-well plate, followed by $200 \mu \mathrm{L}$ of working reagent mix. After 5 minutes of incubation at room temperature with gentle shaking, absorbance was measured on a Biotek Microplate Reader at $480 \mathrm{~nm}$. The concentration of unknown samples was calculated based on the standard curve generated from BSA standards provided and expressed in $\mu \mathrm{g} / \mathrm{mL}$.

\subsection{DPP4 Activity}

DPP4 enzymatic activity in tissue lysates, cell lysates, and plasma samples was measured by a fluorometric assay. All samples were prepared as described for the BCA assay. Then, $10 \mu \mathrm{L}$ of plasma or $25 \mu \mathrm{L}$ of tissue/cell homogenate sample were incubated with $8 \mathrm{mM} \mathrm{MgCl}_{2}$ and $50 \mu \mathrm{L}$ of $\mathrm{AMC}$ substrate $(\mathrm{H}$ Gly-Pro-AMC, Bachem, USA) in a black flat-bottom 96-well plate for 20 minutes at RT with gentle shaking. Fluorescence intensity was measured on a Biotek Microplate Reader at $450 \mathrm{~nm}$, and the enzymatic activity of each sample was calculated from the standard curve generated based on the blank-corrected standards. Tissue DPP4 activity was normalized to total protein concentration in a sample and expressed as nmol $\mathrm{AMC} /$ minute/ng of protein (or $\mathrm{nmol} \mathrm{AMC} / \mathrm{mL}$ for plasma).

\subsection{Circulating DPP4 Concentration}

Mouse DPP4 ELISA (Mouse DPPIV/CD26 DuoSet ELISA, R\&D Systems) was used to measure circulating plasma DPP4 concentrations in plasma without a DPP4 inhibitor according to the manufacturer's protocol. Samples were diluted 1:100 with reagent diluent (1\% BSA in PBS) prior to the assay, and $100 \mu \mathrm{L}$ of diluted sample or standard were added per well. Absorbance was measured on a Biotek Microplate Reader at $450 \mathrm{~nm}$, and measurements at $540 \mathrm{~nm}$ were subtracted to correct for optical imperfections of the plate. Circulating DPP4 concentration was calculated using a standard curve generated from the standards of known concentrations and expressed in $\mathrm{ng} / \mathrm{mL}$.

\subsection{Active GIP Measurements}

Plasma was collected with a DPP4 inhibitor 15 minutes post-glucose administration and assayed using active GIP ELISA kit (CrystalChem, USA) according to the manufacturer's instructions. Briefly, $15 \mu \mathrm{l}$ of sample was added to each well and incubated for 2 hours at room temperature with gentle shaking. The plate was washed, followed by a 1-hour incubation with HRP-labelled antibody. After adding the substrate and the stop solution, optical density was measured on a Biotek Microplate Reader at 460 and $630 \mathrm{~nm}$, and measurements at $630 \mathrm{~nm}$ were subtracted to correct for optical imperfections of the plate. Active GIP concentration was calculated using a standard curve generated from the standards of known concentrations and expressed in $\mathrm{pM}$. 


\subsection{Insulin Measurements}

Mouse Ultrasensitive Insulin ELISA kit (ALPCO 80-INSMSU) or Mouse High Range Insulin ELISA kit (ALPCO 80-INSMSH) were used to measure insulin concentrations in mouse plasma and perifusion fractions, respectively. Briefly, $5 \mu \mathrm{L}$ of sample or standard and $75 \mu \mathrm{L}$ of conjugate solution were added to each well and incubated at room temperature at $800 \mathrm{rpm}$. The plate was then washed and incubated with $100 \mu \mathrm{L}$ of TMB substrate per well for 15 minutes. $100 \mu \mathrm{L}$ of stop solution was added, and absorbance at $450 \mathrm{~nm}$ was measured using Biotek Microplate Reader. Sample concentrations were calculated using a 5parameter logistic curve fit.

\subsection{Immunofluorescent Analysis}

Tissues (pancreas, liver) were fixed in 4\% paraformaldehyde for 24-48 hours at room temperature before paraffin wax embedding. Embedded tissues were sectioned into $5 \mu \mathrm{m}$-thick sections and deparaffinized using a series of xylene and alcohol washes at 5 minutes per wash. Heat-induced antigen retrieval was performed using sodium citrate buffer. Slides were heated in a $10 \mathrm{mM}$ sodium citrate buffer until boiling using a microwave, then allowed to cool for 15 minutes and washed with cold water. All sections were blocked with $10 \%$ horse serum in PBS for 2 hours at room temperature prior to staining. Sections were incubated with primary antibodies overnight at $4^{\circ} \mathrm{C}$ followed by secondary antibody incubation for 2 hours, and with DAPI for 5 minutes in the dark at room temperature. Fluorescent images were captured with Zeiss fluorescent microscope and processed with Zen software package.

Primary antibodies used: polyclonal goat anti-mouse DPP-4/CD 26 (1:50, R\&D Systems, AF954), monoclonal rabbit anti-mouse insulin (1:200, Abcam, ab181547); monoclonal rabbit anti-mouse glucagon (1:200, Abcam, ab92517). Secondary antibodies used: Alexa Fluor 488 goat anti-rabbit antibody (1:1000, Abcam, ab6702), Alexa Fluor 555 donkey anti-goat antibody (1:1000, Abcam, ab150134), Alexa Fluor 488 donkey anti-goat antibody (1:1000, ab150129).

\subsection{Statistical analysis}

All data were expressed as the mean \pm SEM, unless stated otherwise. Comparisons between groups were performed using One- or Two-Way ANOVA with post-hoc Tukey correction using GraphPad Prism 8. Area Under the Curve (AUC) analysis was performed using GraphPad Prism 8. Statistically significant differences are indicated as ${ }^{*} p \leq 05,{ }^{* *} p \leq 0.01,{ }^{* * *} p \leq 0.001$, and ${ }^{* * * *} p \leq 0.0001$. For AUC graphs, different letters indicate statistical differences between groups. 


\section{Results}

\subsection{Activation of the GLP-1R and GIPR Within the $\beta$-cell Is Critical for Regulation of Glucose by DPP4i}

Previous studies have demonstrated the glucoregulatory effects of the DPP4 inhibitor sitagliptin are dependant on the activation of GLP-1 and GIP receptors (Waget et al., 2011). However, doubts have been raised as to whether receptors in the islet mediate the entirety of the glucose-lowering response or if receptors within the portal circulation, enteric nervous system, or central nervous system also substantially contribute (Aulinger et al., 2020; Varin et al., 2019b). Here, we assessed the importance of intra-islet incretin receptors for DPP4i-dependent glucose-lowering using a murine model with selected elimination of both GLP1R and GIPR within $\beta$-cells: the Double Incretin Receptor Knock-Out (DIRKO). While both low (14 $\mu \mathrm{g} / \mathrm{mouse}$, selective enteral inhibition) and high (10 mg/kg body weight, systemic inhibition) concentrations of sitagliptin were able to reduce glycemia and total area under the curve in response to oral glucose gavage in control mice (Fig.3.1 A, C), it had no effect on glucose clearance in the DIRKO group (Fig.3.1 B, C). Since the expression of Gipr and Glp1r mRNA is known to be relatively high in the white adipose tissue (WAT) and the lung, respectively, compared to other tissues (Beaudry et al., 2019; Viby et al., 2013; Zhu et al., 2019), we analyzed the islet, jejunum, WAT, and lung tissue lysates by PCR to verify the $\beta$-cellspecific incretin receptor elimination. The levels of Gipr and Glp1r mRNA transcripts were significantly

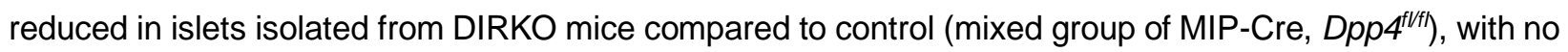
differences detected in the relative expression of Gipr and Glp1r in the jejunum, epididymal white adipose tissue (eWAT), and the lung (Fig.3.1 D-F). 

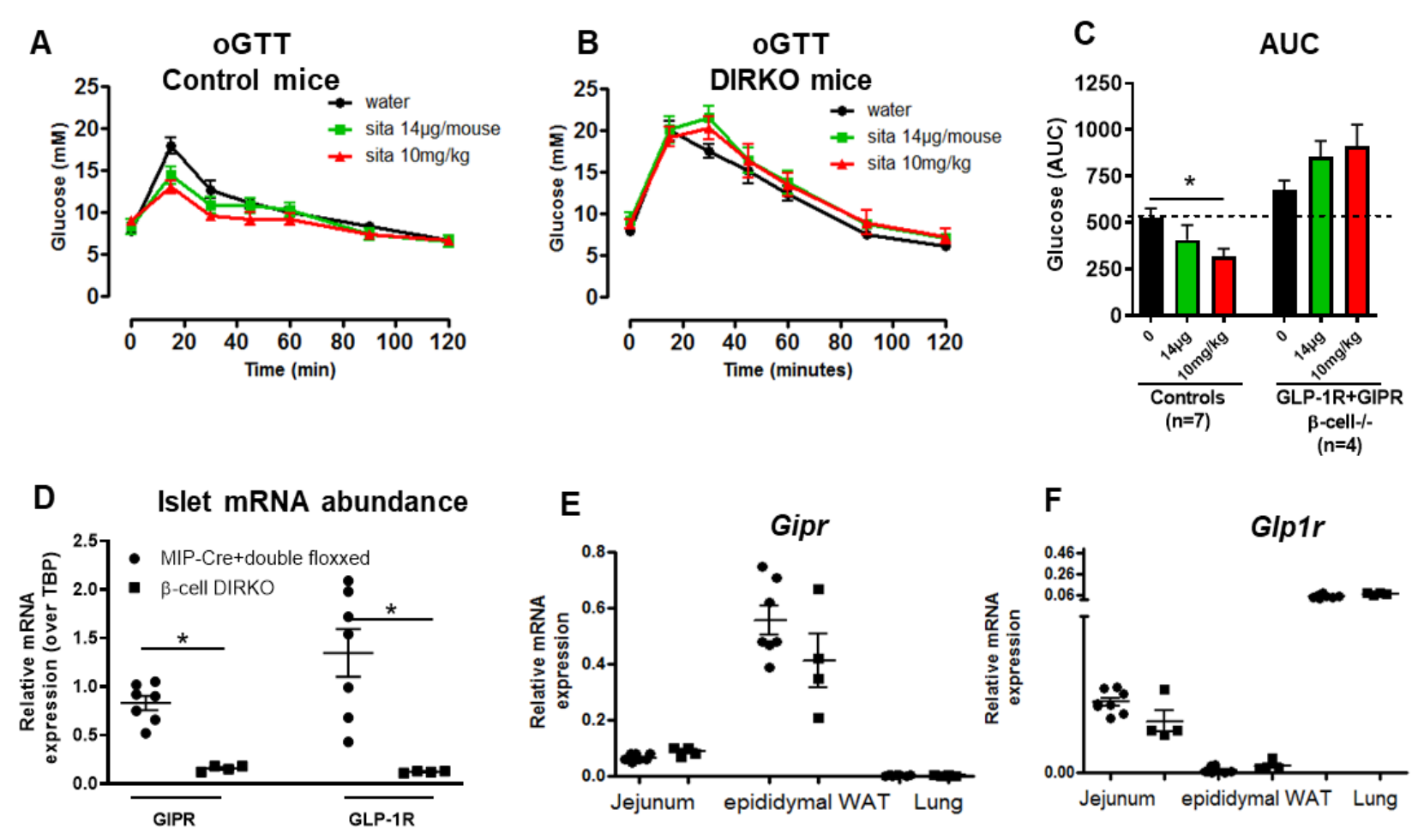

Figure 3.1. Activation of the GLP-1R and GIPR Within the $\beta$-cell Is Critical for Regulation of Glucose by DPP4i

(A) Oral glucose tolerance test $(2 \mathrm{~g} / \mathrm{kg})$ in control (MIP-Cre and $\left.D p p 4^{f / f / f}\right)$ or $(\mathrm{B}) \beta$-cell-specific double incretin receptor knockout (DIRKO) mice administered water or sitagliptin (14 $\mu \mathrm{g} / \mathrm{mouse}$ or $10 \mathrm{mg} / \mathrm{kg})$ by oral gavage 30 min prior to gavage of glucose. (C) Area under the curve depicting blood excursions during oGTTs in control ( $n=7)$ versus DIRKO ( $n=4)$ mice. (D) Abundance of Gipr and Glp1r mRNA in islets of control and $\beta$ cell-specific DIRKO mice (normalized to Ppia). (E) Relative expression of Gipr and (F) Glp1r mRNA transcripts in whole extracts of jejunum, epididymal white adipose tissue (WAT), and lung tissue (normalized to Ppia). Data are represented as the mean \pm SEM, ${ }^{*}$ indicates $p<0.05$. 


\subsection{Genetic Elimination of Dpp4 Leads to Increased Pancreatic Insulin Content in HFD-Fed Mice, but Has No Significant Effects On Islet Function While On Regular Chow}

Following our findings, we set out to investigate the role of endogenous DPP4 in islet physiology and function. First, we found no significant differences in islet Dpp4 mRNA transcript levels between wildtype C57BL6J mice fed chow or a HFD (Fig.3.2 A). Interestingly, genetic whole-body Dpp4 knockout resulted in significantly elevated pancreatic insulin content compared to WT controls in young mice fed a HFD, but had no effects while on regular chow (Fig.3.2 B). To evaluate the role of DPP4 in the dynamic hormone release from the islet, we isolated islets from 45-50 week-old chow-fed mice and sequentially perifused them with a buffer containing glucose, arginine, GLP-1, and $\mathrm{KCl}$ with and without the addition of DPP4 inhibitor sitagliptin. Interestingly, sitagliptin did not increase glucose-stimulated insulin secretion (GSIS) in islets isolated from chow-fed WT (Fig.3.2 C) or Dpp4 ${ }^{-/}$mice compared to their untreated controls (Fig.3.2 D). In addition, no significant differences in GSIS were detected between WT and Dpp $4^{-/}$islets (Fig.3.2 E), suggesting that intra-islet DPP4 is not a significant regulator of islet function in chow-fed mice. 
A

Dpp4 in Islets

52 w.o.
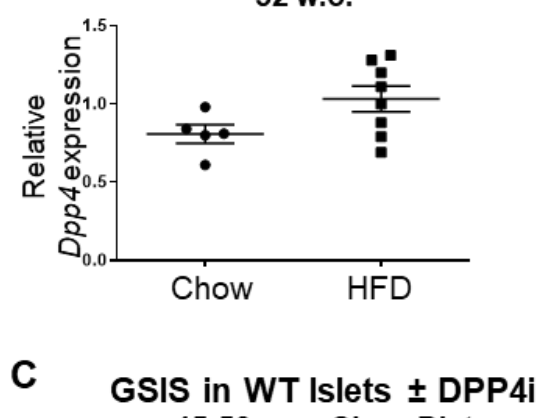

45-50 w.o., Chow Diet

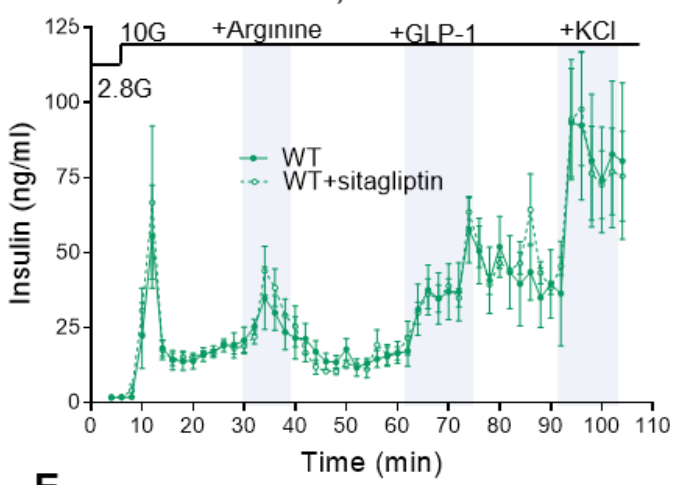

$\mathbf{E}$

GSIS in Islets
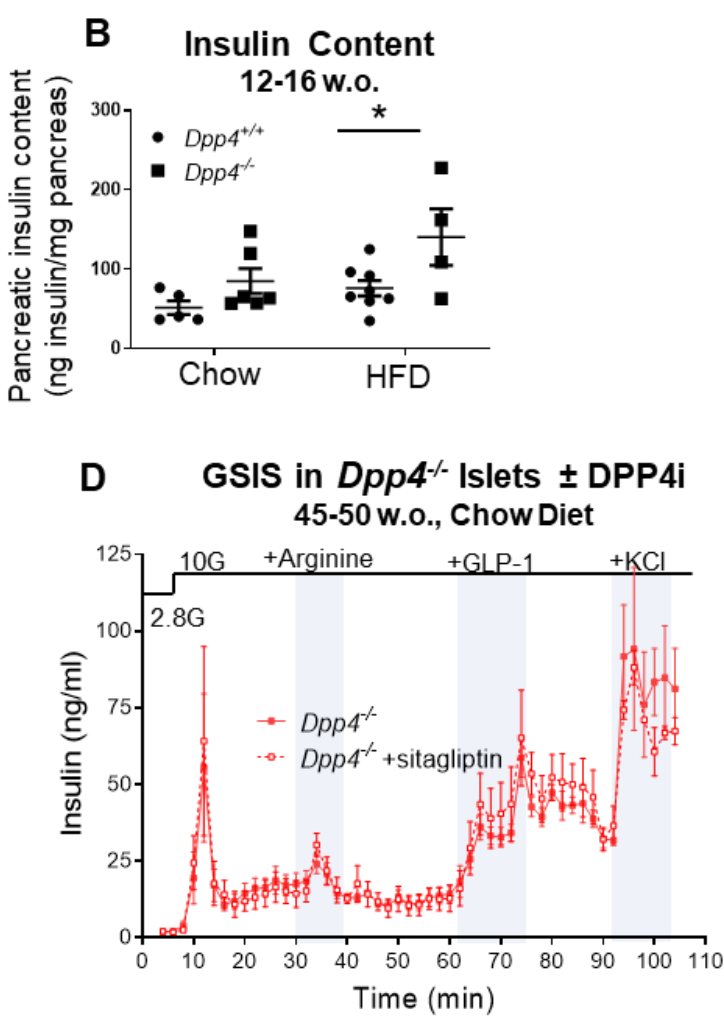

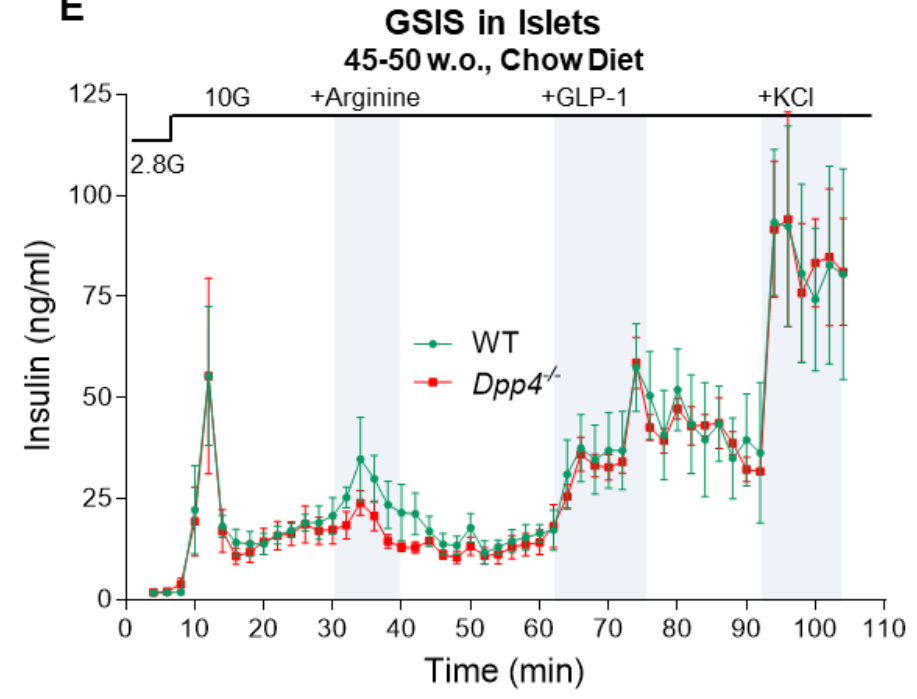

Figure 3.2. Elimination of Dpp4 Leads to Increased Pancreatic Insulin Content in HFD-Fed Mice, but Has No Significant Effects On Islet Function While On Regular Chow.

(A) Relative expression of Dpp4 mRNA in islets isolated from wildtype C57BL6J mice fed a chow diet or mice fed a high-fat diet for 52 weeks. (B) Insulin content measured in the pancreas of 12-week old $D p p 4^{+/+}$ or $D p p 4^{-/}$littermate controls fed chow or after continuing on a HFD (+4 weeks). (C-E) Insulin secretion measured in islets isolated from $45-50$-week-old chow-fed mice in perifusion ( $n=4$ per group). Following a 48-minute equilibration with $2.8 \mathrm{mM}$ glucose-containing buffer, islets were sequentially perifused with $10 \mathrm{mM}$ glucose buffer containing stimuli as indicated at the top of each graph. Sitagliptin (200nM) was added directly to the buffer solution. Data are represented as the mean \pm SEM, ${ }^{*}$ indicates $p<0.05$. 


\subsection{Dpp $4^{\beta-c e l l-/}$ Mice Have Significantly Reduced Islet DPP4 Activity and Expression}

Based on our findings in HFD-fed Dpp4 ${ }^{-/}$mice, we hypothesized that intra-islet DPP4 may have a distinct role in glucose regulation under the condition of higher metabolic demand. To evaluate its contribution to islet function, we created a $\beta$-cell-specific Dpp4 knockout model using a Dpp4 $4^{f / f l}$ line expressing a tamoxifen-inducible Cre under the control of Mouse Insulin Promoter (MIP-Cre). At 8-10 weeks, MIP-Cre recombinase activity was induced by oral administration of tamoxifen in corn oil ( $50 \mathrm{mg} / \mathrm{ml})$

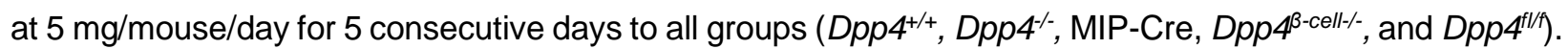

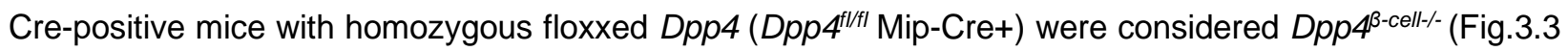
A) with recombination limited to $\beta$-cell. Mice expressing MIP-Cre and homozygous wildtype Dpp4 allele $\left(\mathrm{Dpp}^{+/+} \mathrm{Mip}-\mathrm{Cre}+\right)$ were denoted as MIP-Cre and used as a Cre-positive control (Fig.2 A). Using a fluorometric DPP4 activity assay we found a significant decrease in DPP4 activity in islets isolated from chow-fed Dpp $4^{\beta-c e l l-/-}$ mice compared to their age- and weight-matched controls ( $D p p 4^{+/+}$, MIP-Cre, Dpp $\left.4^{f / / f}\right)$, with no significant changes observed in other tissues (Fig.3.3 B). The residual islet DPP4 activity measured by the assay could be attributed to DPP4 found in other cell types within the islet ( $\alpha$-cell, $\delta$-cell), as well as the activity of DPP4-like (DASH) proteins (Wagner et al., 2016). We further confirmed the reduction in $\beta$ cell-derived DPP4 protein using fluorescence microscopy of paraformaldehyde-fixed pancreatic sections taken at sacrifice, with representative images shown in Fig.3.3 C. Paraffin blocks containing tissues of interest from 40-week-old HFD-fed male mice were sectioned to $5 \mu \mathrm{m}$-thick sections using a microtome, and stained with DPP4-specific antibody as described in methods. Wildtype mice exhibited uniform DPP4positive staining within the islet (Fig.3.3 C, top left panel), while Dpp4 $4^{\beta-c e l l-1-}$ mice had greatly reduced expression (Fig.3.3 C, middle left panel). Confirming the tissue-specific knockout, no differences in DPP4 protein expression were observed in fixed liver sections of both groups (Fig.3 top right, middle right panels). Furthermore, no detectable DPP4 expression was found in the pancreas or liver of the whole-body Dpp4 knockout $\left(D p p 4^{-/-}\right)$group (Fig.3.3 C bottom panels). 
A

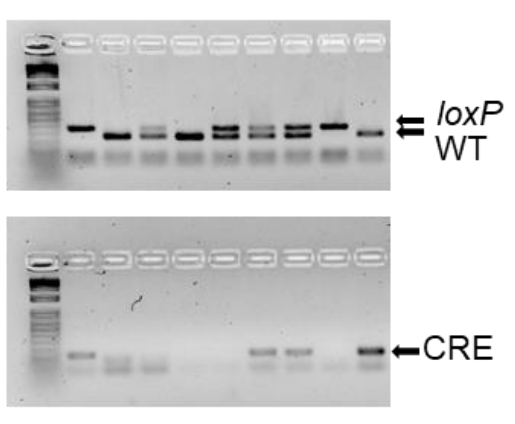

B

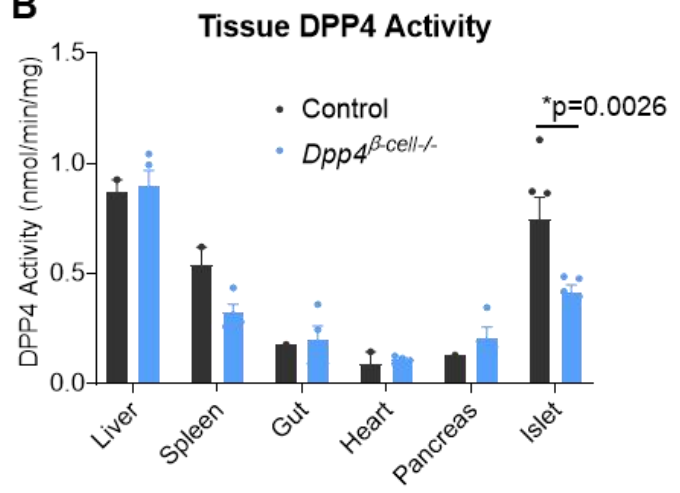

C
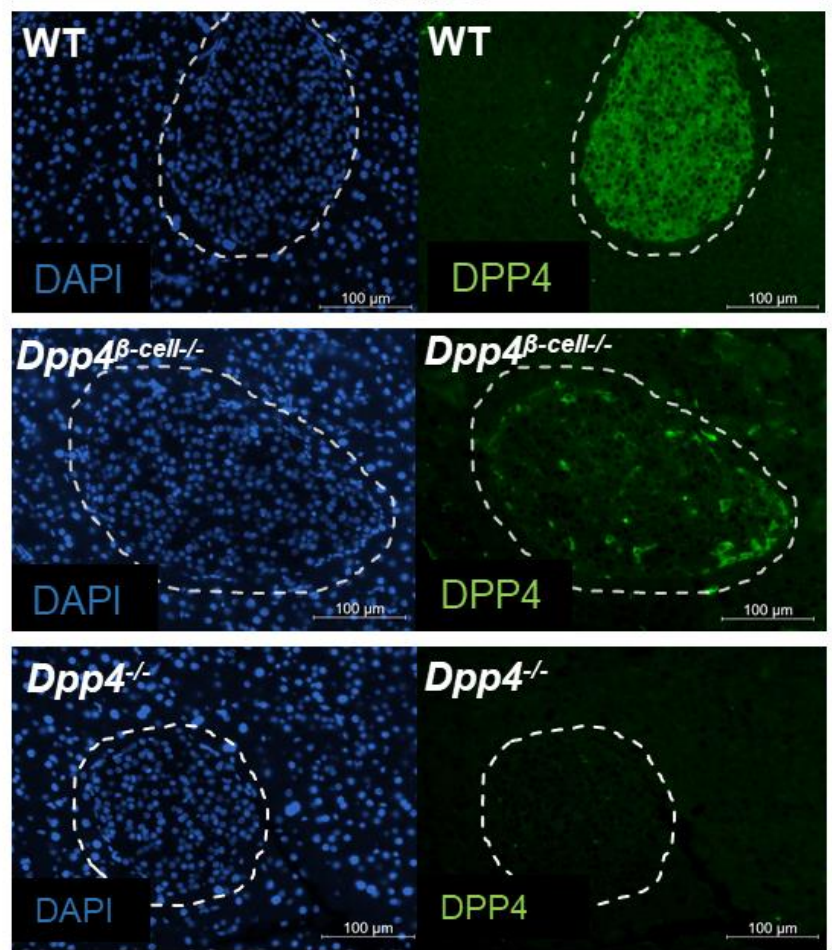

Liver
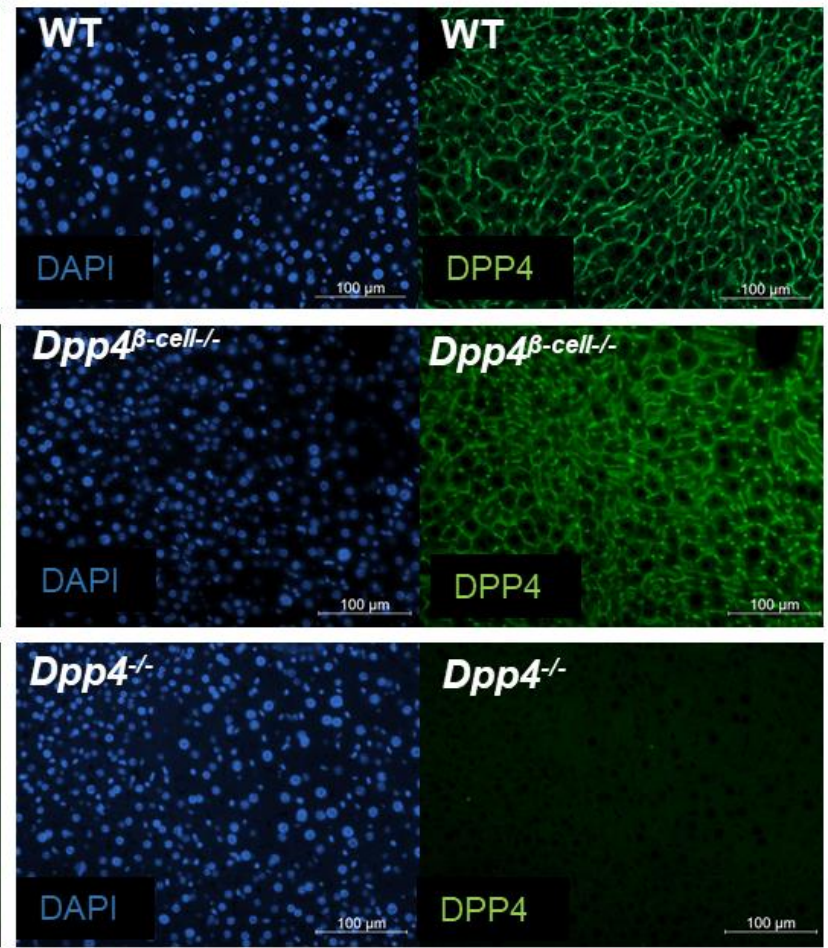

Figure 3.3. Islets from $D p p 4^{\beta-c e l l-/}$ Mice Have Significantly Reduced Islet DPP4 Activity and Expression.

(A) Representative genotyping gel used to identify WT, Dpp4 $4^{\mathrm{wt} / f l}$, and $D p p 4^{f / f t}$ mice (top), as well as Cre+ or Cre- status (bottom). (B) DPP4 activity normalized to total protein measured in whole extracts of tissues (liver, spleen, gut, heart, pancreas, islets from control (WT, Mic-Cre, $D p p 4^{f / / f l}$ ) and $D p p 4^{\beta \text {-cell-/ }}$ young, chowfed male mice ( $n=2-6$ per group, except gut and pancreas where $n=1-6)$. Data are represented as the mean \pm SEM, * indicates $p<0.05$. (C) Immunofluorescence staining showing DPP4 expression (green) in paraffinfixed mouse pancreatic sections (WT - top, Dpp $4^{\beta-c e l l-/}$ - middle, Dpp $4^{-/-}$- bottom). DAPI staining (blue) was used to identify nuclei; white dashed lines are used to outline islets; liver stained as a positive control. 


\subsection{Islets from HFD-Fed Dpp4 ${ }^{\beta-c e l l-/}$ Mice Exhibit Increased Glucose-Stimulated Insulin Secretion in Perifusion}

Once the knockout model was confirmed, we set out to evaluate the role of intra-islet DPP4 on islet secretory function in vitro. All mice were fed a HFD for 15 weeks and sacrificed at 40 weeks. Pancreatic islets were isolated from $D p p 4^{\beta-c e l l-/}$ and control $\left(D p p 4^{+/+}\right.$, MIP-Cre, $\left.D p p 4^{f / f}\right)$ mice using collagenase-aided digestion of the pancreas, followed by density gradient separation with Histopaque. While basal and $\mathrm{KCl}-$ induced insulin release remained similar between groups, a trend toward higher glucose-stimulated insulin secretion (GSIS) was observed in Dpp $4^{\beta-c e l l-/}$ islets compared to control in response to perifusion with high (16.7 mM) concentration of glucose (Fig.3.4 A). In addition, total insulin released in response to stimulation, depicted by the area under the curve (AUC) analysis, was significantly higher in the Dpp $4^{\beta-c e l l-/}$ mice compared to control (Fig.3.4 A).

To further investigate these differences, we compared GSIS in islets from the two groups with and without the addition of a highly potent and specific DPP4 inhibitor, sitagliptin (Sangle et al., 2012). Interestingly, when perifused with the same stimuli, addition of sitagliptin significantly increased both firstand second-phase GSIS, as well as total insulin secreted in islets from control mice $(n=9)$, but had no measurable effects on islets with DPP4 eliminated from the $\beta$-cell $(n=2)$ (Fig.3.4 B, C). Of note, a conclusive interpretation of these results is limited due to a small sample size of the $D p p 4^{\beta-c e l l-/}$ group. However, the difference in GSIS between the control and Dpp4 $4^{\beta-c e l l-r}$ islets (Fig.3.4 A), combined with the marked increase in GSIS of the sitagliptin-treated versus untreated control islets (Fig.3.4 B) strongly suggests that the catalytic action of DPP4 is a regulator of glucose-stimulated islet insulin secretion in vitro. 

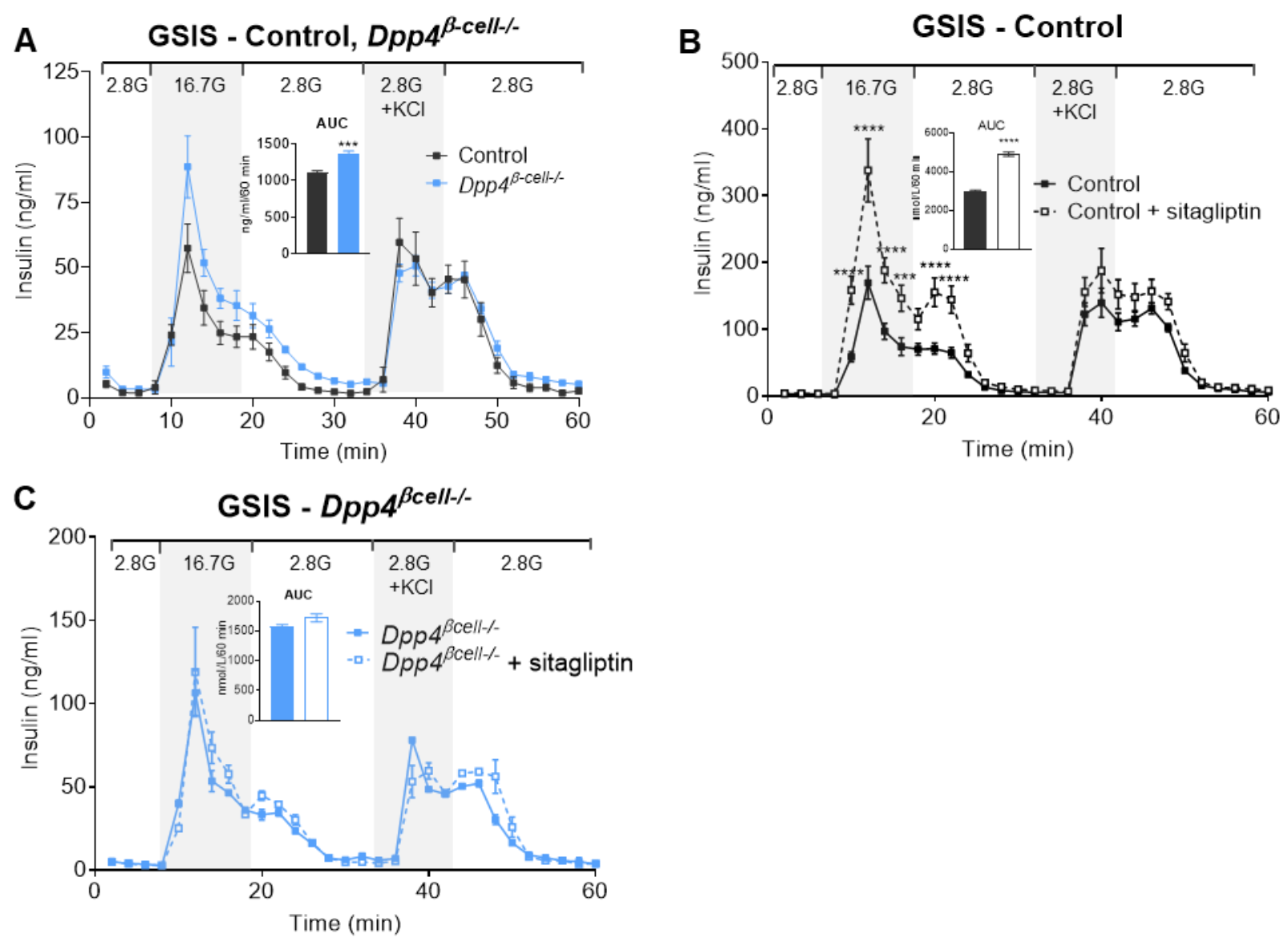

\section{Figure 3.4. Islets from HFD-Fed Dpp4 $4^{\beta \text {-cell-/ }}$ Mice Exhibit Increased Glucose-Stimulated Insulin Secretion in Perifusion}

(A) Glucose-stimulated insulin secretion (GSIS) measured in islets isolated from control (WT, Dpp4 $4^{f / f t}$, and MIP-Cre, $n=9)$ and Dpp4 ${ }^{\beta-c e l l-/}(\mathrm{n}=4)$ 40-week-old HFD-fed male mice in response to perifusion with buffer containing $2.8 \mathrm{mM}$ glucose, $16.7 \mathrm{mM}$ glucose, or $2.8 \mathrm{mM}$ glucose $+\mathrm{KCl}$. (B) GSIS measured in islets isolated from control (WT, Dpp4 ${ }^{f / f l}$, and MIP-Cre, n=9) 40-week-old HFD-fed male mice in response to perifusion with glucose with and without DPP4 inhibitor sitagliptin. (C) GSIS in islets from Dpp $4^{\beta \text {-cell-/ }} 40$-week-old HFD-fed male mice in response to perifusion with glucose with and without DPP4 inhibitor sitagliptin $(n=2)$. Data are represented as the mean \pm SEM. ${ }^{* * *} p<0.001,{ }^{* * *} p<0.0001$. 


\subsection{Dpp $4^{\beta \text {-cell-- }}$ Male Mice on Chow Diet Exhibit Normal Glucose Tolerance and Retain Glucoregulatory Responses to Sitagliptin}

To directly assess the importance of $\beta$-cell-derived DPP4 on glucose metabolism in-vivo, we subjected mice with MIP-Cre-targeted elimination of Dpp4 (Dpp ${ }^{\beta-c e l l-}-$ ) and littermate MIP-Cre-positive control mice (MIP-Cre) to a series of glucose and insulin tolerance tests while on regular chow or after being fed a HFD. Prior to the glucose tests, mice were gavaged with a high concentration of the DPP4 inhibitor sitagliptin (10 mg/kg of body weight) to induce systemic DPP4 inhibition, or an equivalent amount of water. MIP-Cre and Dpp $4^{\beta-c e l l-/-}$ mice exhibited similar glucose excursions in response to oral glucose gavage ( $2 \mathrm{~g} / \mathrm{kg}$ ), and intraperitoneal glucose injection ( $2 \mathrm{~g} / \mathrm{kg}$ ) on chow diet (Fig.3.5 A, B), with no significant differences in fasting glucose. Systemic DPP4 inhibition with sitagliptin prior to oral glucose test improved glucose excursion in both groups, leading to a $40 \%$ reduction in the initial glucose spike from baseline in the MIP-Cre and $45 \%$ in the Dpp $4^{\beta-c e l l-/-}$ group (Fig.3.5 A). Unsurprisingly, sitagliptin had no favourable effects on glucose metabolism during an i.p. glucose challenge, a setting in which plasma active incretin concentrations remain low (Fig.3.5 B). Lastly, insulin sensitivity was slightly decreased in the Dpp ${ }^{\beta-c e l l-/-}$ group, as demonstrated by the AUC analysis of total insulin response (Fig.3.5 C).

In a separate experiment, we collected plasma from this cohort following a 5-hour fast without

adding a DPP4i. Unexpectedly, plasma DPP4 activity was elevated in the Dpp $4^{\beta-c e l l-l-}$ group compared to the age- and sex-matched MIP-Cre control group, but no significant differences were found in plasma DPP4 concentration between all groups fed a chow diet (Fig.3.5 D, E). 


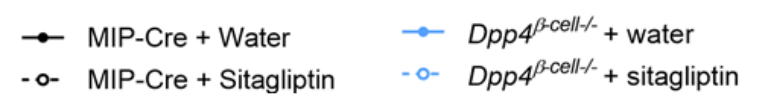
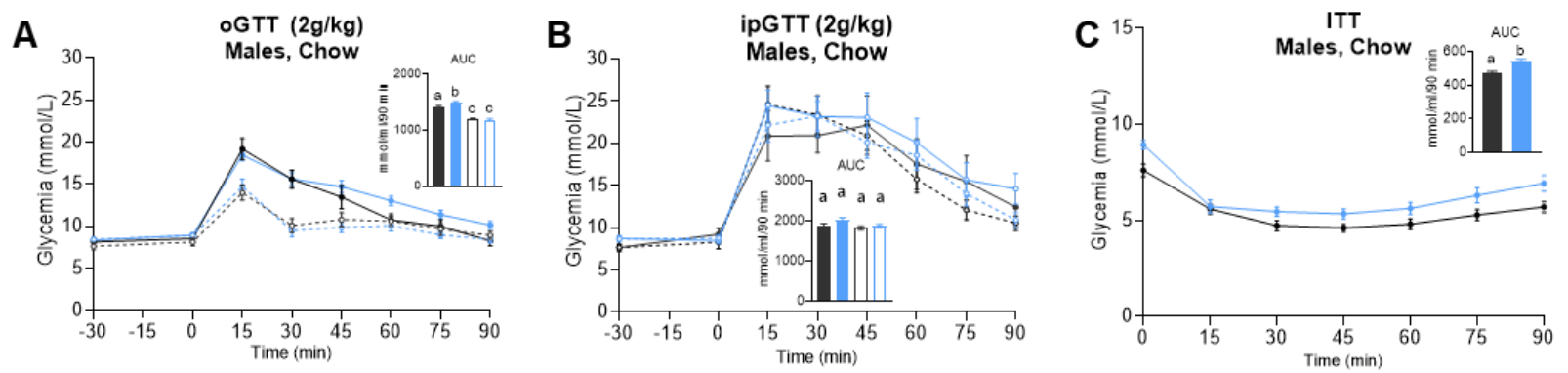

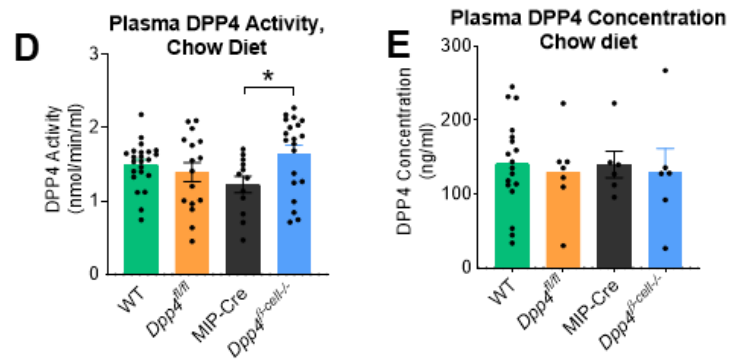

Figure 3.5. Dpp4 ${ }^{\beta-c e l l-/-}$ Male Mice on Chow Diet Exhibit Normal Glucose Tolerance and Retain Glucoregulatory Responses to Sitagliptin.

(A) Oral glucose, (B) i.p. glucose, and (C) insulin tolerance tests in chow-fed Dpp4 ${ }^{\beta-c e l l-/}(\mathrm{n}=21)$ and MIP-Cre $(n=12)$ control mice. Sitagliptin was given by oral gavage 30 minutes prior to glucose tolerance tests. $A$ solution of $30 \%$ glucose in PBS was given at $2 \mathrm{~g} / \mathrm{kg}$ of body weight either orally or via an i.p. injection. Insulin was injected at $0.6 \mathrm{IU} / \mathrm{kg}$ of body weight. Inset graphs represent area under the curve (AUC) for each group and treatment, and different letters indicate statistical differences between groups by ANOVA with post-hoc Tukey test. (D) DPP4 activity and (E) concentration measured in plasma of chow-fed wildtype, Dpp4 ${ }^{f / f l}$, MIPCre, and $D p p 4^{\beta-c e l l-/}$ mice. Data are represented as the mean $\pm \mathrm{SEM},{ }^{*} p<0.05$. 


\subsection{Elimination of $\beta$-cell-Derived Dpp4 Fails to Improve Glucose Tolerance or Prevent Incretin Degradation in HFD-fed Mice in vivo}

Mice were put on HFD to facilitate weight gain and induce metabolic stress. After 5 weeks of HFD feeding both $D p p 4^{\beta-c e l l-/}$ and MIP-Cre mice exhibited similar, elevated response to both oral and i.p. glucose administration (Fig.3.6 A, B). Again, consistent with findings in chow-fed mice, sitagliptin was able to reduce glucose excursion with oral, but not i.p. glucose challenge in both groups. While no significant differences were found in blood glucose in response to a $0.6 \mathrm{IU}$ injection of insulin at every time point, overall HFD-fed $D p p 4^{\beta-c e l l-/-}$ mice demonstrated slightly improved overall insulin sensitivity compared to control (Fig.3.6 C). Consistent with previous findings by Mulvihill et al., (2017) systemic inhibition with sitagliptin prior to glucose tolerance tests increased the concentration of active circulating GIP (Fig.3.6 D, E), and insulin (Fig.3.6 F, G) 15 minutes post-glucose, however, no preferential increase was observed in HFD-fed Dpp4 $4^{\beta-c e l l-/-}$ compared to MIP-Cre mice. Circulating DPP4 activity and concentration remained similar between all groups on HFD (Fig.3.6 H, I).

Finally, to assess islet function in vitro, mice were sacrificed at 60-63 weeks after being on a HFD for 35-40 weeks. Islets were isolated and sequentially perifused with $\mathrm{KRBH}$ buffer containing (in order): 2.8 $\mathrm{mM}$ glucose, $10 \mathrm{mM}$ glucose, followed by the addition of arginine, GLP-1, GIP, and glucagon to the $10 \mathrm{mM}$ glucose-containing KRBH buffer. No significant differences in GSIS were observed in islets isolated from $D p p 4^{\beta-c e l l-/-}(n=4)$ or MIP-Cre control $(n=4)$ mice (Fig.3.6 J). Taken together, these data demonstrate that elimination of DPP4 from the pancreatic $\beta$-cells may lead to enhanced insulin sensitivity, but is not sufficient to improve glucose tolerance or GIP levels achieved by the whole-body Dpp4 ${ }^{-/}$mice or systemic DPP4 inhibition with sitagliptin. 

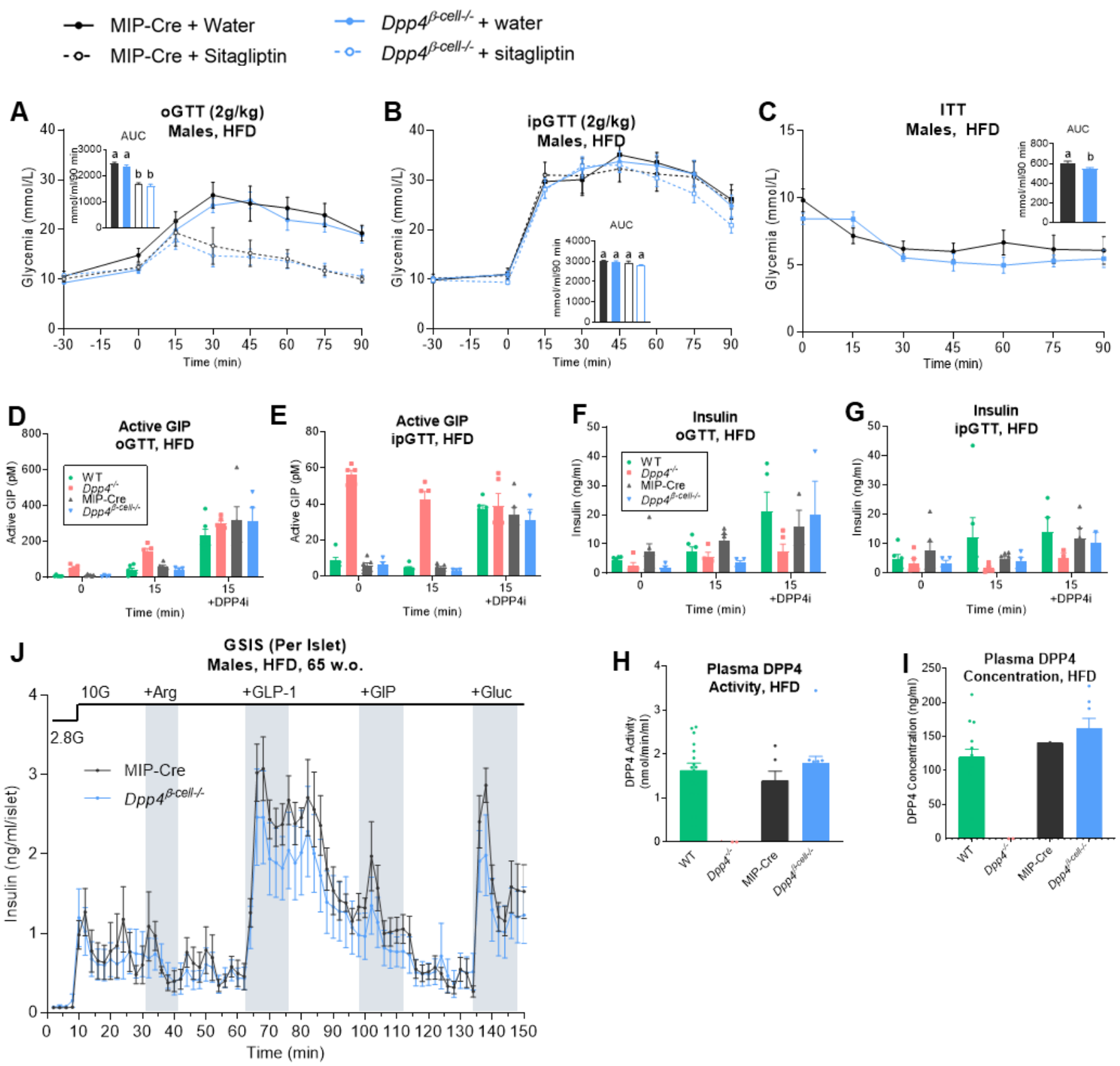

Figure 3.6. Elimination of $\beta$-cell-derived DPP4 Does Not Improve Glucose Tolerance, or Prevent Incretin Degradation in vivo.

(A) Oral glucose, (B) i.p. glucose, and (C) insulin tolerance tests in HFD-fed Dpp4 ${ }^{\beta-c e l l--}(\mathrm{n}=13)$ and MIP-Cre control $(n=6)$ mice. Sitagliptin was given by oral gavage 30 minutes prior to GTTs. A solution of $50 \%$ glucose in PBS was given at $2 \mathrm{~g} / \mathrm{kg}$ body weight. Insulin was injected at $0.6 \mathrm{IU} / \mathrm{kg}$ of body weight. Inset graphs represent area under the curve (AUC), different letters indicate statistical differences between groups by ANOVA with post-hoc Tukey test. (D) Plasma active GIP measured in response to oral and (E) i.p. glucose in HFD-fed $D p p 4^{\beta-c e l l-/-}$ and control mice. (F) Plasma insulin measured in response to oral and (G) i.p. glucose in HFD-fed $D p p 4^{\beta-c e l l-l}$ and control mice. (H) Plasma DPP4 activity and (I) concentration measured in plasma of HFD-fed Dpp $4^{\beta \text {-cell-- }}$ and control mice without sitagliptin. $(J)$ Insulin secretion measured during perifusion of islets isolated from 65-week old HFD-fed Dpp4 $4^{\beta \text {-cell-/- }}$ mice $(n=4)$ and MIP-Cre control $(n=4)$ mice with stimuli as indicated at the top of the graph. All data are represented as the mean $\pm S E M,{ }^{*} p<0.05$. 


\section{7 $\quad \beta$-Cell-Derived Dpp4 Has a Role in Glucose Regulation in Female Mice Fed Chow Diet}

To examine potential sex differences in the paracrine action of intra-islet DPP4 we also evaluated a female mouse model with DPP4 eliminated from the pancreatic $\beta$-cell ( $\left.D p p 4^{\beta-c e l l-}-{ }^{-}\right)$and assessed its ability to regulate glycemia in vivo. Unlike the male mice, female $D p p 4^{\beta-c e l l--}$ and their age- and weight-matched MIP-Cre-positive control exhibited different responses to an oral glucose gavage. Overall, the untreated MIP-Cre control group demonstrated the highest total rise in blood glucose during the oral glucose challenge as represented by the AUC analysis (Fig.3.7 A). This rise was also significantly reduced by sitagliptin treatment (Fig.3.7A). In contrast, sitagliptin had no further glucose-lowering effects on the Dpp $4^{\beta-}$ cell-- group (Fig.3.7 A). In addition, glucose excursion of both sitagliptin-treated and untreated Dpp4 $4^{\beta-c e l l-/-}$ females was comparable to the sitagliptin-treated control group, suggesting a potential deletion of the DPP4 site important for glucose regulation in female $D p p 4^{\beta-c e l l-/}$ mice. Unexpectedly, while MIP-Cre female mice were unaffected by sitagliptin treatment prior to i.p. glucose injection, Dpp $4^{\beta-c e l l-r}$ group exhibited a modest decrease in glycemia during ipGTT as demonstrated by the AUC analysis (Fig.3.7 B). Lastly, no significant differences in insulin tolerance were observed between female Dpp $4^{\beta-c e l l-/-}$ and Cre-control mice (Fig.3.7 C). 
$\rightarrow$ MIP-Cre + water $\quad \rightarrow D p p 4^{\beta-c e l l-/-}+$ water

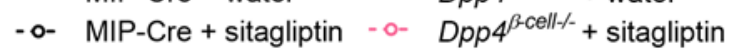
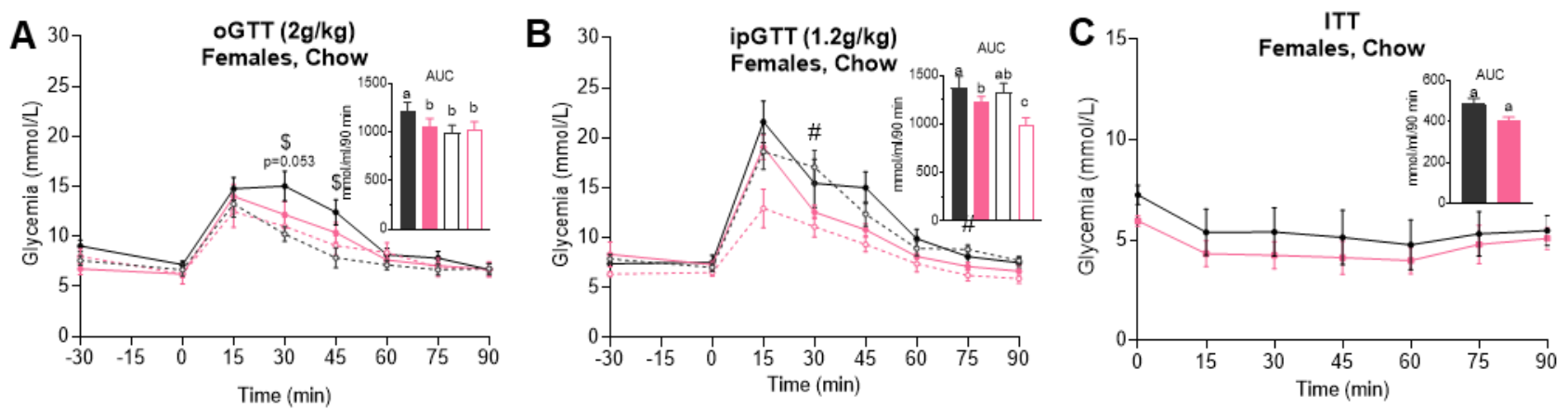

Figure 3.7. $\beta$-Cell-Derived Dpp4 Has a Role in Glucose Regulation in Female Mice Fed Chow Diet.

(A) Oral glucose, $(B)$ intraperitoneal glucose, and $(C)$ insulin tolerance tests in young chow-fed female $D p p 4^{\beta-}$ ${ }_{\text {cell-- }}(n=7)$ and MIP-Cre control $(n=10)$ mice. Sitagliptin was given by oral gavage 30 minutes prior to glucose tolerance tests. $30 \%$ glucose in PBS was given at $2 \mathrm{~g} / \mathrm{kg}$ of body weight for oral glucose tolerance and at $1.2 \mathrm{~g} / \mathrm{kg}$ of body weight for i.p. glucose tolerance tests. Inset graphs represent area under the curve (AUC), different letters indicate statistical differences between groups by ANOVA with post-hoc Tukey test. Data are represented as the mean \pm SEM, ${ }^{*} p<0.05$.

$\$$ indicates difference between sitagliptin-treated vs. water-treated MIP-Cre group; \# indicates difference between sitagliptin-treated MIP-Cre and $D p p 4^{\beta \text {-cell-/ }}$ groups. 


\subsection{Elimination of $\beta$-cell-derived DPP4 Improves Oral Glucose Tolerance and Enhances Insulin Sensitivity in HFD-Fed Female Mice}

After 5 weeks of HFD feeding to induce weight gain and metabolic dysregulation, we measured glycemic response to a gavage or an injection of glucose. Again, the untreated MIP-Cre control group exhibited the highest total rise in blood glucose when it was given orally, and the rise was significantly reduced by sitagliptin (Fig.3.8 A). HFD-fed Dpp4 $4^{\beta-c e l l-/}$ group, however, saw no further improvements in glycemia with systemic DPP4 inhibition, providing further support for the intra-islet DPP4 being an important target for DPP4 inhibition in glycemia regulation in females. No significant differences in glucose excursions were found between groups with i.p. (1.2 g/kg of body weight) glucose administration (Fig.3.8 B), and treatment with sitagliptin was unable to significantly improve glycemia regulation in either group. Finally, Dpp4-cell-- mice exhibited a slight improvement in insulin sensitivity compared to control after 8 weeks of HFD-feeding as demonstrated by the AUC analysis (Fig.3.8 C).

Plasma collected during glucose tests was assayed for active GIP (Fig.3.8 D, E) and insulin (Fig.3.8 $F, G$ ) with no significant differences found between groups at any time point (baseline, 15 minutes postglucose, or 15 minutes post-glucose with sitagliptin). Of note, systemic DPP4 inhibition achieved comparable increases in active circulating GIP levels in HFD-fed male and female mice (Fig.3.8 D, E, Fig.3.6 D, E). However, it resulted in approximately 1.5- to 2.5-fold increase in plasma insulin in females (unlike the 2- to 6 -fold increase observed in males, Fig.6 F) during the OGTT. Finally, islets isolated from $D p p 4^{\beta-c e l l-/-}$ and MIP-Cre control mice exhibited similar glucose-stimulated insulin secretion in perifusion, with no significant differences observed during stimulation with arginine, GLP-1, or GIP (Fig.3.8 H). 

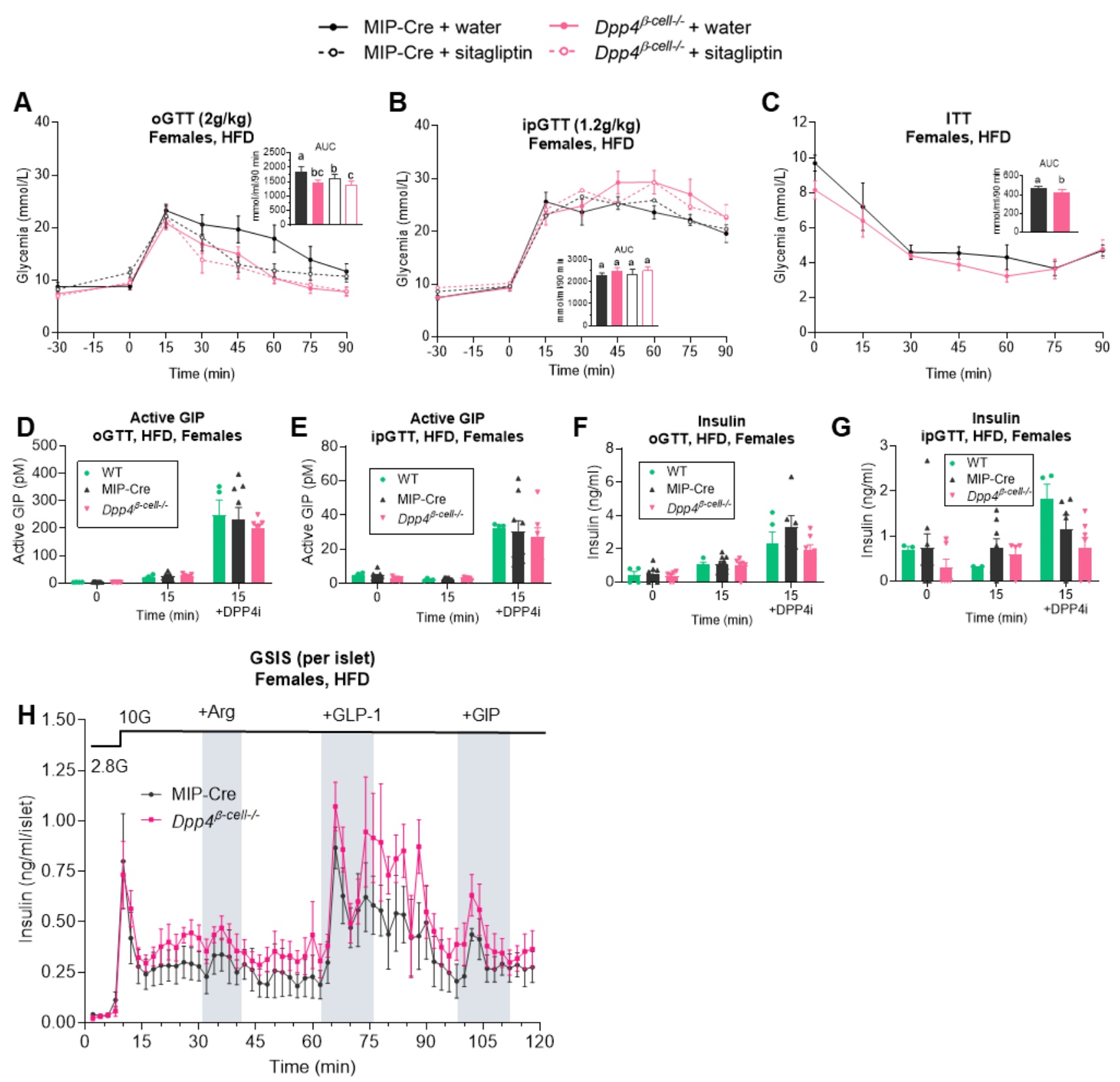

Figure 3.8. Elimination of $\beta$-cell-derived DPP4 Improves Oral Glucose Tolerance and Enhances Insulin Sensitivity in HFD-Fed Female Mice in vivo.

(A) Oral glucose, (B) intraperitoneal glucose, and (C) insulin tolerance tests in HFD-fed female Dpp4-cell-and MIP-Cre control mice. 30\% glucose (chow) or 50\% glucose (HFD) in PBS was given at $2 \mathrm{~g} / \mathrm{kg}$ of body weight for oral glucose tolerance and at $1.2 \mathrm{~g} / \mathrm{kg}$ of body weight for i.p. glucose tolerance tests. $\mathrm{n}=7-10$ per group. (D) Plasma active GIP measured at baseline and 15 minutes post-glucose in response to oral and (E) i.p. glucose tolerance tests in HFD-fed Dpp4 $4^{\beta-c e l l-/-}$ and control mice. (F) Plasma insulin measured at baseline and 15 minutes post-glucose during oral and (G) i.p. glucose tolerance tests in HFD-fed Dpp4 ${ }^{\beta-c e l l-}$ ${ }^{1}$ and control mice. $(\mathrm{H})$ Stimulated insulin secretion measured during perifusion of islets isolated from HFDfed Dpp4 $4^{\beta-c e l l--/}(n=4)$ and MIP-Cre control $(n=4)$ female mice with stimuli as indicated at the top of the graph. All data are represented as the mean \pm SEM. ${ }^{*} p<0.05$. 


\subsection{Genetic Elimination of Dpp4 in the Whole Pancreas $\left(D p p 4^{\text {Pan-- })}\right.$ Fails to Improve Glucose Tolerance in Mice Fed Normal Chow or a High-Fat Diet}

Since our previous experiments found that elimination of $\beta$-cell-derived DPP4 had no consistent or significant effects on glucose metabolism and insulin sensitivity in male mice, we next examined whether whole pancreas-derived DPP4 could be overcompensating for this knockout. We generated a whole pancreas-specific Dpp4 knockout mouse model (Dpp4 $4^{\text {Pan-- }}$ ) using mice with the Cre recombinase expressed under the control of the mouse pancreatic duodenal homeobox (PDX1) promoter. Oral and i.p. glucose tolerance was compared to age- and sex-matched control groups that combined $D p p 4^{+/+}$(wildtype), $D p p 4^{f / / f l}$, and PDX-Cre mice. Male Dpp4 ${ }^{\text {Pan- } /}$ and their littermate controls exhibited similar glucose excursions in response to oral glucose gavage while on chow diet (Fig.3.9 A) and after HFD-feeding (Fig.3.9 C). Surprisingly, male Dpp4 ${ }^{\text {Pan- - }}$ mice had significantly elevated plasma glucose levels after an i.p. injection of glucose versus control on regular chow (Fig.9 B), with a similar elevation also observed after switching to a HFD (Fig.3.9 D). Accordingly, area under the curve (AUC) analysis of glucose excursion over 90 minutes of the experiment demonstrated a significantly higher total rise in blood glucose during ipGTT on both diets. (Fig.3.9 B, D). Finally, female Dpp4 $4^{\text {Pan-/ }}$ mice displayed similar glucose excursions compared with controls regardless of route of glucose administration on a regular chow diet or after switching to HFDfeeding (Fig.3.9 E-H) 
A

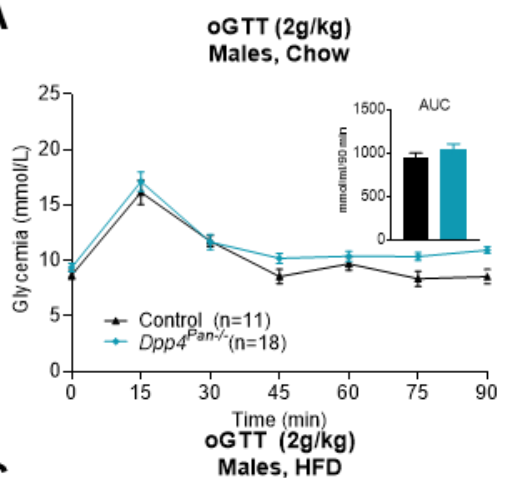

C

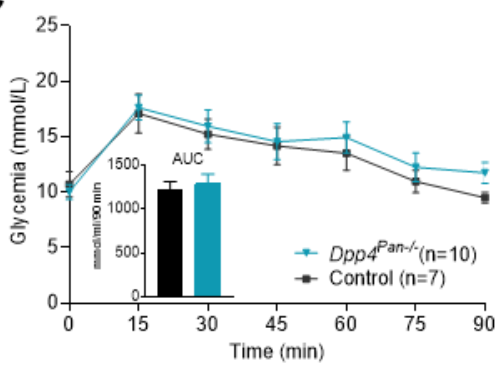

E

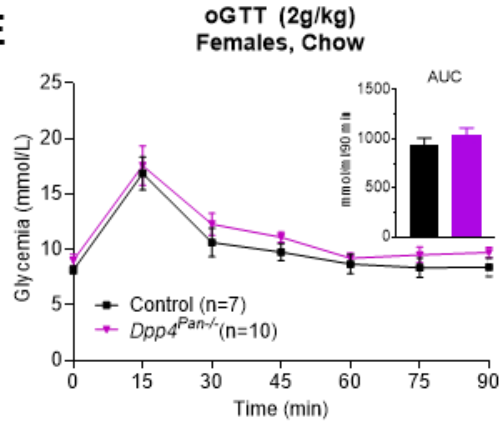

G

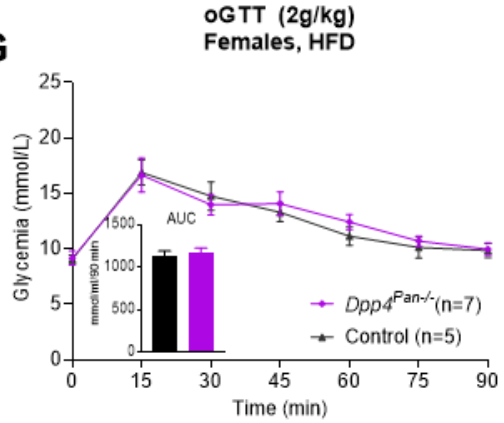

B
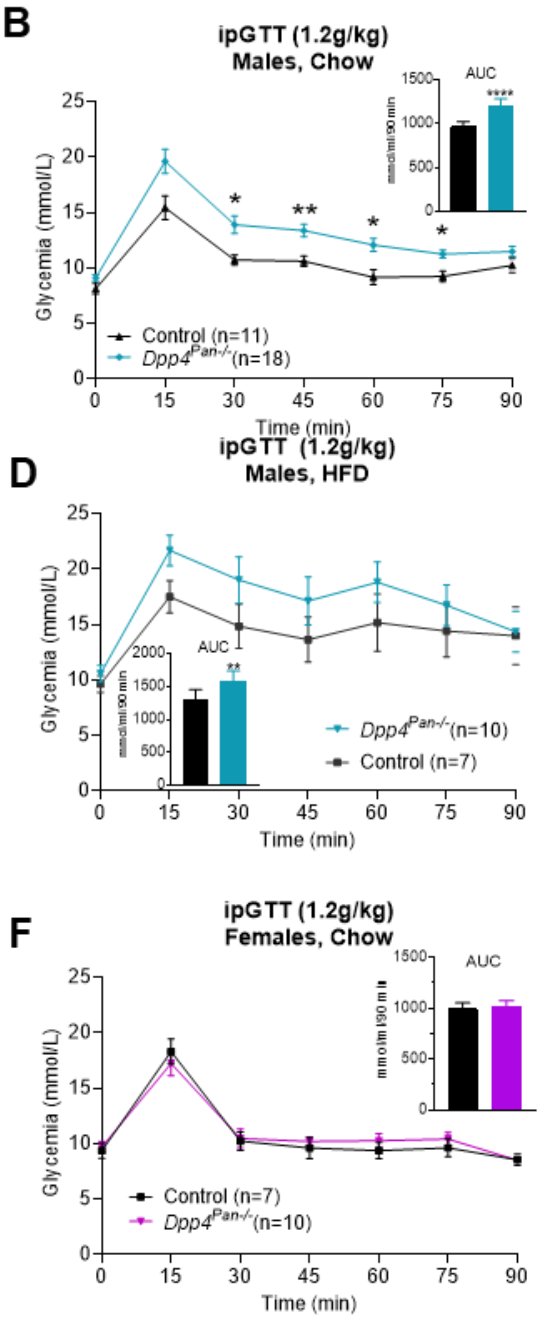

ipgTT $(1.2 \mathrm{~g} / \mathrm{kg})$
Females, HFD

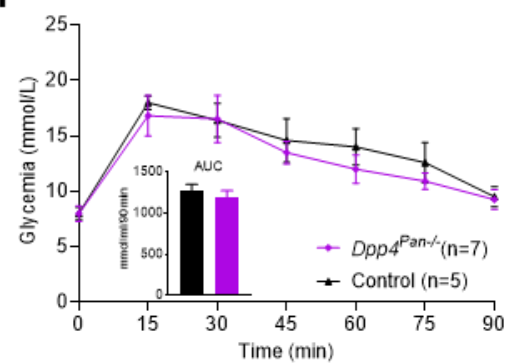

Figure 3.9. Genetic Elimination of Dpp4 in the Whole Pancreas (Dpp $4^{\text {Pan-// }}$ ) Fails to Improve Glucose Tolerance in Mice Fed Normal Chow or High-Fat Diet.

(A-D) Oral and i.p. glucose tolerance in male, chow-fed (A, B) or HFD-fed (C, D) Dpp4 ${ }^{\text {Pan-/ }}$ and control mice. $(\mathrm{E}-\mathrm{H})$ Oral and i.p. glucose tolerance in female, chow-fed (E, F) and HFD-fed (G, H) Dpp4 ${ }^{\text {Pan- } /}$ and control mice. A solution containing 30\% glucose (chow) or $50 \%$ glucose (HFD) in PBS was administered at $2 \mathrm{~g} / \mathrm{kg}$ for oral and $1.2 \mathrm{~g} / \mathrm{kg}$ for i.p. glucose tests at $\mathrm{t}=0$. Inset graphs represent area under the curve (AUC) for each group. Control groups combined PDX-Cre, WT, and Dpp $4^{f / f f l}$. All data are represented as the mean \pm SEM, ${ }^{*} p<0.05$. 


\section{Discussion and Future Directions}

\subsection{Discussion}

Previous studies have identified the gastrointestinal tract and vascular endothelial cells as the principal site of action for the acute glucoregulatory actions of DPP4 inhibitors (Mulvihill et al., 2017; Waget et al., 2011). However, despite a significant improvement in glycemia regulation and increased circulating incretin levels in HFD-fed mice with endothelial cell Dpp4 knockout (Dpp4EC-/--), these mice did not exhibit resistance to diet-induced obesity as seen in whole-body knockout $D p p 4^{-/}$, highlighting the potential role for DPP4 inhibition in cell types beyond ECs (Mulvihill et al., 2017). Recently, studies in transgenic mice have identified pancreatic GLP-1 production as a requirement for glucose homeostasis during metabolic stress, and the deficiency in a-cell-derived GLP-1 could be rescued by DPP4 inhibitors (Traub et al., 2017). Therefore, in this project, we set out to evaluate the role of pancreatic and, more specifically, $\beta$-cell-derived DPP4 in the regulation of glycemia. The main findings of this thesis are summarized below.

\section{Regulation of Glucose by DPP4 Inhibitors Is Dependent on The Activation of the Incretin Receptors on the $\beta$-Cell.}

Under normal conditions, the binding of the incretin hormones GLP-1 and GIP to their receptors on the $\beta$-cell provides the essential stimulus for the nutrient-stimulated insulin secretion (Baggio and Drucker, 2007). Moreover, complete genetic elimination of the incretin receptors leads to impaired glucose tolerance and suppressed insulin response to oral glucose in mice (Ahrén et al., 2020; Hansotia et al., 2004). In line with previously published data (Mulvihill et al., 2017; Varin et al., 2019a; Waget et al., 2011), our data indicate that selective enteral inhibition of DPP4 with sitagliptin ( $14 \mu \mathrm{g} / \mathrm{mouse})$ is sufficient to significantly improve post-prandial blood glucose regulation, and can be improved further with systemic (10 mg/kg) DPP4 inhibition in mice (Fig.1 A). However, compared to their wildtype counterparts, we found that mice with genetic deletion of both GIPR and GLP-1R (Double Incretin Receptor Knock Out, DIRKO) specifically within the $\beta$-cell exhibit elevated glucose excursion in response to oral glucose ingestion that could not be improved with either dose of DPP4 inhibitor sitagliptin (Fig.1 B). These data demonstrate that the activation of the incretin receptors GIPR and GLP-1R on the islet $\beta$-cell is essential for the glucose-lowering action by DPP4 inhibitors.

\section{DPP4 Regulates Pancreatic Insulin Content and Glucose-Stimulated Insulin Secretion in Islets from HFD-Fed Mice in vitro}

Previous studies have established that pancreatic DPP4 is localized mostly to glucagon-producing islet $\alpha$-cells in humans and insulin-producing $\beta$-cells in rodents (Liu et al., 2014a). In humans, islet DPP4 activity and expression are reduced in T2D islets compared to islets from non-diabetic patients, and direct inhibition of islet DPP4 has been shown to improve $\beta$-cell function, survival, and insulin secretion (Bugliani et al., 2018; Omar et al., 2014). Conversely, DPP4 activity is increased in diet-induced obese mice, although its inhibition also results in potentiated insulin secretion in a GLP-1-dependent manner (Omar et al., 2014). 
We showed here that genetic knockout of Dpp4 can significantly increase pancreatic insulin content measured in pancreatic lysates of mice fed a high-fat, but not regular chow diet (Fig. 2C).

In order to further explore the link between islet-derived DPP4 and islet secretory function, we generated a line of tamoxifen-inducible $\beta$-cell-specific Dpp4 knockout mice (Dpp $\left.{ }^{\beta-c e l l-/}\right)$ using a Cre recombinase under the control of Mouse Insulin Promoter (MIP-Cre). The reduction in islet, but not liver DPP4 expression and activity, as demonstrated by a DPP4 activity assay and immunofluorescent analysis (Fig.3 B, C), confirmed the tissue-specific DPP4 knockout. Islets from both HFD-fed Dpp4 $4^{\beta-c e l l-/-}$ and control mice were isolated, and their response to glucose stimulation was assessed in perifusion (Fig.4 A-C). We found that $D p p 4^{\beta-c e l l-r}$ islets have a modest, albeit not a significant increases in first- and second-phase insulin secretion in response to perifusion with $16.7 \mathrm{mM}$ glucose, resulting in significantly more overall insulin secreted after 60 minutes of stimulation (Fig.4 A). Concurrently, $\mathrm{KCl}$-stimulated membrane depolarization resulted in comparable insulin secretion in both groups of islets, suggesting the initial difference observed was likely glucose-dependent (Brüning et al., 2017; Pizarro-Delgado et al., 2015). Therefore, to investigate whether this increase in GSIS occurred specifically due to a reduction in intra-islet DPP4 activity, we compared GSIS in these islets with and without the addition of a highly potent and specific DPP4 inhibitor, sitagliptin (Sangle et al., 2012). DPP4 inhibition resulted in a greatly increased GSIS in the control DPP4positive islets (fig.4 B), however, did not further increase GSIS from the Dpp ${ }^{\beta-c e l l-/}$ islets (Fig.4 C). This is in agreement with previously published findings reporting increased islet GLP-1 production in islets from patients with T2D, and the ability of DPP4 inhibitors to increase glucose-stimulated insulin granule exocytosis in T2D islets (Campbell et al., 2020; Ferdaoussi et al., 2020).Taken together, these results suggest that enzymatic cleavage by DPP4 is a significant regulator of glucose-stimulated insulin secretion in vitro. As such, pharmacological inhibition of intra-islet DPP4 may be an effective way so enhance insulin secretion from the islet.

\section{DPP4 Expressed in MIP-Cre-Positive Cells (Islet $\beta$ cells) Does Not Contribute to Glucose Regulation or Incretin Cleavage, but May Influence Insulin Tolerance in Male Mice.}

The production of competent, active GLP-1 has been observed in both mouse and human islet $\alpha$ cells, however, whether it is essential or dispensable for glucose regulation in vivo remains a debated topic (Chambers et al., 2017; Hansen et al., 2011; Marchetti et al., 2012; Song et al., 2019). It's been previously shown that treatment of islets from T2D patients with DPP4 inhibitor sitagliptin led to increased GLP-1 secretion, which was associated with improved $\beta$-cell health and survival (Bugliani et al., 2018; Buteau et al., 2004; Campbell et al., 2019; Farilla et al., 2003; Li et al., 2003). As such, we hypothesized that the deletion of intra-islet Dpp4 could prevent the cleavage of GLP-1 by DPP4 within the islet, thus resulting in improved glucose tolerance via the augmented paracrine action on the $\beta$-cell.

While glucose excursion in response to oral glucose gavage remained comparable between groups throughout the experiment, overall glucose index, as shown by the AUC graph, was elevated in the Dpp $4^{\beta-}$ cell-- mice (Fig.5 A). Accordingly, their circulating DPP4 activity, but not concentration was increased (Fig.5 
D, E), which may explain the trend for slower glucose clearance during oGTT. In fact, recently published research suggests fluctuations in plasma DPP4 activity and protein concentration are dissociated, and it is the cellular origin of circulating DPP4 that determines whether one or both will be affected (Varin et al., 2019). More specifically, hepatocyte-derived circulating DPP4 was found to increase plasma DPP4 activity and promote insulin resistance, while adipocyte-derived DPP4 did not. Interestingly, we also saw a slight reduction in insulin sensitivity in Dpp $4^{\beta-c e l l-r}$ mice on chow diet (Fig.5 C), an effect which could also be attributed to the increase in circulating DPP4 observed in these mice. However, the exact mechanism behind the observed differences remains to be explored.

Following the experiments on chow, we introduced HFD-feeding for a further 5 weeks to promote the development of the metabolic syndrome (Della Vedova et al., 2016). We hypothesized that diet-induced weight gain and metabolic stress may induce increased PC1/3 expression (Sancho et al., 2017) and subsequent increase in GLP-1 production in the islet, amplifying the potential differences in glucose tolerance or insulin sensitivity between groups. However, no differences in oral glucose tolerance were

observed between the Dpp $4^{\beta \text {-cell-/ }}$ and Cre-positive control mice on HFD (Fig.6 A, B), suggesting that intraislet DPP4 does not significantly regulate glucose metabolism in vivo under HFD conditions. Accordingly, our data demonstrate that intra-islet DPP4 does not contribute to circulating DPP4 concentration (Fig.6 I), activity (Fig.6 H), incretin cleavage (Fig.6 D, E) or insulin secretion (Fig.6 F, G) following glucose gavage or injection in mice fed a HFD. Here, DPP4 inhibition with sitagliptin improved glycemic excursion to an oral glucose gavage of both groups, but had no effects during an i.p. injection of glucose in either group regardless of the diet (Fig.5 B, Fig.6 B), providing further evidence for the gut-dominant incretin response in mice. In contrast to the results on chow diet, $D p p 4^{\beta-c e l l-/}$ mice on HFD exhibited a slightly enhanced insulin sensitivity (Fig.6 C), however, this improvement was not correlated with any other parameter measured. As such, identifying a mechanism behind this effect becomes challenging. Finally, islet GSIS was without change in 65-week-old male control or Dpp4-cell-/ mice fed a HFD for 40 weeks when perifused with $10 \mathrm{mM}$ glucose-containing buffer or any other stimuli (Fig.6 J). Importantly, islet size was greatly and visibly increased in both groups at the age of takedown (65 weeks vs. 40 weeks shown in Fig.3 and Fig.4), indicative of extensive $\beta$-cell hypertrophy and hyperplasia (Ahrén et al., 2010). Our data, therefore, suggest that eliminating $\beta$-cell-derived DPP4 does not have a significant protective effect over chronic HFD feedinginduced $\beta$-cell dysfunction or islet function in male mice.

\section{Female Dpp $4^{\beta-c e l l-/-M i c e ~ E x h i b i t ~ I m p r o v e d ~ O r a l ~ G l u c o s e ~ T o l e r a n c e ~ a n d ~ I n s u l i n ~ S e n s i t i v i t y, ~ b u t ~}$ No Changes in Incretin Response or Insulin Secretion.}

The protective effects of estrogen in diet-induced obesity and glucose homeostasis in female mice have previously been reported (Dakin et al., 2015; Hong et al., 2009; Pettersson et al., 2012; Stubbins et al., 2012). Following our findings in male mice, we set out to investigate the potential differences in islet function and glucose metabolism in female mice with induced Dpp4 deletion from the islet $\beta$-cell. Here, chow-fed $D p p 4^{\beta \text {-cell-/ }}$ mice exhibited significantly lower total glucose response to oGTT compared to control, 
and the glucose-lowering effect of DPP4i was absent, suggesting the site of DPP4 inhibition mediating the improvements in glycemia was no longer present. Curiously, when the glucose was administered i.p., sitagliptin inhibited glucose response in $D p p 4^{\beta-c e l l-/}$, but not in control mice. Since glucose is administered by an i.p. injection and bypasses the gut in the process, these data may suggest the presence of another gut-independent glucoregulatory mechanism sensitive to DPP4 inhibition in female mice.

Further validating intra-islet DPP4 as a target for DPP4i-mediated glucose regulation in females, HFD-fed $D p p 4^{\beta-c e l l-/-}$ females showed the lowest overall increase in plasma glucose, and no improvements in plasma glucose excursion in oGTT with the sitagliptin treatment (fig.8 A). However, i.p. glucose tolerance, as well as active circulating GIP and insulin measured 15 minutes after glucose injection (Fig.8 B, E, G) were not significantly improved in the $D p p 4^{\beta-c e l l-/}$ females compared to Mip-Cre controls. Both groups remained sensitive to insulin as demonstrated by the insulin tolerance test (Fig.8 C), with a slight improvement in the $D p p 4^{\beta-c e l l-l-}$ mice. Overall, our findings show that female mice may have different mechanisms regulating their metabolic processes and glucose metabolism, and once again highlight the importance of researching as well as validating the therapeutic potential of drugs in both sexes.

\section{Genetic Elimination of Dpp4 in the Whole Pancreas Fails to Improve Glucose Tolerance in Mice Fed Normal Chow or a High-Fat Diet}

Both human and mouse islets express active DPP4, but the localization pattern was found to be species-dependent: almost exclusively in a cells in the human islet, and mostly in $\beta$-cells in mouse islets (Liu et al., 2014a). However, recent findings using electron microscopy immunogold analysis demonstrated that approximately $25 \%$ of $\beta$-cells in human islets also express DPP4 (Bugliani et al., 2018). Our ability to generate an inducible $\alpha$-cell specific Dpp4 knockout, or a double $\alpha / \beta$-cell Dpp4 knockout was impeded by the linkage disequilibrium (LD) found between the Dpp4 and Gcg genes (Appendix 1). LD mapping identified 3 linkage blocks within the recombination region, preventing homologous recombination and

generation of our model of interest, or $D p p 4^{\alpha-c e l l-/}$, by crossing Dpp $4^{f / f \mid l}$ line with a line where the Gcg promoter drives Cre expression. Therefore, in order to control for any remaining pancreatic or islet DPP4 activity in the Dpp $4^{\beta-c e l l--}$ mice, we generated a mouse model with a pancreas-specific DPP4 knockout $\left(D p p 4^{\text {Pan-/ }}\right)$ and evaluated its response to glucose in vivo. Male Dpp $4^{\text {Pan-/ }}$ mice exhibited no changes in oral glucose tolerance on chow or HFD compared to their DPP4-positive controls (wildtype, Dpp4 $4^{f / f l}$, PDX-Cre). Elimination of pancreatic DPP4 failed to improve glucose tolerance in female mice regardless of diet or route of glucose administration (Fig.9 E-H).

Unexpectedly, Dpp4 deletion in the pancreas resulted in sustained elevated plasma glucose throughout the i.p. glucose challenge experiment in chow-fed male mice (Fig.9 B), and a trend toward elevated glycemia after HFD-feeding (Fig.9 D). In both experiments, Dpp4 $4^{\text {Pan- }}$ - males showed significantly higher total glucose response as measured by the AUC analysis after 90 minutes of the experiment. This pattern was not expected, but several possibilities may be considered. First, the knockout mouse model used here was generated using mice expressing Cre recombinase under the control of the mouse 
pancreatic and duodenal homeobox 1 (PDX1) promoter. PDX-Cre is active in the pancreatic epithelium, antral stomach and duodenum in neonates and in pancreatic $\beta$-cells in adults. Therefore, PDX-Cremediated deletion of the Dpp4 sequences during the early stages of development may have resulted in unintended changes in pancreatic or gastrointestinal tract development, leading to impaired i.p. glucose tolerance in the Dpp4 $4^{\text {Pan-/ }}$ group. Indeed, PYY, a physiological substrate of DPP4, is highly expressed in the embryonic pancreas, and thus may be implicated in the endocrine cell differentiation (Bugliani et al., 2018; Jackerott et al., 1996). Furthermore, PYY was reported to be a negative regulator of bone mass, and its inhibition by DPP4 may be necessary for proper development in the early embryonic stages (Leitch et al., 2019). In addition, DPP4 binding to fibronectin and collagen, components of the extracellular matrix involved in cell adhesion and matrix remodelling (Piazza et al., 1989), was also disrupted in Dpp4 $4^{\text {Pan-/ }}$ mice. Lastly, while we made effort to only use Cre-positive mice in control groups, the sample size of the PDXCre-positive control groups was too small for any statistical analysis $(n=2)$. This led us to combine their results with results from other DPP4-positive mice (wildtype, Dpp $\left.4^{f / f}\right)$ ), which may have skewed the final glucose curve (Song and Palmiter, 2018). Overall, this experiment recapitulates the findings from the Dpp $4^{\beta-}$

cell-r mice, and the data suggest that targeted pancreatic deletion of Dpp4 is not sufficient to improve glycemia in mice.

\subsection{Future directions}

In view of the failure of $\beta$-cell- or pancreas-specific deletion of $D p p 4$ to improve glucose regulation in mice, there are now several themes that future studies could explore. First, our understanding of the biologically relevant substrates of DPP4 is currently very limited as many have been identified using in vitro approaches. Over the last several years, incretin-based therapeutic agents have been evaluated both in animals and humans, proving their safety, low rate of adverse effects, and efficacy in treating T2D symptoms. However, the implications of long-term pharmacological DPP4 inhibition in humans is an important area that remains to be investigated (Karagiannis et al., 2014). Moreover, as our results indicate, Dpp4 may play an important role in the developing pancreas, and so the effect of embryonic, pancreasspecific Dpp4 deletion should be explored.

Second, targeted inhibition of enzymatically active proteins in the DASH family, such as FAP, may provide an effective strategy to lower blood glucose as a single or dual therapy with other incretin-based interventions. DPP4 and FAP share a number of substrates, although with varied affinities, and FAPmediated cleavage regulates other unique processes, such as ECM remodelling, cell migration, and cell signaling (Lay et al., 2019). Recently, FAP was found to regulate the bioactivity of human fibroblast growth factor 21 (FGF-21), a predominantly liver-derived protein involved in weight control, and glucose and lipid metabolism (Coppage et al., 2016). Interestingly, mouse FGF-21 lacks the FAP cleavage site and is therefore not affected by it (Coppage et al., 2016). Thus, studies evaluating selected FAP inhibition may lead to novel developments in treatment of T2D, however, would need to be carefully designed to accommodate any inter-species differences. 


\subsection{Limitations}

There are several caveats to be considered with the findings presented in the thesis above, including the use of murine models of disease, and the use of Cre recombinases to induce genetic recombination. Although overall insulin signaling and glucose metabolism are mediated through similar mechanisms in mice and humans, important differences remain. Human pancreatic islet structure and cellular composition differs substantially from that of mouse. In addition, DPP4 colocalizes with a-cells in humans, and $\beta$-cells in mice. As our islet perifusion and DPP4 inhibition studies were limited to mouse islets, it remains to be determined whether intra-islet DPP4 has an effect in humans in the context of insulin secretion. Also, while the use of CreERT2/loxP system is a widely used tool to induce conditional genetic recombination in mice, its use also implies some major considerations. Several Cre strains have demonstrated unreported or unexpected deletion activity resulting from being expressed in off-target tissue types (Heffner et al., 2012). On the other hand, variability in Cre expression and activity may lead to Cre mosaicism and inconsistent or incomplete recombination in target tissues even between littermates (Heffner et al., 2012). Moreover, tamoxifen used to induce the Cre translocation was found to inhibit $\beta$-cell proliferation and induce acute fat loss, followed by de novo lipogenesis in mouse studies (Ahn et al., 2019; Ye et al., 2015). To mitigate these effects, all animals in the experiments reported here received the same dose of tamoxifen prior to metabolic experiments, followed by a 4-week washout period, and Cre-positive control mice were used whenever possible.

Separately, our research was interrupted due to the COVID-19 pandemic and the resulting quarantine, which severely limited our ability to conduct animal and laboratory experiments from March 16 , 2020 to June 15, 2020. This included the use of any off-site facilities and equipment (access to Mesoscale Discovery Equipment for active GLP-1 measurements), age-matching male and female mice, tracking animal weights and food intake throughout the study, and a drastic reduction in the overall number of animals used. 


\subsection{Final conclusions}

To examine the role of intra-islet DPP4, we generated two murine models with Dpp4 genetically eliminated from the adult islet $\beta$-cell or embryonically through the entire pancreas using the Cre-loxP system under the control of mouse insulin promoter or the mouse pancreatic and duodenal homeobox 1 , respectively. We evaluated the differences in their glucose regulation, insulin tolerance, incretin degradation, and circulating DPP4 activity and concentration. In addition, we subjected islets isolated from these animals to perifusion in order to assess their glucose-stimulated insulin secretion in-vitro. The results reported in this thesis have several important implications in the research of the physiological functions of DPP4 and incretin-based therapies. In summary, we have demonstrated that 1) the glucose-lowering action of DPP4 inhibitors requires activation of the incretin receptors on the islet $\beta$-cell; 2) Enzymatic cleavage by DPP4 is a significant regulator of glucose-stimulated insulin secretion in vitro; 3) Targeting pancreas- or $\beta$ cell-derived DPP4 fails to improve glucose metabolism or incretin cleavage, but may improve insulin sensitivity in male mice fed a HFD; and 4) $\beta$-cell-derived DPP4 may be an effective target of DPP4 inhibitors in regulating glycemia in female mice. As demonstrated above, we found sex to be an important variable in experiments involving metabolism and glucose regulation, however, the exact mechanisms underlying the improvements seen in female mice remain to be elucidated. 


\section{References}

Adeghate, E., and Ponery, A.S. (2002). Ghrelin stimulates insulin secretion from the pancreas of normal and diabetic rats. J. Neuroendocrinol. 14, 555-560.

Adeva-Andany, M.M., Pérez-Felpete, N., Fernández-Fernández, C., Donapetry-García, C., and PazosGarcía, C. (2016). Liver glucose metabolism in humans. Biosci. Rep. 36, e00416.

Ahn, S.H., Granger, A., Rankin, M.M., Lam, C.J., Cox, A.R., and Kushner, J.A. (2019). Tamoxifen suppresses pancreatic $\beta$-cell proliferation in mice. PLoS One 14, e0214829.

Ahrén, B. (2007). Dipeptidyl peptidase-4 inhibitors: Clinical data and clinical implications. Diabetes Care 30, 1344-1350.

Ahrén, B., Yamada, Y., and Seino, Y. (2020). The incretin effect in female mice with double deletion of GLP-1 and GIP receptors. J. Endocr. Soc. 4, bvz036.

Ahrén, J., Ahrén, B., and Wierup, N. (2010). Increased $\beta$-cell volume in mice fed a high-fat diet: A dynamic study over 12 months. Islets 2, 353-356.

Ali, O. (2013). Genetics of type 2 diabetes. World J Diabetes 4, 114-123.

Andralojc, K.M., Mercalli, A., Nowak, K.W., Albarello, L., Calcagno, R., Luzi, L., Bonifacio, E., Doglioni, C., and Piemonti, L. (2009). Ghrelin-producing epsilon cells in the developing and adult human pancreas. Diabetologia 52, 486-493.

Anoop, S., Misra, A., Bhatt, S.P., Gulati, S., Pandey, R.M., and Mahajan, H. (2017). High circulating plasma dipeptidyl peptidase- 4 levels in non-obese Asian Indians with type 2 diabetes correlate with fasting insulin and LDL-C levels, triceps skinfolds, total intra-abdominal adipose tissue volume and presence of diabetes: a case-control study. BMJ Open Diabetes Res. Care 5, e000393.

Aragón, F., Karaca, M., Novials, A., Maldonado, R., Maechler, P., and Rubí, B. (2015). Pancreatic polypeptide regulates glucagon release through PPYR1 receptors expressed in mouse and human alphacells. Biochim. Biophys. Acta - Gen. Subj. 1850, 343-351.

Arta Korbonits, M., Goldstone, A.P., Gueorguiev, M., and Grossman, A.B. (2004). Ghrelin-a hormone with multiple functions. 25, 27-68.

Aulinger, B.A., Vahl, T.P., Prigeon, R.L., D'Alessio, D.A., and Elder, D.A. (2016). The incretin effect in obese adolescents with and without type 2 diabetes: Impaired or intact? Am. J. Physiol. - Endocrinol. Metab. 310, E774-E781.

Aulinger, B.A., Perabo, M., Seeley, R.J., Parhofer, K.G., and D’Alessio, D.A. (2020). Rapid hepatic metabolism blunts the endocrine action of portally infused GLP-1 in male rats. Am. J. Physiol. Metab. 
318, E189-E197.

Baggio, L.L., and Drucker, D.J. (2007). Biology of Incretins: GLP-1 and GIP. Gastroenterology 132, 21312157.

Baker, E.N., Blundell, T.L., Cutfield, J.F., Cutfield, S.M., Dodson, E.J., Dodson, G.G., Hodgkin, D.M., Hubbard, R.E., Isaacs, N.W., and Reynolds, C.D. (1988). The structure of $2 Z n$ pig insulin crystals at $1.5 \mathrm{~A}$ resolution . Philos. Trans. R. Soc. London 319, 369-456.

Ban, K., Noyan-Ashraf, M.H., Hoefer, J., Bolz, S.S., Drucker, D.J., and Husain, M. (2008).

Cardioprotective and vasodilatory actions of glucagon-like peptide 1 receptor are mediated through both glucagon-like peptide 1 receptor-dependent and -independent pathways. Circulation 117, 2340-2350.

Barg, S., Ping, H., Eliasson, L., Nelson, D.J., Obermüller, S., Rorsman, P., Thévenod, F., and Renström, E. (2001). Priming of insulin granules for exocytosis by granular $\mathrm{Cl}-$ uptake and acidification. J. Cell Sci. $114,2145-2154$.

Bass, J., Chiu, G., Argon, Y., and Steiner, D.F. (1998). Folding of insulin receptor monomers is facilitated by the molecular chaperones calnexin and calreticulin and impaired by rapid dimerization. J. Cell Biol. $141,637-646$.

Bastidas, J.A., Couse, N.F., Yeo, C.J., Schmieg, R.E., Andersen, D.K., Gingerich, R.L., and Zinner, M.J. (1990). The effect of pancreatic polypeptide infusion on glucose tolerance and insulin response in longitudinally studied pancreatitis-induced diabetes. Surgery 107, 661-668.

Batterham, R.L., Cowley, M.A., Small, C.J., Herzog, H., Cohen, M.A., Dakin, C.L., Wren, A.M., Brynes, A.E., Low, M.J., Ghatei, M.A., et al. (2002). Gut hormone PYY3-36 physiologically inhibits food intake. Nature 418, 650-654.

Batterham, R.L., Le Roux, C.W., Cohen, M.A., Park, A.J., Ellis, S.M., Patterson, M., Frost, G.S., Ghatei, M.A., and Bloom, S.R. (2003). Pancreatic polypeptide reduces appetite and food intake in humans. J. Clin. Endocrinol. Metab. 88, 3989-3992.

Bauvois, B., Djavaheri-Mergny, M., Rouillard, D., Dumont, J., and Wietzerbin, J. (2000). Regulation of CD26/DPPIV gene expression by interferons and retinoic acid in tumor B cells. Oncogene 19, 265-272.

Belfiore, A., Frasca, F., Pandini, G., Sciacca, L., and Vigneri, R. (2009). Insulin receptor isoforms and insulin receptor/insulin-like growth factor receptor hybrids in physiology and disease. Endocr. Rev. 30, 586-623.

Bergman, A.J., Stevens, C., Zhou, Y.Y., Yi, B., Laethem, M., De Smet, M., Snyder, K., Hilliard, D., Tanaka, W., Zeng, W., et al. (2006). Pharmacokinetic and pharmacodynamic properties of multiple oral doses of sitagliptin, a dipeptidyl peptidase-IV inhibitor: A double-blind, randomized, placebo-controlled 
study in healthy male volunteers. Clin. Ther. 28, 55-72.

Blanco, A., and Blanco, G. (2017). Carbohydrate Metabolism. In Medical Biochemistry, (Elsevier), pp. 283-323.

Bogardus, C., Lillioja, S., Howard, B. V., Reaven, G., and Mott, D. (1984). Relationships between insulin secretion, insulin action, and fasting plasma glucose concentration in nondiabetic and noninsulindependent diabetic subjects. J. Clin. Invest. 74, 1238-1246.

Bokhari, S., Emerson, P., Israelian, Z., Gupta, A., and Meyer, C. (2009). Metabolic fate of plasma glucose during hyperglycemia in impaired glucose tolerance: Evidence for further early defects in the pathogenesis of type 2 diabetes. Am. J. Physiol. - Endocrinol. Metab. 296, E440-E444.

Böni-Schnetzler, M., and Meier, D.T. (2019). Islet inflammation in type 2 diabetes. Semin. Immunopathol. $41,501-513$.

Bratanova-Tochkova, T.K., Cheng, H., Daniel, S., Gunawardana, S., Liu, Y.J., Mulvaney-Musa, J., Schermerhorn, T., Straub, S.G., Yajima, H., and Sharp, G.W.G. (2002). Triggering and augmentation mechanisms, granule pools, and biphasic insulin secretion. In Diabetes, (American Diabetes Association), pp. S83-S90.

Brereton, M.F., Vergari, E., Zhang, Q., and Clark, A. (2015). Alpha-, Delta- and PP-cells: Are They the Architectural Cornerstones of Islet Structure and Co-ordination? J. Histochem. Cytochem. 63, 575-591.

Brissova, M., Fowler, M.J., Nicholson, W.E., Chu, A., Hirshberg, B., Harlan, D.M., and Powers, A.C. (2005). Assessment of human pancreatic islet architecture and composition by laser scanning confocal microscopy. J. Histochem. Cytochem. 53, 1087-1097.

Broglio, F., Arvat, E., Benso, A., Gottero, C., Muccioli, G., Papotti, M., Lely, A.J. van der, Deghenghi, R., and Ghigo, E. (2001). Ghrelin, a Natural GH Secretagogue Produced by the Stomach, Induces Hyperglycemia and Reduces Insulin Secretion in Humans. J. Clin. Endocrinol. Metab. 86, 5083-5083.

Brown, A.F., Ettner, S.L., Piette, J., Weinberger, M., Gregg, E., Shapiro, M.F., Karter, A.J., Safford, M., Waitzfelder, B., Prata, P.A., et al. (2004). Socioeconomic Position and Health among Persons with Diabetes Mellitus: A Conceptual Framework and Review of the Literature. Epidemiol. Rev. Hopkins Bloom. Sch. Public Heal. All Rights Reserv. 26, 63-77.

Brown, J.C., Dryburgh, J.R., Ross, S.A., and Dupre, J. (1975). Identification and actions of gastric inhibitory polypeptide. Recent Prog. Horm. Res. Vol.31, 487-532.

Brüning, D., Reckers, K., Drain, P., and Rustenbeck, I. (2017). Glucose but not KCL diminishes submembrane granule turnover in mouse beta-cells. J. Mol. Endocrinol. 59, 311-324.

Brunmair, B., Staniek, K., Gras, F., Scharf, N., Althaym, A., Clara, R., Roden, M., Gnaiger, E., Nohl, H., 
WaldhäusI, W., et al. (2004). Thiazolidinediones, Like Metformin, Inhibit Respiratory Complex I: A Common Mechanism Contributing to Their Antidiabetic Actions? Diabetes 53, 1052-1059.

Bryant, N.J., Govers, R., and James, D.E. (2002). Regulated transport of the glucose transporter GLUT4. Nat. Rev. Mol. Cell Biol. 3, 267-277.

Buchan, A.M.J., Polak, J.M., Capella, C., Solcia, E., and Pearse, A.G.E. (1978).

Electronimmunocytochemical evidence for the $\mathrm{K}$ cell localization of gastric inhibitory polypeptide (GIP) im man. Histochemistry 56, 37-44.

Bugliani, M., Syed, F., Paula, F.M.M., Omar, B.A., Suleiman, M., Mossuto, S., Grano, F., Cardarelli, F., Boggi, U., Vistoli, F., et al. (2018). DPP-4 is expressed in human pancreatic beta cells and its direct inhibition improves beta cell function and survival in type 2 diabetes. Mol. Cell. Endocrinol. 473, 186-193.

Butcher, M.J., Hallinger, D., Garcia, E., Machida, Y., Chakrabarti, S., Nadler, J., Galkina, E. V., and Imai, Y. (2014). Association of proinflammatory cytokines and islet resident leucocytes with islet dysfunction in type 2 diabetes. Diabetologia 57, 491-501.

Buteau, J., El-Assaad, W., Rhodes, C.J., Mosenberg, L., Joly, E., and Prentki, M. (2004). Glucagon-like peptide-1 prevents beta cell glucolipotoxicity. Diabetologia 47, 806-815.

Butler, A.E., Janson, J., Bonner-Weir, S., Ritzel, R., Rizza, R.A., and Butler, P.C. (2003). $\beta$-cell deficit and increased $\beta$-cell apoptosis in humans with type 2 diabetes. Diabetes 52, 102-110.

Cabrera, O., Berman, D.M., Kenyon, N.S., Ricordi, C., Berggren, P.-O., and Caicedo, A. (2006). The unique cytoarchitecture of human pancreatic islets has implications for islet cell function. PNAS Febr. 14, 2334-2339.

Calderon, B., Suri, A., Miller, M.J., and Unanue, E.R. (2008). Dendritic cells in islets of Langerhans constitutively present $\beta$ cell-derived peptides bound to their class II MHC molecules. Proc. Natl. Acad. Sci. U. S. A. $105,6121-6126$.

Calderon, B., Carrero, J.A., Ferris, S.T., Sojka, D.K., Moore, L., Epelman, S., Murphy, K.M., Yokoyama, W.M., Randolph, G.J., and Unanue, E.R. (2015). The pancreas anatomy conditions the origin and properties of resident macrophages. J. Exp. Med. 212, 1497-1512.

Campbell, S.A., Hubert, M., Johnson, J., Salamon, N., and Light, P.E. (2019). The DPP4 Inhibitor Sitagliptin Increases Active Glp-1 Levels from Human Islets and May Increase Islet Cell Survival Prior to Transplantation. OBM Transplant. 3, 14.

Campbell, S.A., Golec, D., Hubert, M., Johnson, J., Salamon, N., Barr, A., Macdonald, P.E., Philippaert, K., and Light, P.E. (2020). Human islets contain a subpopulation of glucagon-like peptide-1 secreting a cells that is increased in type 2 diabetes. Mol. Metab. 39, 101014. 
Capozzi, M.E., Svendsen, B., Encisco, S.E., Lewandowski, S.L., Martin, M.D., Lin, H., Jaffe, J.L., Coch, R.W., Haldeman, J.M., MacDonald, P.E., et al. (2019). $\beta$ Cell tone is defined by proglucagon peptides through cAMP signaling. JCI Insight 4(5), e126742.

Carmen, G.Y., and Víctor, S.M. (2006). Signalling mechanisms regulating lipolysis. Cell. Signal. 18, 401408.

Cejvan, K., Coy, D.H., and Efendic, S. (2003). Intra-islet somatostatin regulates glucagon release via type 2 somatostatin receptors in rats. Diabetes $52,1176-1181$.

Chambers, A.P., Sorrell, J., Haller, A., Roelofs, K., Hutch, C.R., Kim, S., Gutierrez-aguilar, R., Li, B., Drucker, D.J., Alessio, D.A.D., et al. (2017). The role of pancreatic preproglucagon in glucose homeostasis in mice. 25, 927-934.

Chandarana, K., Gelegen, C., Irvine, E.E., Choudhury, A.I., Amouyal, C., Andreelli, F., Withers, D.J., and Batterham, R.L. (2013). Peripheral activation of the Y2-receptor promotes secretion of GLP-1 and improves glucose tolerance. Mol. Metab. 2, 142-152.

Chanoine, J.P., and Wong, A.C.K. (2004). Ghrelin gene expression is markedly higher in fetal pancreas compared with fetal stomach: Effect of maternal fasting. Endocrinology 145, 3813-3820.

Charles, S., Tamagawa, T., and Henquin, J.C. (1982). A single mechanism for the stimulation of insulin release and $86 \mathrm{Rb}+$ efflux from rat islets by cationic amino acids. Biochem. J. 208, 301-308.

Charron, M.J., and Vuguin, P.M. (2015). Lack of glucagon receptor signaling and its implications beyond glucose homeostasis. J. Endocrinol. 224, R123-R130.

Chen, L., Tuo, B., and Dong, H. (2016). Regulation of intestinal glucose absorption by ion channels and transporters. Nutrients $8,43$.

Chien, C.H., Huang, L.H., Chou, C.Y., Chen, Y.S., Han, Y.S., Chang, G.G., Liang, P.H., and Chen, X. (2004). One site mutation disrupts dimer formation in human DPP-IV proteins. J. Biol. Chem. 279, 5233852345 .

Cohrs, C.M., Chen, C., Jahn, S.R., Stertmann, J., Chmelova, H., Weitz, J., Bähr, A., Klymiuk, N., Steffen, A., Ludwig, B., et al. (2017). Vessel Network Architecture of Adult Human Islets Promotes Distinct CellCell Interactions In Situ and Is Altered After Transplantation. Endocrinology 158, 1373-1385.

Colombo, M., Gregersen, S., Xiao, J., and Hermansen, K. (2003). Effects of ghrelin and other neuropeptides (CART, $M C H$, orexin $A$ and $B$, and GLP-1) on the release of insulin from isolated rat islets. Pancreas 27, 161-166.

Conarello, S.L., Li, Z., Ronan, J., Roy, R.S., Zhu, L., Jiang, G., Liu, F., Woods, J., Zycband, E., Moller, D.E., et al. (2003). Mice lacking dipeptidyl peptidase IV are protected against obesity and insulin 
resistance. Proc. Natl. Acad. Sci. U. S. A. 100, 6825-6830.

Coppage, A.L., Heard, K.R., DiMare, M.T., Liu, Y., Wu, W., Lai, J.H., and Bachovchin, W.W. (2016). Human FGF-21 Is a Substrate of Fibroblast Activation Protein. PLoS One 11, e0151269.

Cucak, H., Grunnet, L.G., and Rosendahl, A. (2014). Accumulation of M1-like macrophages in type 2 diabetic islets is followed by a systemic shift in macrophage polarization. J. Leukoc. Biol. 95, 149-160.

Dakin, R.S., Walker, B.R., Seckl, J.R., Hadoke, P.W.F., and Drake, A.J. (2015). Estrogens protect male mice from obesity complications and influence glucocorticoid metabolism. Int. J. Obes. 39, 1539-1547.

Date, Y., Nakazato, M., Hashiguchi, S., Dezaki, K., Mondal, M.S., Hosoda, H., Kojima, M., Kangawa, K., Arima, T., Matsuo, H., et al. (2002). Ghrelin is present in pancreatic $\alpha$-cells of humans and rats and stimulates insulin secretion. Diabetes $51,124-129$.

Davidson, J.A., and Kuritzky, L. (2014). Sodium glucose co-transporter 2 inhibitors and their mechanism for improving glycemia in patients with type 2 diabetes. Postgrad. Med. 126, 33-48.

Dawood, A., El Ghobashy, Y., and Elgamal, A. (2018). The relationship between serum dipeptidyl peptidase-4 enzyme and nonalcoholic fatty liver disease in diabetic and nondiabetic patients. Egypt. J. Intern. Med. 30, 49.

Deacon, C.F. (2019). Physiology and Pharmacology of DPP-4 in Glucose Homeostasis and the Treatment of Type 2 Diabetes. Front. Endocrinol. (Lausanne). 10, 80.

Deacon, C.F., Nauck, M.A., Toft-Nielsen, M., Pridal, L., Willms, B., and Holst, J.J. (1995). Both subcutaneously and intravenously administered glucagon-like peptide I are rapidly degraded from the $\mathrm{NH} 2$-terminus in type II diabetic patients and in healthy subjects. Diabetes $44,1126-1131$.

Deacon, C.F., Nauck, M.A., Meier, J., Hücking, K., and Holst, J.J. (2000). Degradation of Endogenous and Exogenous Gastric Inhibitory Polypeptide in Healthy and in Type 2 Diabetic Subjects as Revealed Using a New Assay for the Intact Peptide ${ }^{1}$. J. Clin. Endocrinol. Metab. 85, 3575-3581.

Degen, L., Oesch, S., Casanova, M., Graf, S., Ketterer, S., Drewe, J., and Beglinger, C. (2005). Effect of peptide YY3-36 on food intake in humans. Gastroenterology 129, 1430-1436.

Desouza, C. V., Gupta, N., and Patel, A. (2015). Cardiometabolic Effects of a New Class of Antidiabetic Agents. Clin. Ther. 37, 1178-1194.

Diaz, A., Romero, M., Vazquez, T., Lechner, S., Blomberg, B.B., and Frasca, D. (2017). Metformin improves in vivo and in vitro B cell function in individuals with obesity and Type-2 Diabetes. Vaccine 35, 2694-2700.

Dimeglio, L.A., Pottorff, T.M., Boyd, S.R., France, L., Fineberg, N., and Eugster, E.A. (2004). A 
randomized, controlled study of insulin pump therapy in diabetic preschoolers. J. Pediatr. 145, 380-384. Ding, W.-G., and Gromada, J. (1997). Protein Kinase A-Dependent Stimulation of Exocytosis in Mouse Pancreatic -Cells by Glucose-Dependent Insulinotropic Polypeptide. Diabetes 46, 615-621.

Donath, M.Y., and Halban, P.A. (2004). Decreased beta-cell mass in diabetes: Significance, mechanisms and therapeutic implications. Diabetologia 47, 581-589.

Donnelly, D. (2012). The structure and function of the glucagon-like peptide-1 receptor and its ligands. Br. J. Pharmacol. 166, 27-41.

Drucker, D.J. (2006). Review The biology of incretin hormones. Cell Metab. 3, 153-165.

Drucker, D.J., Philippe, J., Mojsov, S., Chick, W.L., and Habener, J.F. (1987). Glucagon-like peptide I stimulates insulin gene expression and increases cyclic AMP levels in a rat islet cell line. Proc. Natl. Acad. Sci. U. S. A. 84, 3434-3438.

Drucker, D.J., Habener, J.F., and Holst, J.J. (2017). Discovery, characterization, and clinical development of the glucagon-like peptides. J. Clin. Invest. 127, 4217-4227.

Dujic, T., Zhou, K., Donnelly, L.A., Tavendale, R., Palmer, C.N.A., and Pearson, E.R. (2015). Association of organic cation transporter 1 with intolerance to metformin in type 2 diabetes: A GoDARTS study.

Diabetes 64, 1786-1793.

Ebina, Y., Ellis, L., Jarnagin, K., Edery, M., Graf, L., Clauser, E., Ou, J. hsiung, Masiarz, F., Kan, Y.W., Goldfine, I.D., et al. (1985). The human insulin receptor cDNA: The structural basis for hormone-activated transmembrane signalling. Cell 40,747-758.

Ebinger, M., Jehle, D.R., Fussgaenger, R.D., Fehmann, H.C., and Jehle, P.M. (2000). Glucagon-like peptide-1 improves insulin and proinsulin binding on RINm5F cells and human monocytes. Am. J. Physiol. - Endocrinol. Metab. 279, E88-E94.

Edwards, C.M.B., Todd, J.F., Mahmoudi, M., Wang, Z., Wang, R.M., Ghatei, M.A., and Bloom, S.R. (1999). Glucagon-like peptide 1 has a physiological role in the control of postprandial glucose in humans: Studies with the antagonist exendin 9-39. Diabetes 48, 86-93.

Egido, E.M., Rodríguez-Gallardo, J., Silvestre, R.A., and Marco, J. (2002). Inhibitory effect of ghrelin on insulin and pancreatic somatostatin secretion. Eur. J. Endocrinol. 146, 241-244.

Eguchi, K., and Manabe, I. (2013). Macrophages and islet inflammation in type 2 diabetes. Diabetes, Obes. Metab. 15, 152-158.

Ehses, J.A., Perren, A., Eppler, E., Ribaux, P., Pospisilik, J.A., Maor-Cahn, R., Gueripel, X., Ellingsgaard, H., Schneider, M.K.J., Biollaz, G., et al. (2007). Increased number of islet-associated macrophages in 
type 2 diabetes. Diabetes 56, 2356-2370.

Eliasson, L., Renström, E., Ding, W.G., Proks, P., and Rorsman, P. (1997). Rapid ATP-dependent priming of secretory granules precedes $\mathrm{Ca2+-induced} \mathrm{exocytosis} \mathrm{in} \mathrm{mouse} \mathrm{pancreatic} \mathrm{B-cells.} \mathrm{J.} \mathrm{Physiol.}$ 503, 399-412.

Ellingsgaard, H., Hauselmann, I., Schuler, B., Habib, A.M., Baggio, L.L., Meier, D.T., Eppler, E., Bouzakri, K., Wueest, S., Muller, Y.D., et al. (2011). Interleukin-6 enhances insulin secretion by increasing glucagon-like peptide-1 secretion from L cells and alpha cells. Nat. Med. 17, 1481-1489.

Engel, M., Hoffmann, T., Wagner, L., Wermann, M., Heiser, U., Kiefersauer, R., Huber, R., Bode, W., Demuth, H.-U., and Brandstetter, H. (2003). The crystal structure of dipeptidyl peptidase IV (CD26) reveals its functional regulation and enzymatic mechanism. Proc. Natl. Acad. Sci. U. S. A. 100, 5063.

Faidley, T.D., Leiting, B., Pryor, K.D., Lyons, K., Hickey, G.J., and Thompson, D.R. (2006). Inhibition of dipeptidyl-peptidase IV does not increase circulating IGF-1 concentrations in growing pigs. Exp. Biol. Med. 231, 1373-1378.

Farilla, L., Bulotta, A., Hirshberg, B., Li Calzi, S., Khoury, N., Noushmehr, H., Bertolotto, C., Di Mario, U., Harlan, D.M., and Perfetti, R. (2003). Glucagon-Like Peptide 1 Inhibits Cell Apoptosis and Improves Glucose Responsiveness of Freshly Isolated Human Islets. Endocrinology 144, 5149-5158.

Fehmann, H.C., and Habener, J.F. (1992). Insulinotropic hormone glucagon-like peptide-i (7-37) stimulation of proinsulin gene expression and proinsulin biosynthesis in insulinoma $\beta$ tc-1 cells. Endocrinology 130, 159-166.

Ferdaoussi, M., Smith, N., Lin, H., Bautista, A., Spigelman, A.F., Lyon, J., Dai, X., Manning, J.E., and Macdonald, P.E. (2020). Improved glucose tolerance with DPPIV inhibition requires $\beta$-cell SENP1 amplification of glucose-stimulated insulin secretion. 1-8.

Ferrannini, E., Bjorkman, O., Reichard, G.A., Pilo, A., Olsson, M., Wahren, J., and DeFronzo, R.A. (1985). The disposal of an oral glucose load in healthy subjects. A quantitative study. Diabetes $34,580-588$.

Frohman, L.A., Downs, T.R., Heimer, E.P., and Felix, A.M. (1989). Dipeptidylpeptidase IV and trypsin-like enzymatic degradation of human growth hormone-releasing hormone in plasma. J. Clin. Invest. 83, 15331540.

Fujimiya, M., and Inui, A. (2000). Peptidergic regulation of gastrointestinal motility in rodents. Peptides 21, 1565-1582.

Furuta, M., Carroll, R., Martin, S., Swift, H.H., Ravazzola, M., Orci, L., and Steiner, D.F. (1998). Incomplete processing of proinsulin to insulin accompanied by elevation of Des-31,32 proinsulin intermediates in islets of mice lacking active PC2. J. Biol. Chem. 273, 3431-3437. 
Geisler, C.E., Hepler, C., Higgins, M.R., and Renquist, B.J. (2016). Hepatic adaptations to maintain metabolic homeostasis in response to fasting and refeeding in mice. Nutr. Metab. 13, 62.

Gelling, R.W., Vuguin, P.M., Xiu, Q. Du, Cui, L., Rømer, J., Pederson, R.A., Leiser, M., Sørensen, H., Holst, J.J., Fledelius, C., et al. (2009). Pancreatic $\beta$-cell overexpression of the glucagon receptor gene results in enhanced $\beta$-cell function and mass. Am. J. Physiol. - Endocrinol. Metab. 297, E695-E707. Ghersi, G., Chen, W.T., Lee, E.W., and Zukowska, Z. (2001). Critical role of dipeptidyl peptidase IV in neuropeptide $\mathrm{Y}$-mediated endothelial cell migration in response to wounding. Peptides 22, 453-458.

Gibbons, C., Caudwell, P., Finlayson, G., Webb, D.-L., Hellström, P.M., Näslund, E., and Blundell, J.E. (2013). Comparison of Postprandial Profiles of Ghrelin, Active GLP-1, and Total PYY to Meals Varying in Fat and Carbohydrate and Their Association With Hunger and the Phases of Satiety. J. Clin. Endocrinol. Metab. 98, E847-E855.

Gin, H., Messerchmitt, C., Brottier, E., and Aubertin, J. (1985). Metformin improved insulin resistance in type I, insulin-dependent, diabetic patients. Metabolism 34, 923-925.

Giorgetti, S., Pelicci, P.G., Pelicci, G., and Obberghen, E. (1994). Involvement of Src-homology/collagen $(\mathrm{SHC})$ proteins in signaling through the insulin receptor and the insulin-like-growth-factor-I-receptor. Eur. J. Biochem. 223, 195-202.

Giovannone, B., Scaldaferri, M.L., Federici, M., Porzio, O., Lauro, D., Fusco, A., Sbraccia, P., Borboni, P., Lauro, R., and Sesti, G. (2000). Insulin receptor substrate (IRS) transduction system: distinct and overlapping signaling potential. Diabetes. Metab. Res. Rev. 16, 434-441.

Gray, S.M., Niu, J., Zhang, A., Svendsen, B., Campbell, J.E., D’Alessio, D.A., and Tong, J. (2019). Intraislet ghrelin signaling does not regulate insulin secretion from adult mice. Diabetes 68, 1795-1805.

Gribble, F.M., Reimann, F., and Roberts, G.P. (2018). Physiology of the Gastrointestinal Tract. 31-70 Gromada, J., Bokvist, K., Ding, W.G., Holst, J.J., Nielsen, J.H., and Rorsman, P. (1998). Glucagon-like peptide 1(7-36) amide stimulates exocytosis in human pancreatic $\beta$-cells by both proximal and distal regulatory steps in stimulus- secretion coupling. Diabetes $47,57-65$.

Guizzetti, L., McGirr, R., and Dhanvantari, S. (2014). Two dipolar $\alpha$-helices within hormone-encoding regions of proglucagon are sorting signals to the regulated secretory pathway. J. Biol. Chem. 289, 14968-14980.

Guo, S. (2014). Insulin signaling, resistance, and metabolic syndrome: Insights from mouse models into disease mechanisms. J. Endocrinol. 220, T1.

Han, H.S., Kang, G., Kim, J.S., Choi, B.H., and Koo, S.H. (2016). Regulation of glucose metabolism from a liver-centric perspective. Exp. Mol. Med. 48, e218-e218. 
Hanas, R., and Ludvigsson, J. (2006). Hypoglycemia and ketoacidosis with insulin pump therapy in children and adolescents. Pediatr. Diabetes 7, 32-38.

Hansen, A.M.K., Bödvarsdottir, T.B., Nordestgaard, D.N.E., Heller, R.S., Gotfredsen, C.F., Maedler, K., Fels, J.J., Holst, J.J., and Karlsen, A.E. (2011). Upregulation of alpha cell glucagon-like peptide 1 (GLP-1) in Psammomys obesus - An adaptive response to hyperglycaemia? Diabetologia 54, 1379-1387.

Hansen, L., Deacon, C.F., Ørskov, C., and Holst, J.J. (1999). Peptidase IV in the Capillaries Supplying the L Cells of the Porcine Intestine *. Society 140, 5356-5363.

Hansotia, T., Baggio, L.L., Delmeire, D., Hinke, S.A., Yamada, Y., Tsukiyama, K., Seino, Y., Holst, J.J., Schuit, F., and Drucker, D.J. (2004). Double Incretin Receptor Knockout (DIRKO) Mice Reveal an Essential Role for the Enteroinsular Axis in Transducing the Glucoregulatory Actions of DPP-IV Inhibitors. Diabetes 53, 1326-1335.

Heffner, C.S., Herbert Pratt, C., Babiuk, R.P., Sharma, Y., Rockwood, S.F., Donahue, L.R., Eppig, J.T., and Murray, S.A. (2012). Supporting conditional mouse mutagenesis with a comprehensive cre characterization resource. Nat. Commun. 3, 1218.

Henquin, J.C., and Meissner, H.P. (1981). Effects of amino acids on membrane potential and 86Rb+ fluxes in pancreatic beta-cells. Am. J. Physiol. 240, E245-E252.

Hermans, M.P., Schmeer, W., and Henquin, J.C. (1987). Modulation of the effect of acetylcholine on insulin release by the membrane potential of b cells. Endocrinology 120, 1765-1773.

Hill, M.E., Asa, S.L., and Drucker, D.J. (1999). Essential requirement for Pax6 in control of enteroendocrine proglucagon gene transcription. Mol. Endocrinol. 13, 1474-1486.

Hjøllund, K.R., Deacon, C.F., and Holst, J.J. (2011). Dipeptidyl peptidase-4 inhibition increases portal concentrations of intact glucagon-like peptide-1 (GLP-1) to a greater extent than peripheral concentrations in anaesthetised pigs. Diabetologia 54, 2206-2208.

Holman, R.R., Bethel, M.A., Mentz, R.J., Thompson, V.P., Lokhnygina, Y., Buse, J.B., Chan, J.C., Choi, J., Gustavson, S.M., Iqbal, N., et al. (2017). Effects of once-weekly exenatide on cardiovascular outcomes in type 2 diabetes. N. Engl. J. Med. 377, 1228-1239.

Holst, J.J. (1994). Glucagonlike peptide 1: A newly discovered gastrointestinal hormone. Gastroenterology 107, 1848-1855.

Holst, J.J., Knop, F.K., Vilsbøll, T., Krarup, T., and Madsbad, S. (2011). Loss of incretin effect is a specific, important, and early characteristic of type 2 diabetes. Diabetes Care 34, S251-S257.

Holz IV, G.G., Kiihtreiber, W.M., and Habener, J.F. (1993). Pancreatic beta-cells are rendered glucosecompetent by the insulinotropic hormone glucagon-like peptide-1(7-37). Nature 361, 362-365. 
Holzer, P., Reichmann, F., and Farzi, A. (2012). Neuropeptide Y, peptide YY and pancreatic polypeptide in the gut-brain axis. Neuropeptides 46, 261-274.

Hong, J., Stubbins, R.E., Smith, R.R., Harvey, A.E., and Nũez, N.P. (2009). Differential susceptibility to obesity between male, female and ovariectomized female mice. Nutr. J. 8, 11.

Hoyt, E.C., Lund, P.K., Winesett, D.E., Fuller, C.R., Ghatei, M.A., Bloom, S.R., and Ulshen, M.H. (1996). Effects of Fasting, Refeeding, and Intraluminal Triglyceride on Proglucagon Expression in Jejunum and lleum. Diabetes 45, 434-439.

Hsia, D.S., Grove, O., and Cefalu, W.T. (2017). An update on sodium-glucose co-transporter-2 inhibitors for the treatment of diabetes mellitus. Curr. Opin. Endocrinol. Diabetes Obes. 24, 73-79.

Hu, F.B. (2011). Globalization of Diabetes The role of diet, lifestyle, and genes. Diabetes Care 34, 12491257.

Hui, H., Nourparvar, A., Zhao, X., and Perfetti, R. (2003). Glucagon-like peptide-1 inhibits apoptosis of insulin-secreting cells via a cyclic 5'-adenosine monophosphate-dependent protein kinase $A$ - and a phosphatidylinositol 3-kinase-dependent pathway. Endocrinology 144, 1444-1455.

Ihara, Y., Toyokuni, S., Uchida, K., Odaka, H., Tanaka, T., Ikeda, H., Hiai, H., Seino, Y., and Yamada, Y. (1999). Hyperglycemia causes oxidative stress in pancreatic $\beta$-cells of GK rats, a model of type 2 diabetes. Diabetes 48, 927-932.

Jackerott, M., Qster, A., and Larsson', L.-I. (1996). PYY in Developing Murine Islet Cells: Comparisons to Development of Islet Hormones, NPY, and BrdU Incorporation. J. Histochem. Cytochem. 44, 809-817.

Jackson, R.A., Hawa, M.I., Jaspan, J.B., Sim, B.M., DiSilvio, L., Featherbe, D., and Kurtz, A.B. (1987). Mechanism of metformin action in non-insulin-dependent diabetes. Diabetes 36, 632-640.

Kaneko, M., and Narukawa, M. (2017). Assessment of the Risk of Hospitalization for Heart Failure With Dipeptidyl Peptidase-4 Inhibitors, Saxagliptin, Alogliptin, and Sitagliptin in Patients With Type 2 Diabetes, Using an Alternative Measure to the Hazard Ratio. Ann. Pharmacother. 51, 570-576.

Karagiannis, T., Boura, P., and Tsapas, A. (2014). Safety of dipeptidyl peptidase 4 inhibitors: A perspective review. Ther. Adv. Drug Saf. 5, 138-146.

Katsuura, G., Asakawa, A., and Inui, A. (2002). Roles of pancreatic polypeptide in regulation of food intake. Peptides 23, 323-329.

Kelley, D., Mitrakou, A., Marsh, H., Schwenk, F., Benn, J., Sonnenberg, G., Arcangeli, M., Aoki, T., Sorensen, J., Berger, M., et al. (1988). Skeletal muscle glycolysis, oxidation, and storage of an oral glucose load. J. Clin. Invest. 81, 1563-1571. 
Khan, M.A.B., Hashim, M.J., King, J.K., Govender, R.D., Mustafa, H., and Al Kaabi, J. (2020). Epidemiology of Type 2 Diabetes - Global Burden of Disease and Forecasted Trends. J. Epidemiol. Glob. Health 10, 107-111.

Kieffer, T.J., Mc Intosh, C.H.S., and Pederson, R.A. (1995). Degradation of glucose-dependent insulinotropic polypeptide and truncated glucagon-like peptide 1 in vitro and in vivo by dipeptidyl peptidase iv. Endocrinology 136, 3585-3596.

Kilimnik, G., Kim, A., Steiner, D.F., Friedman, T.C., and Hara, M. (2010). Intraislet production of GLP-1 by activation of prohormone convertase $1 / 3$ in pancreatic $\alpha$-cells in mouse models of -cell regeneration. Islets 2, 149-155.

Kim, A., Miller, K., Jo, J., Kilimnik, G., Wojcik, P., and Hara, M. (2009). Islet architecture: A comparative study. Islets 1, 129-136.

Kim, S.C., Schneeweiss, S., Glynn, R.J., Doherty, M., Goldfine, A.B., and Solomon, D.H. (2015). Dipeptidyl peptidase- 4 inhibitors in type 2 diabetes may reduce the risk of autoimmune diseases: A population-based cohort study. Ann. Rheum. Dis. 74, 1968-1975.

Kim, S.J., Winter, K., Nian, C., Tsuneoka, M., Koda, Y., and Mclntosh, C.H.S. (2005). Glucose-dependent insulinotropic polypeptide (GIP) stimulation of pancreatic $\beta$-cell survival is dependent upon phosphatidylinositol 3-kinase (PI3K)/protein kinase B (PKB) signaling, inactivation of the Forkhead transcription factor Foxo1, and down-regulation of bax expression. J. Biol. Chem. 280, 22297-22307.

Knop, F.K., Aaboe, K., Vilsbøll, T., Vølund, A., Holst, J.J., Krarup, T., and Madsbad, S. (2012). Impaired incretin effect and fasting hyperglucagonaemia characterizing type 2 diabetic subjects are early signs of dysmetabolism in obesity. Diabetes, Obes. Metab. 14, 500-510.

Knudsen, L.B., and Pridal, L. (1996). Glucagon-like peptide-1-(9-36) amide is a major metabolite of glucagon-like peptide-1-(7-36) amide after in vivo administration to dogs, and it acts as an antagonist on the pancreatic receptor. Eur. J. Pharmacol. 318, 429-435.

Komatsu, M., Takei, M., Ishii, H., and Sato, Y. (2013). Glucose-stimulated insulin secretion: A newer perspective. J. Diabetes Investig. 4, 511-516.

Krssak, M., Brehm, A., Bernroider, E., Anderwald, C., Nowotny, P., Dalla Man, C., Cobelli, C., Cline, G.W., Shulman, G.I., Waldhä Usl, W., et al. (2004). Alterations in Postprandial Hepatic Glycogen Metabolism in Type 2 Diabetes. Diabetes 53, 3048-3056.

Lafferty, R.A., Gault, V.A., Flatt, P.R., and Irwin, N. (2019). Effects of 2 Novel PYY(1-36) Analogues, (P3L31P34)PYY(1-36) and PYY(1-36)(Lys12PAL), on Pancreatic Beta-Cell Function, Growth, and Survival. Clin. Med. Insights Endocrinol. Diabetes 12, 1-8. 
LaMoia, T.E., and Shulman, G.I. (2020). Cellular and Molecular Mechanisms of Metformin Action. Endocr. Rev. Advance online publication. bnaa023.

Lawrence, M.C., McKern, N.M., and Ward, C.W. (2007). Insulin receptor structure and its implications for the IGF-1 receptor. Curr. Opin. Struct. Biol. 17, 699-705.

Lay, A.J., Zhang, H.E., McCaughan, G.W., and Gorrell, M.D. (2019). Fibroblast activation protein in liver fibrosis - PubMed. Front. Biosci. 24, 1-17.

Lee, H.-M., Wang, G., Englander, E.W., Kojima, M., and Greeley Jr., G.H. (2002). Ghrelin, A New Gastrointestinal Endocrine Peptide that Stimulates Insulin Secretion: Enteric Distribution, Ontogeny, Influence of Endocrine, and Dietary Manipulations. Endocrinology 143, 185-190.

Leibiger, B., Moede, T., Muhandiramlage, T.P., Kaiser, D., Sanchez, P.V., Leibiger, I.B., and Berggren, P.O. (2012). Glucagon regulates its own synthesis by autocrine signaling. Proc. Natl. Acad. Sci. U. S. A. 109, 20925-20930.

Leitch, V.D., Brassill, M.J., Rahman, S., Butterfield, N.C., Ma, P., Logan, J.G., Boyde, A., Evans, H., Croucher, P.I., Batterham, R.L., et al. (2019). PYY is a negative regulator of bone mass and strength. Bone 127, 427-435.

Van Der Lely, A.J., Tschöp, M., Heiman, M.L., and Ghigo, E. (2004). Biological, physiological, pathophysiological, and pharmacological aspects of ghrelin. Endocr. Rev. 25, 426-457.

Levin, F., Edholm, T., Schmidt, P.T., Grybäck, P., Jacobsson, H., Degerblad, M., Höybye, C., Holst, J.J., Rehfeld, J.F., Hellström, P.M., et al. (2006). Ghrelin Stimulates Gastric Emptying and Hunger in NormalWeight Humans. J. Clin. Endocrinol. Metab. 91, 3296-3302.

Li, L., Najafi, A.H., Kitlinska, J.B., Neville, R., Laredo, J., Epstein, S.E., Burnett, M.S., and Zukowska, Z. (2011). Of mice and men: Neuropeptide $Y$ and its receptors are associated with atherosclerotic lesion burden and vulnerability. J. Cardiovasc. Transl. Res. 4, 351-362.

Li, N., Yang, Z., Li, Q., Yu, Z., Chen, X., Li, J.C., Li, B., Ning, S.L., Cui, M., Sun, J.P., et al. (2018). Ablation of somatostatin cells leads to impaired pancreatic islet function and neonatal death in rodents article. Cell Death Dis. 9, 1-12.

Li, Y., Hansotia, T., Yusta, B., Ris, F., Halban, P.A., and Drueker, D.J. (2003). Glucagon-like peptide-1 receptor signaling modulates $\beta$ cell apoptosis. J. Biol. Chem. 278, 471-478.

Lin, C.T., Tang, H.Y., Han, Y.S., Liu, H.P., Huang, S.F., Chien, C.H., Shyy, J., Chiu, J.J., and Chen, X. (2010). Downregulation of signaling-active IGF-1 by dipeptidyl peptidase IV (DPP-IV). Int. J. Biomed. Sci. 6, 301-309.

Lin, S., Shi, Y.C., Yulyaningsih, E., Aljanova, A., Zhang, L., Macia, L., Nguyen, A.D., Lin, E.J.D., During, 
M.J., Herzog, H., et al. (2009). Critical role of arcuate Y4 receptors and the melanocortin system in pancreatic polypeptide-induced reduction in food intake in mice. PLoS One 4, e8488.

Lindqvist, A., Shcherbina, L., Prasad, R.B., Miskelly, M.G., Abels, M., Martínez-Lopéz, J.A., Fred, R.G., Nergård, B.J., Hedenbro, J., Groop, L., et al. (2020). Ghrelin suppresses insulin secretion in human islets and type 2 diabetes patients have diminished islet ghrelin cell number and lower plasma ghrelin levels. Mol. Cell. Endocrinol. 511, 110835.

Liu, Z., and Habener, J.F. (2008). Glucagon-like peptide-1 activation of TCF7L2-dependent Wnt signaling enhances pancreatic beta cell proliferation. J. Biol. Chem. 283, 8723-8735.

Liu, L., Omar, B., Marchetti, P., and Ahrén, B. (2014a). Dipeptidyl peptidase-4 (DPP-4): Localization and activity in human and rodent islets. Biochem. Biophys. Res. Commun. 453, 398-404.

Liu, M., Wright, J., Guo, H., Xiong, Y., and Arvan, P. (2014b). Proinsulin entry and transit through the endoplasmic reticulum in pancreatic beta cells. In Vitamins and Hormones, (Academic Press Inc.), pp. 35-62.

Lovshin, J.A., and Drucker, D.J. (2009). Incretin-based therapies for type 2 diabetes mellitus. Nat. Rev. Endocrinol 5, 262-269.

Lucidi, P., Murdolo, G., Di Loreto, C., Parlanti, N., De Cicco, A., Fatone, C., Taglioni, C., Fanelli, C., Broglio, F., Ghigo, E., et al. (2005). Metabolic and endocrine effects of physiological increments in plasma ghrelin concentrations. Nutr. Metab. Cardiovasc. Dis. 15, 410-417.

Lynn, F.C., Pamir, N., Ng, E.H.C., McIntosh, C.H.S., Kieffer, T.J., and Pederson, R.A. (2001). Defective glucose-dependent insulinotropic polypeptide receptor expression in diabetic fatty Zucker rats. Diabetes 50, 1004-1011.

Ma, X., Zhang, Y., Gromada, J., Sewing, S., Berggren, P.-O., Buschard, K., Salehi, A., Vikman, J., Rorsman, P., and Eliasson, L. (2005). Glucagon Stimulates Exocytosis in Mouse and Rat Pancreatic aCells by Binding to Glucagon Receptors. Mol. Endocrinol. 19, 198-212.

Maedler, K., Sergeev, P., Ris, F., Oberholzer, J., Joller-Jemelka, H.I., Spinas, G.A., Kaiser, N., Halban, P.A., and Donath, M.Y. (2002). Glucose-induced $\beta$ cell production of IL-1 $\beta$ contributes to glucotoxicity in human pancreatic islets. J. Clin. Invest. 110, 851-860.

Manchester, K.L. (1972). Effect of Insulin on Protein Synthesis. Diabetes 21, 447-452.

Mann, J.F.E., Ørsted, D.D., Brown-Frandsen, K., Marso, S.P., Poulter, N.R., Rasmussen, S., Tornøe, K., Zinman, B., and Buse, J.B. (2017). Liraglutide and renal outcomes in type 2 diabetes. N. Engl. J. Med. 377, 839-848.

Marchetti, P., Lupi, R., Bugliani, M., Kirkpatrick, C.L., Sebastiani, G., Grieco, F.A., Guerra, S. Del, D’Aleo, 
V., Piro, S., Marselli, L., et al. (2012). A local glucagon-like peptide 1 (GLP-1) system in human pancreatic islets. Diabetologia 55, 3262-3272.

Marguet, D., Baggio, L., Kobayashi, T., Bernard, A.M., Pierres, M., Nielsen, P.F., Ribel, U., Watanabe, T., Drucker, D.J., and Wagtmann, N. (2000). Enhanced insulin secretion and improved glucose tolerance in mice lacking CD26. Proc. Natl. Acad. Sci. U. S. A. 97, 6874-6879.

Marso, S.P., Bain, S.C., Consoli, A., Eliaschewitz, F.G., Jodar, E., Leiter, L.A., Lingvay, I., Rosenstock, J., Seufert, J., Warren, M.L., et al. (2016a). Semaglutide and cardiovascular outcomes in patients with type 2 diabetes. N. Engl. J. Med. 375, 1834-1844.

Marso, S.P., Daniels, G.H., Frandsen, K.B., Kristensen, P., Mann, J.F.E., Nauck, M.A., Nissen, S.E., Pocock, S., Poulter, N.R., Ravn, L.S., et al. (2016b). Liraglutide and cardiovascular outcomes in type 2 diabetes. N. Engl. J. Med. 375, 311-322.

McCreight, L.J., Bailey, C.J., and Pearson, E.R. (2016). Metformin and the gastrointestinal tract. Diabetologia 59, 426-435.

McKinnon, C.M., Ravier, M.A., and Rutter, G.A. (2006). FoxO1 is required for the regulation of preproglucagon gene expression by insulin in pancreatic aTC1-9 cells. J. Biol. Chem. 281, 39358-39369. Meissner, H.P. (1976). Electrophysiological evidence for coupling between B cells of pancreatic islets. Nature 262, 502-504.

Mentlein, R., Gallwitz, B., and Schmidt, W.E. (1993). Dipeptidyl-peptidase IV hydrolyses gastric inhibitory polypeptide, glucagon-like peptide-1(7-36)amide, peptide histidine methionine and is responsible for their degradation in human serum. Eur. J. Biochem. 214, 829-835.

De Meyts, P. (2000). The Insulin Receptor and Its Signal Transduction Network (MDText.com, Inc.). Michaliszyn, S.F., Mari, A., Lee, S., Bacha, F., Tfayli, H., Farchoukh, L., Ferrannini, E., and Arslanian, S. (2014). $\beta$-cell function, incretin effect, and incretin hormones in obese youth along the span of glucose tolerance from normal to prediabetes to type 2 diabetes. Diabetes 63, 3846-3855.

Mihalache, L., Gherasim, A., Niță, O., Ungureanu, M.C., Pădureanu, S.S., Gavril, R.S., and Arhire, L.I. (2016). Effects of ghrelin in energy balance and body weight homeostasis. Hormones 15, 186-196.

Mojsov, S., Weir, G.C., and Habener, J.F. (1987). Insulinotropin: Glucagon-like peptide I (7-37) coencoded in the glucagon gene is a potent stimulator of insulin release in the perfused rat pancreas. J. Clin. Invest. 79, 616-619.

Monami, M., Dicembrini, I., Martelli, D., and Mannucci, E. (2011). Safety of dipeptidyl peptidase-4 inhibitors: A meta-analysis of randomized clinical trials. Curr. Med. Res. Opin. 27, 57-64. 
Monami, M., Nardini, C., and Mannucci, E. (2014). Efficacy and safety of sodium glucose co-transport-2 inhibitors in type 2 diabetes: A meta-analysis of randomized clinical trials. Diabetes, Obes. Metab. 16, 457-466.

Mortensen, K., Christensen, L.L., Holst, J.J., and Orskov, C. (2003). GLP-1 and GIP are colocalized in a subset of endocrine cells in the small intestine. Regul. Pept. 114, 189-196.

Motola, D., Piccinni, C., Biagi, C., Raschi, E., Marra, A., Marchesini, G., and Poluzzi, E. (2012).

Cardiovascular, ocular and bone adverse reactions associated with thiazolidinediones: $\mathrm{A}$

disproportionality analysis of the US FDA adverse event reporting system database. Drug Saf. 35, 315323.

Mulvihill, E.E., and Drucker, D.J. (2014). Pharmacology, physiology, and mechanisms of action of dipeptidyl peptidase-4 inhibitors. Endocr. Rev. 35, 992-1019.

Mulvihill, E.E., Varin, E.M., Gladanac, B., Campbell, J.E., Ussher, J.R., Baggio, L.L., Yusta, B., Ayala, J., Burmeister, M.A., Matthews, D., et al. (2017). Cellular Sites and Mechanisms Linking Reduction of Dipeptidyl Peptidase-4 Activity to Control of Incretin Hormone Action and Glucose Homeostasis. Cell Metab. 25, 152-165.

Natali, A., and Ferrannini, E. (2006). Effects of metformin and thiazolidinediones on suppression of hepatic glucose production and stimulation of glucose uptake in type 2 diabetes: A systematic review. Diabetologia 49, 434-441.

Nauck, M.A., and Meier, J.J. (2018). Incretin hormones: Their role in health and disease. Diabetes, Obes. Metab. 20, 5-21.

Nauck, M.A., Homberger, E., Siegel, E.G., Allen, R.C., Eaton, R.P., Ebert, R., and Creutzfeldt, W. (1986). Incretin Effects of Increasing Glucose Loads in Man Calculated from Venous Insulin and C-Peptide Responses*. J. Clin. Endocrinol. Metab. 63, 492-498.

Nauck, M.A., Meier, J.J., Cavender, M.A., El Aziz, M.A., and Drucker, D.J. (2017). Cardiovascular actions and clinical outcomes with glucagon-like peptide-1 receptor agonists and dipeptidyl peptidase-4 inhibitors. Circulation 136, 849-870.

Nauck, M.A., McGuire, D.K., Pieper, K.S., Lokhnygina, Y., Strandberg, T.E., Riefflin, A., Delibasi, T., Peterson, E.D., White, H.D., Scott, R., et al. (2019). Sitagliptin does not reduce the risk of cardiovascular death or hospitalization for heart failure following myocardial infarction in patients with diabetes: Observations from TECOS. Cardiovasc. Diabetol. 18, 116.

Newsholme, P., Brennan, L., and Bender, K. (2006). Amino acid metabolism, $\beta$-cell function, and diabetes. Diabetes 55, S39-S47. 
Nikolaidis, L.A., Elahi, D., Shen, Y.T., and Shannon, R.P. (2005). Active metabolite of GLP-1 mediates myocardial glucose uptake and improves left ventricular performance in conscious dogs with dilated cardiomyopathy. Am. J. Physiol. - Hear. Circ. Physiol. 289, 2401-2408.

Ohkubo, Y., Kishikawa, H., Araki, E., Miyata, T., Isami, S., Motoyoshi, S., Kojima, Y., Furuyoshi, N., and Shichiri, M. (1995). Intensive insulin therapy prevents the progression of diabetic microvascular complications in Japanese patients with non-insulin-dependent diabetes mellitus: a randomized prospective 6-year study. Diabetes Res. Clin. Pract. 28, 103-117.

Olofsson, C.S., Göpel, S.O., Barg, S., Galvanovskis, J., Ma, X., Salehi, A., Rorsman, P., and Eliasson, L. (2002). Fast insulin secretion reflects exocytosis of docked granules in mouse pancreatic B-cells. Pflugers Arch. Eur. J. Physiol. 444, 43-51.

Omar, B.A., Liehua, L., Yamada, Y., Seino, Y., Marchetti, P., and Ahrén, B. (2014). Dipeptidyl peptidase 4 (DPP-4) is expressed in mouse and human islets and its activity is decreased in human islets from individuals with type 2 diabetes. Diabetologia 57, 1876-1883.

Orskov, C., Wettergren, A., and Holst, J.J. (1993). Biological effects and metabolic rates of glucagonlike peptide-1 7-36 amide and glucagonlike peptide-1 7-37 in healthy subjects are indistinguishable. Diabetes $42,658-661$.

Ozawa, K., Miyazaki, M., Matsuhisa, M., Takano, K., Nakatani, Y., Hatazaki, M., Tamatani, T., Yamagata, K., Miyagawa, J.I., Kitao, Y., et al. (2005). The endoplasmic reticuluin chaperone improves insulin resistance in type 2 diabetes. Diabetes 54, 657-663.

Perley, M.J., and Kipnis, D.M. (1967). Plasma insulin responses to oral and intravenous glucose: studies in normal and diabetic sujbjects. J. Clin. Invest. 46, 1954-1962.

Perriello, G., Misericordia, P., Volpi, E., Santucci, A., Santucci, C., Ferrannini, E., Ventura, M.M., Santeusanio, F., Brunetti, P., and Bolli, G.B. (1994). Acute Antihyperglycemic Mechanisms of Metformin in NIDDM Evidence for Suppression of Lipid Oxidation and Hepatic Glucose Production. Diabetes 43, 920-928.

Petersen, M.C., Vatner, D.F., and Shulman, G.I. (2017). Regulation of hepatic glucose metabolism in health and disease HHS Public Access. Nat Rev Endocrinol 13, 572-587.

Pettersson, U.S., Waldén, T.B., Carlsson, P.O., Jansson, L., and Phillipson, M. (2012). Female Mice are Protected against High-Fat Diet Induced Metabolic Syndrome and Increase the Regulatory $\mathrm{T}$ Cell Population in Adipose Tissue. PLoS One 7, e46057.

Pfeffer, M.A., Claggett, B., Diaz, R., Dickstein, K., Gerstein, H.C., Køber, L. V., Lawson, F.C., Ping, L., Wei, X., Lewis, E.F., et al. (2015). Lixisenatide in patients with type 2 diabetes and acute coronary syndrome. N. Engl. J. Med. 373, 2247-2257. 
Philippe, J. (1991). Insulin regulation of the glucagon gene is mediated by an insulin-responsive DNA element. Proc. Natl. Acad. Sci. U. S. A. 88, 7224-7227.

Phillippe, J. (1989). Glucagon gene transcription is negatively regulated by insulin in a hamster islet cell line. J. Clin. Invest. 84, 672-677.

Piazza, G.A., Callanan, H.M., Mowery, J., and Hixson, D.C. (1989). Evidence for a role of dipeptidyl peptidase IV in fibronectin-mediated interactions of hepatocytes with extracellular matrix. Biochem. J. 262, 327-334.

Pickup, J.C., and Renard, E. (2008). Long-Acting Insulin Analogs Versus Insulin Pump Therapy for the Treatment of Type 1 and Type 2 Diabetes. Diabetes Care 31, s140-s145.

Pizarro-Delgado, J., Deeney, J.T., Martín-Del-Río, R., Corkey, B.E., and Tamarit-Rodriguez, J. (2015). $\mathrm{KCl}$ - Permeabilized pancreatic islets: An experimental model to explore the messenger role of ATP in the mechanism of insulin secretion. PLoS One 10, e0140096.

Popkin, B.M., and Gordon-Larsen, P. (2004). The nutrition transition: worldwide obesity dynamics and their determinants. Int. J. Obes. 28, 2-9.

Prasad, R.B., and Groop, L. (2015). Genetics of type 2 diabetes-pitfalls and possibilities. Genes (Basel). 6, 87-123.

Prentki, M., and Nolan, C.J. (2006). Islet $\beta$ cell failure in type 2 diabetes. J. Clin. Invest. 116, 1802-1812.

Proks, P., Reimann, F., Green, N., Gribble, F., and Ashcroft, F. (2002). Sulfonylurea Stimulation of Insulin Secretion. Diabetes 51, s368-s376.

Qaid, M.M., and Abdelrahman, M.M. (2016). Role of insulin and other related hormones in energy metabolism. Cogent Food Agric. 2, 1.

Quesada, I., Tudurí, E., Ripoll, C., and Nadal, Á. (2008). Physiology of the pancreatic $\alpha$-cell and glucagon secretion: Role in glucose homeostasis and diabetes. J. Endocrinol. 199, 5-19.

Ramracheya, R., Ward, C., Shigeto, M., Walker, J.N., Amisten, S., Zhang, Q., Johnson, P.R., Rorsman, P., and Braun, M. (2010). Membrane potential-dependent inactivation of voltage-gated ion channels in $\alpha-$ cells inhibits glucagon secretion from human islets. Diabetes 59, 2198-2208.

Ravier, M.A., Güldenagel, M., Charollais, A., Gjinovci, A., Caille, D., Söhl, G., Wollheim, C.B., Willecke, K., Henquin, J.C., and Meda, P. (2005). Loss of connexin36 channels alters $\beta$-cell coupling, islet synchronization of glucose-induced $\mathrm{Ca} 2+$ and insulin oscillations, and basal insulin release. Diabetes 54 , 1798-1807.

Reddy, E.P. (2000). Cell cycle control of pancreatic beta cell proliferation Novel Kinase inhibitors View 
project BCR-ABL inhibitors View project. Artic. Front. Biosci 5. D1-D19.

Rhodes, C.J., Lincoln, B., and Shoelson, S.E. (1992). Preferential Cleavage of des-31,32-proinsulin Over Intact Proinsulin by the Insulin Secretory Granule Type II Endopeptidase. Implication of a Favored Route for Prohormone Processing. J. Biol. Chem. 267, 22719-22727.

Robich, M.P., Matyal, R., Chu, L.M., Feng, J., Xu, S.H., Laham, R.J., Hess, P.E., Bianchi, C., and Sellke, F.W. (2010). Effects of neuropeptide $Y$ on collateral development in a swine model of chronic myocardial ischemia. J. Mol. Cell. Cardiol. 49, 1022-1030.

Rodriguez-Diaz, R., Abdulreda, M.H., Formoso, A.L., Gans, I., Ricordi, C., Berggren, P.O., and Caicedo, A. (2011). Innervation patterns of autonomic axons in the human endocrine pancreas. Cell Metab. 14, $45-54$.

Röhrborn, D., Eckel, J., and Sell, H. (2014). Shedding of dipeptidyl peptidase 4 is mediated by metalloproteases and up-regulated by hypoxia in human adipocytes and smooth muscle cells. FEBS Lett. 588, 3870-3877.

Röhrborn, D., Wronkowitz, N., and Eckel, J. (2015). DPP4 in diabetes. Front. Immunol. 6, 386.

Rorsman, P., and Huising, M.O. (2018). The somatostatin-secreting pancreatic $\delta$-cell in health and disease. Nat. Rev. Endocrinol. 14, 404-414.

Rorsman, P., and Renström, E. (2003). Insulin granule dynamics in pancreatic beta cells. Diabetologia 46, 1029-1045.

Ross Laybutt, D., Kaneto, H., Hasenkamp, W., Grey, S., Jonas, J.C., Sgroi, D.C., Groff, A., Ferran, C., Bonner-Weir, S., Sharma, A., et al. (2002). Increased expression of antioxidant and antiapoptotic genes in islets that may contribute to $\beta$-cell survival during chronic hyperglycemia. Diabetes $51,413-423$.

Saito, K., Iwama, N., and Takahashi, T. (1978). Morphometrical Analysis on Topographical Difference in Size Distribution, Number and Volume of Islets in the Human Pancreas. Tohoku J. Exp. Med 124, 177186.

Samuel, V.T., and Shulman, G.I. (2012). Mechanisms for insulin resistance: Common threads and missing links. Cell 148, 852-871.

Sancho, V., Daniele, G., Lucchesi, D., Lupi, R., Ciccarone, A., Penno, G., Bianchi, C., Dardano, A., Miccoli, R., and Del Prato, S. (2017). Metabolic regulation of GLP-1 and PC1/3 in pancreatic $\alpha$-cell line. PLoS One 12, e0187836.

Sandoval, D.A., and D'alessio, D.A. (2015). Physiology of Proglucagon Peptides: Role of Glucagon and GLP-1 in Health and Disease. Physiol Rev 95, 513-548. 
Sangle, G. V., Lauffer, L.M., Grieco, A., Trivedi, S., lakoubov, R., and Brubaker, P.L. (2012). Novel Biological Action of the Dipeptidylpeptidase-IV Inhibitor, Sitagliptin, as a Glucagon-Like Peptide-1 Secretagogue. Endocrinology 153, 564-573.

Santamarina, M., and Carlson, C.J. (2019). Review of the cardiovascular safety of dipeptidyl peptidase-4 inhibitors and the clinical relevance of the CAROLINA trial. BMC Cardiovasc. Disord. 19, 60.

Sarkar, J., Nargis, T., Tantia, O., Ghosh, S., and Chakrabarti, P. (2019). Increased Plasma Dipeptidyl Peptidase-4 (DPP4) Activity Is an Obesity-Independent Parameter for Glycemic Deregulation in Type 2 Diabetes Patients. Front. Endocrinol. (Lausanne). 10, 505.

Sarwar, N., Gao, P., Kondapally Seshasai, S.R., Gobin, R., Kaptoge, S., Di Angelantonio, E., Ingelsson, E., Lawlor, D.A., Selvin, E., Stampfer, M., et al. (2010). Diabetes mellitus, fasting blood glucose concentration, and risk of vascular disease: A collaborative meta-analysis of 102 prospective studies. Lancet 375, 2215-2222.

Schmid, D.A., Held, K., Ising, M., Uhr, M., Weikel, J.C., and Steiger, A. (2005). Ghrelin stimulates appetite, imagination of food, $\mathrm{GH}, \mathrm{ACTH}$, and cortisol, but does not affect leptin in normal controls. Neuropsychopharmacology 30, 1187-1192.

Schwartz, M.W., and Porte, D.J. (2005). Diabetes, Obesity, and the Brain. Science (80-. ). 307, 375-379. Schwartz, M.W., Seeley, R.J., Tschöp, M.H., Woods, S.C., Morton, G.J., Myers, M.G., and Alessio, D.D.' (2013). Cooperation between brain and islet in glucose homeostasis and diabetes. Nature 503, 59-66.

Shaw, R.J., Lamia, K.A., Vasquez, D., Koo, S.-H., Bardeesy, N., Depinho, R.A., Montminy, M., and Cantley, L.C. (2005). The Kinase LKB1 Mediates Glucose Homeostasis in Liver and Therapeutic Effects of Metformin. Science (80-. ). 310, 1642-1646.

Shi, Y.C., Lin, Z., Lau, J., Zhang, H., Yagi, M., Kanzler, I., Sainsbury, A., Herzog, H., and Lin, S. (2013). PYY3-36 and pancreatic polypeptide reduce food intake in an additive manner via distinct hypothalamic dependent pathways in mice. Obesity 21, E669-E678.

Shulman, G.I., Rothman, D.L., Jue, T., Stein, P., Defronzo, R.A., and Shulman, R.G. (1990). Quantitation of muscle glycogen synthesis in normal subjects and subjects with non-insulin-dependent diabetes by 13C nuclear magnetic resonance spectroscopy. N. Engl. J. Med. 322, 223-228.

Soccio, R.E., Chen, E.R., and Lazar, M.A. (2014). Thiazolidinediones and the promise of insulin sensitization in type 2 diabetes. Cell Metab. 20, 573-591.

Song, A.J., and Palmiter, R.D. (2018). Detecting and Avoiding Problems When Using the Cre-lox System. Trends Genet. 34, 333-340.

Song, Y., Koehler, J.A., Baggio, L.L., Powers, A.C., Sandoval, D.A., and Drucker, D.J. (2019). Gut- 
Proglucagon-Derived Peptides Are Essential for Regulating Glucose Homeostasis in Mice. Cell Metab. 30, 976-986.

Soria, B., Quesada, I., Ropero, A.B., Pertusa, J.A., Martín, F., and Nada, A. (2004). Novel Players in Pancreatic Islet Signaling: From Membrane Receptors to Nuclear Channels. In Diabetes, (American Diabetes Association), pp. S86-S91.

de Souza, A.H., Tang, J., Yadev, A.K., Saghafi, S.T., Kibbe, C.R., Linnemann, A.K., Merrins, M.J., and Davis, D.B. (2020). Intra-islet GLP-1, but not CCK, is necessary for $\beta$-cell function in mouse and human islets. Sci. Rep. 10, 1-10.

Sromova, L., Busek, P., Sedova, L., and Sedo, A. (2015). Intraindividual changes of dipeptidyl peptidaseIV in peripheral blood of patients with rheumatoid arthritis are associated with the disease activity Clinical rheumatology and osteoporosis. BMC Musculoskelet. Disord. 16.

Strowski, M.Z., Parmar, R.M., Blake, A.D., and Schaeffer, J.M. (2000). Somatostatin inhibits insulin and glucagon secretion via two receptor subtypes: An in vitro study of pancreatic islets from somatostatin receptor 2 knockout mice. Endocrinology 141, 111-117.

Stubbins, R.E., Najjar, K., Holcomb, V.B., Hong, J., and Núñez, N.P. (2012). Oestrogen alters adipocyte biology and protects female mice from adipocyte inflammation and insulin resistance. Diabetes, Obes. Metab. 14, 58-66.

Sun, Y., Wang, P., Zheng, H., and Smith, R.G. (2004). Ghrelin stimulation of growth hormone release and appetite is mediated through the growth hormone secretagogue receptor. Proc. Natl. Acad. Sci. U. S. A. 101, 4679-4684.

Svendsen, B., Larsen, O., Buur, M., Gabe, N., Christiansen, C.B., Rosenkilde, M.M., Drucker, D.J., Juul, J., Correspondence, H., and Holst, J.J. (2018). Insulin Secretion Depends on Intra-islet Glucagon Signaling. CellReports 25, 1127-1134.

Svoboda, M., Tastenoy, M., Vertongen, P., and Robberecht, P. (1994). Relative quantitative analysis of glucagon receptor mRNA in rat tissues. Mol. Cell. Endocrinol. 105, 131-137.

Swenne, I. (1992). Pancreatic Beta-cell growth and diabetes mellitus. Diabetologia 35, 193-201.

Takaya, K., Ariyasu, H., Kanamoto, N., Iwakura, H., Yoshimoto, A., Harada, M., Mori, K., Komatsu, Y., Usui, T., Shimatsu, A., et al. (2000). Ghrelin Strongly Stimulates Growth Hormone Release in Humans. J. Clin. Endocrinol. Metab. 85, 4908-4911.

Tan, C.M.J., Green, P., Tapoulal, N., Lewandowski, A.J., Leeson, P., and Herring, N. (2018). The role of neuropeptide $Y$ in cardiovascular health and disease. Front. Physiol. 9, 1281.

Taniguchi, C.M., Emanuelli, B., and Kahn, C.R. (2006). Critical nodes in signalling pathways: Insights into 
insulin action. Nat. Rev. Mol. Cell Biol. 7, 85-96.

Tengholm, A., and Gylfe, E. (2017). cAMP signalling in insulin and glucagon secretion. Diabetes, Obes. Metab. 19, 42-53.

Thompson, N.M., Gill, D.A.S., Davies, R., Loveridge, N., Houston, P.A., Robinson, I.C.A.F., and Wells, T. (2004). Ghrelin and Des-Octanoyl Ghrelin Promote Adipogenesis Directly in Vivo by a Mechanism Independent of the Type 1a Growth Hormone Secretagogue Receptor. Endocrinology 145, 234-242.

Thorens, B. (1996). Glucose transporters in the regulation of intestinal, renal, and liver glucose fluxes. Am. J. Physiol. - Gastrointest. Liver Physiol. 270, 33-34.

Thurmond, D.C. (2009). Insulin-regulated glucagon-like peptide-1 release from I cells: Actin' out. Endocrinology 150, 5202-5204.

Tonelli, J., Li, W., Kishore, P., Pajvani, U.B., Kwon, E., Weaver, C., Scherer, P.E., and Hawkins, M. (2004). Mechanisms of early insulin-sensitizing effects of thiazolidinediones in type 2 diabetes. Diabetes 53, 1621-1629.

Tong, J., Prigeon, R.L., Davis, H.W., Bidlingmaier, M., Kahn, S.E., Cummings, D.E., Tschöp, M.H., and D’Alessio, D. (2010). Ghrelin suppresses glucose-stimulated insulin secretion and deteriorates glucose tolerance in healthy humans. Diabetes 59, 2145-2151.

Tough, I.R., Holliday, N.D., and Cox, H.M. (2006). Y4 receptors mediate the inhibitory responses of pancreatic polypeptide in human and mouse colon mucosa. J. Pharmacol. Exp. Ther. 319, 20-30.

Traub, S., Meier, D.T., Schulze, F., Dror, E., Nordmann, T.M., Goetz, N., Koch, N., Dalmas, E., Stawiski, M., Makshana, V., et al. (2017). Pancreatic a Cell-Derived Glucagon-Related Peptides Are Required for $\beta$ Cell Adaptation and Glucose Homeostasis. Cell Rep. 18, 3192-3203.

Trinh, D.K.Y., Zhang, K., Hossain, M., Brubaker, P.L., and Drucker, D.J. (2003). Pax-6 activates endogenous proglucagon gene expression in the rodent gastrointestinal epithelium. Diabetes 52, 425 433.

Trujillo, J.M., Nuffer, W., and Ellis, S.L. (2015). GLP-1 receptor agonists: A review of head-to-head clinical studies. Ther. Adv. Endocrinol. Metab. 6, 19-28.

Trzaskalski, N.A., Fadzeyeva, E., and Mulvihill, E.E. (2020). Dipeptidyl Peptidase-4 at the Interface Between Inflammation and Metabolism. Clin. Med. Insights Endocrinol. Diabetes 13, 1179551420912972.

Tseng, C.C., and Zhang, X.Y. (1998). Role of regulator of G protein signaling in desensitization of the glucose-dependent insulinotropic peptide receptor. Endocrinology 139, 4470-4475.

Tsuboi, T., Silva Xavier, G. Da, Holz, G.G., Jouaville, L.S., Thomas, A.P., and Rutter, G.A. (2003). 
Glucagon-like peptide-1 mobilizes intracellular $\mathrm{Ca} 2+$ and stimulates mitochondrial ATP synthesis in pancreatic MIN6 $\beta$-cells. Biochem. J. 369, 287-299.

Ugleholdt, R., Poulsen, M.L.H., Holst, P.J., Irminger, J.C., Orskov, C., Pedersen, J., Rosenkilde, M.M., Zhu, X., Steiner, D.F., and Holst, J.J. (2006). Prohormone convertase 1/3 is essential for processing of the glucose-dependent insulinotropic polypeptide precursor. J. Biol. Chem. 281, 11050-11057.

UK Prospective Diabetes Study (UKPDS) Group (1998). Intensive blood-glucose control with sulphonylureas or insulin compared with conventional treatment and risk of complications in patients with type 2 diabetes (UKPDS 33). Lancet 352, 837-853.

Ullrich, A., Bell, J.R., Chen, E.Y., Herrera, R., Petruzzelli, L.M., Dull, T.J., Gray, A., Coussens, L., Liao, Y.C., Tsubokawa, M., et al. (1985). Human insulin receptor and its relationship to the tyrosine kinase family of oncogenes. Nature $313,756-761$.

Valverde, A.M., Lorenzo, M., Pons, S., White, M.F., and Benito, M. (1998). Insulin Receptor Substrate (IRS) Proteins IRS-1 and IRS-2 Differential Signaling in the Insulin/Insulin-Like Growth Factor-I Pathways in Fetal Brown Adipocytes. Mol. Endocrinol. 12, 688-697.

Varin, E.M., Mulvihill, E.E., Beaudry, J.L., Pujadas, G., Fuchs, S., Tanti, J.F., Fazio, S., Kaur, K., Cao, X., Baggio, L.L., et al. (2019a). Circulating Levels of Soluble Dipeptidyl Peptidase-4 Are Dissociated from Inflammation and Induced by Enzymatic DPP4 Inhibition. Cell Metab. 29, 320-334.

Varin, E.M., Mulvihill, E.E., Baggio, L.L., Koehler, J.A., Cao, X., Seeley, R.J., and Drucker, D.J. (2019b). Distinct Neural Sites of GLP-1R Expression Mediate Physiological versus Pharmacological Control of Incretin Action. Cell Rep. 27, 3371-3384.

Vecchio, S., and Protti, A. (2011). Metformin-induced lactic acidosis: no one left behind. Crit. Care 15, 107.

Della Vedova, M.C., Muñoz, M.D., Santillan, L.D., Plateo-Pignatari, M.G., Germanó, M.J., Rinaldi Tosi, M.E., Garcia, S., Gomez, N.N., Fornes, M.W., Gomez Mejiba, S.E., et al. (2016). A mouse model of dietinduced obesity resembling most features of human metabolic syndrome. Nutr. Metab. Insights 9,93102.

Versteyhe, S., Blanquart, C., Hampe, C., Mahmood, S., Christeff, N., De Meyts, P., Gray, S.G., and Issad, T. (2009). Insulin receptor substrates- 5 and -6 are poor substrates for the insulin receptor. Mol. Med. Rep. 3, 189-193.

Vuguin, P.M., Kedees, M.H., Cui, L., Guz, Y., Gelling, R.W., Nejathaim, M., Charron, M.J., and Teitelman, G. (2006). Ablation of the Glucagon Receptor Gene Increases Fetal Lethality and Produces Alterations in Islet Development and Maturation. Endocrinology 147, 3995-4006. 
Waget, A., Cabou, C., Masseboeuf, M., Cattan, P., Armanet, M., Karaca, M., Castel, J., Garret, C., Payros, G., Maida, A., et al. (2011). Physiological and pharmacological mechanisms through which the DPP-4 inhibitor sitagliptin regulates glycemia in mice. Endocrinology 152, 3018-3029.

Wagner, L., Klemann, C., Stephan, M., and Von Hörsten, S. (2016). Unravelling the immunological roles of dipeptidyl peptidase 4 (DPP4) activity and/or structure homologue (DASH) proteins. Clin. Exp. Immunol. 184, 265-283.

Wang, X., Zielinski, M.C., Misawa, R., Wen, P., Wang, T.-Y., Wang, C.-Z., Witkowski, P., and Hara, M. (2013). Quantitative Analysis of Pancreatic Polypeptide Cell Distribution in the Human Pancreas. PLoS One 8, e55501.

Wang, Y., Montrose-Rafizadeh, C., Adams, L., Raygada, M., Nadiv, O., and Egan, J.M. (1996). GIP regulates glucose transporters, hexokinases, and glucose-induced insulin secretion in RIN 1046-38 cells. Mol. Cell. Endocrinol. 116, 81-87.

Whalley, N.M., Pritchard, L.E., Smith, D.M., and White, A. (2011). Processing of proglucagon to GLP-1 in pancreatic $\alpha$-cells: Is this a paracrine mechanism enabling GLP-1 to act on $\beta$-cells? J. Endocrinol. 211, 99-106.

White, J.W., and Saunders, G.F. (1986). Structure of the human glucagon gene. Nucleic Acids Res. 14. Wierup, N., Svensson, H., Mulder, H., and Sundler, F. (2002). The ghrelin cell: A novel developmentally regulated islet cell in the human pancreas. Regul. Pept. 107, 63-69.

Wierup, N., Yang, S., McEvilly, R.J., Mulder, H., and Sundler, F. (2004). Ghrelin Is Expressed in a Novel Endocrine Cell Type in Developing Rat Islets and Inhibits Insulin Secretion from INS-1 (832/13) Cells. J. Histochem. Cytochem. 52, 301-310.

Wilcox, G. (2005). Insulin and Insulin Resistance. Clin Biochem Rev 26, 19-39.

Wilson, J.R., Brown, N.J., Nian, H., Yu, C., Bidlingmaier, M., and Devin, J.K. (2018). Dipeptidyl peptidase4 inhibition potentiates stimulated growth hormone secretion and vasodilation in women. J. Am. Heart Assoc. 7.

Wong, R.H.F., and Sul, H.S. (2010). Insulin signaling in fatty acid and fat synthesis: A transcriptional perspective. Curr. Opin. Pharmacol. 10, 684-691.

Wright, A., Burden, A.C.F., Paisey, R.B., Cull, C.A., and Holman, R.R. (2002). Sulfonylurea inadequacy: Efficacy of addition of insulin over 6 years in patients with type 2 diabetes in the U.K. Prospective Diabetes Study (UKPDS 57). Diabetes Care 25, 330-336.

Wrigley, S., Arafa, D., and Tropea, D. (2017). Insulin-like growth factor 1: At the crossroads of brain development and aging. Front. Cell. Neurosci. 11, 14. 
Xiao, X., Gaffar, I., Guo, P., Wiersch, J., Fischbach, S., Peirish, L., Song, Z., El-Gohary, Y., Prasadan, K., Shiota, C., et al. (2014). M2 macrophages promote beta-cell proliferation by up-regulation of SMAD7. Proc. Natl. Acad. Sci. U. S. A. 111, E1211-E1220.

Xu, T., Rammner, B., Margittai, M., Artalejo, A.R., Neher, E., and Jahn, R. (1999). Inhibition of SNARE complex assembly differentially affects kinetic components of exocytosis. Cell 99, 713-722.

Ye, R., Wang, Q.A., Tao, C., Vishvanath, L., Shao, M., McDonald, J.G., Gupta, R.K., and Scherer, P.E. (2015). Impact of tamoxifen on adipocyte lineage tracing: Inducer of adipogenesis and prolonged nuclear translocation of Cre recombinase. Mol. Metab. 4, 771-778.

Yi, F., Brubaker, P.L., and Jin, T. (2005). TCF-4 mediates cell type-specific regulation of proglucagon gene expression by $\beta$-catenin and glycogen synthase kinase-3 $\beta$. J. Biol. Chem. 280, 1457-1464.

Yi, F., Sun, J., Lim, G.E., Fantus, I.G., Brubaker, P.L., and Jin, T. (2008). Cross Talk between the Insulin and Wnt Signaling Pathways: Evidence from Intestinal Endocrine L Cells. Endocrinology 149, 2341-2351.

Ying, W., Lee, Y.S., Dong, Y., Glass, C.K., Olefsky, J.M., and Fu, W. (2018). Expansion of Islet-Resident Macrophages Leads to Inflammation Affecting b Cell Proliferation and Function in Obesity. Cell Metab. 29, 457-474.e5.

Yu, Z., and Jin, T. (2010). New insights into the role of cAMP in the production and function of the incretin hormone glucagon-like peptide-1 (GLP-1). Cell. Signal. 22, 1-8.

Zhong, J., Maiseyeu, A., Davis, S.N., and Rajagopalan, S. (2015). DPP4 in cardiometabolic disease: Recent insights from the laboratory and clinical trials of DPP4 inhibition. Circ. Res. 116, 1491-1504.

Zhong, J., Kankanala, S., and Rajagopalan, S. (2016). DPP4 Inhibition: Insights From the Bench and Recent Clinical Studies. Curr. Opin. Lipidol. 5, 484-492.

Zinselmeyer, B.H., Vomund, A.N., Saunders, B.T., Johnson, M.W., Carrero, J.A., and Unanue, E.R. (2018). The resident macrophages in murine pancreatic islets are constantly probing their local environment, capturing beta cell granules and blood particles. Diabetologia 61, 1374-1383. 


\section{Appendix}

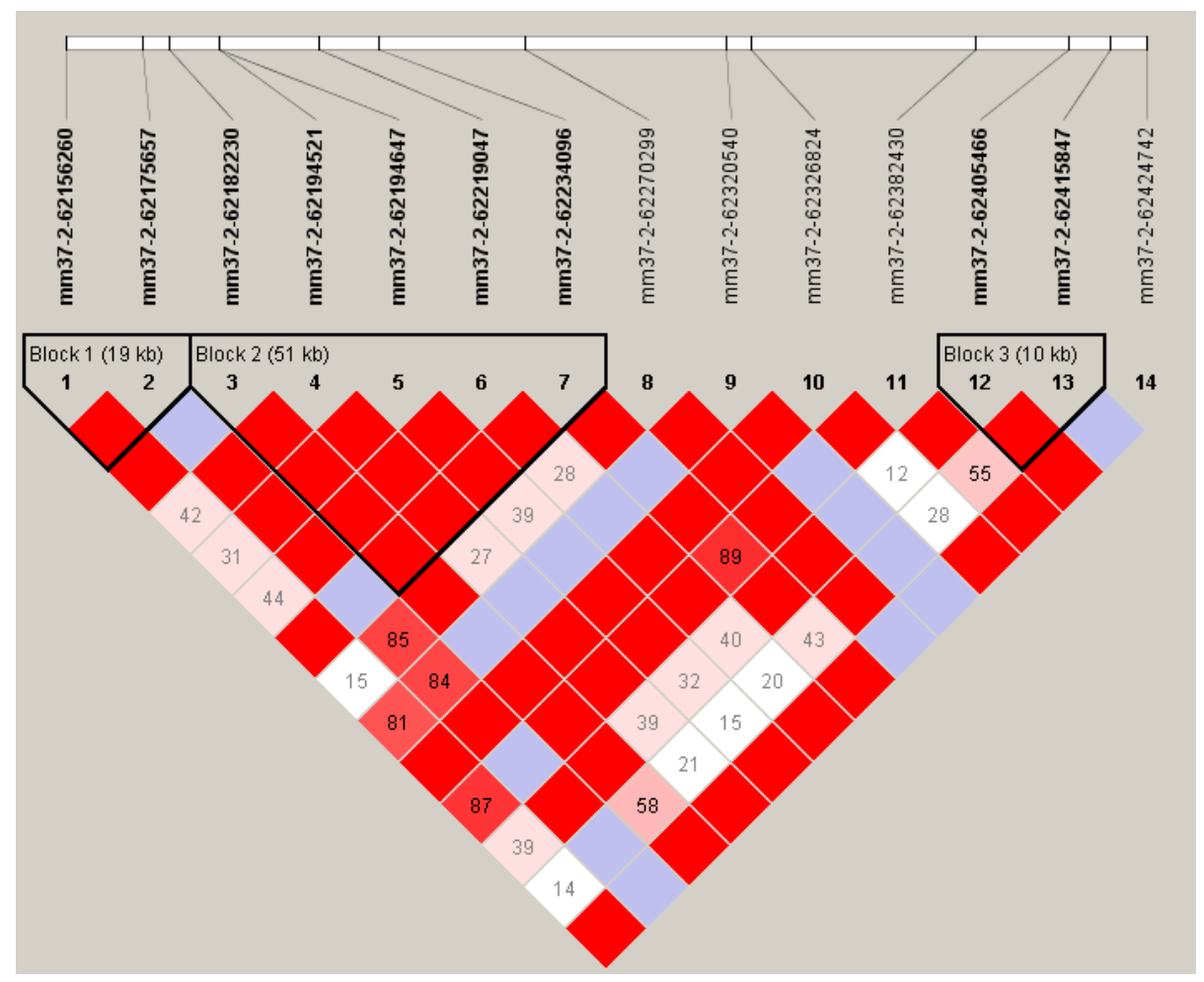

Appendix 1. Linkage Disequilibrium Between Dpp4 and Gcg Interferes with the Creation of $\alpha$-CellSpecific Dpp4 Knockout (Dpp4 ${ }^{\alpha-c e l l-/)}$ ) Mouse.

Linkage disequilibrium (LD) mapping of fourteen SNPs identified in the C57BL6 mouse strain on chromosome 2 (from chr2:62 152 690-62 431 222) region containing Dpp4, Gcg and Fap. Three linkage blocks were identified within this region, thus preventing homologous recombination. 